\title{
NOUVELLES RECHERCHES À L'EMPLACEMENT DU PRÉTENDU SANCTUAIRE LYONNAIS DE CYBÈLE
}

\author{
Premiers résultats
}

\author{
Armand DesBaT*
}

\begin{abstract}
Mots-clés. Lyon, Fourvière, sanctuaire de Cybèle, fondation coloniale, aqueduc du Gier, bâtiment public, insula, " prétoire ", Agrippa, période augustéenne.

Key-words. Lyon, Fourvière, the Cybele sancluary, colonial selllement, Gier aquaduct, public building, insula, praetorium, Agrippa, Augustean period.

Résumé. La reprise des fouilles sur l'édifice désigné depuis le début du siècle comme le "sanctuaire de Cybèle " a permis de rëinterpréter une partie des vestiges mais surloul de proposer de nouvelles datations fondées sur l'élude des stratigraphies et du mobilier qui bouleversent totalement la chronologie du site. L'histoire du site comprend quatre phases : une première occupation correspondant à des habilations de la fondation coloniale vers 40 avan I J.-C. ; une deuxième phase matérialisée par la construction d'un palais vers 20 avant J.-C. ; la troisième, vers 10 après J.-C., voil la construction du grand édifice public; enfin, la quatrième correspond à la construction de la grande cilerne de l'aqueduc du Gier.
\end{abstract}

\begin{abstract}
New excavations on the building known since the beginning of the century as the "sanctuaire de Cybèle " have allowed new interpretations for some parts of the remains and mostly new datations, based on the stratigraphy and the study of finds, which entirely change the chronology. Now the history of the site includes four stages : a first stage which corresponds to the buildings of the beginning of the colony about 40 B.C.; a second stage, with the building of a great place, probably the praetorium of the governor, about 20 B.C.; a third one, about 10 A.D., which squares with the so-called "Cybele sanctuary ", dated until now from 160 A.D. ; at last a forth stage which corresponds to the settlement of the great reservoir of the Gier aquaduct.
\end{abstract}

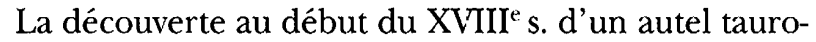
bolique dédié en 160 pour le salut de l'empereur Antonin fut à l'origine de la localisation à Fourvière d'un sanctuaire de Cybèle, que les recherches conduites durant le $\mathrm{XX}^{e}$ s. s'efforcèrent de retrouver. La mise au jour, à l'emplacement supposé du temple, d'un édifice public conforta cette hypothèse qui depuis lors a été reprise nombre de fois au point d'être considérée

\footnotetext{
* Laboratoire de Céramologie, Maison de l'Orient méditerranéen, 7 rue Raulin, F-69365 Lyon cedex 07.
} 
comme une certitude, alors même que ni le plan de l'édifice ni les arguments produits par les publications n'ont fourni d'éléments probants et que la datation de l'édifice n'a jamais été établie sur des données archéologiques fiables.

Les recherches entreprises depuis 1991 ont apporté des éléments nouveaux qui concernent en premier lieu la datation du supposé sanctuaire, mais surtout les édifices construits antérieurement à cet emplacement. Ces nouvelles données changent considérablement la chronologie des différents édifices et, pour certains, l'interprétation qui en avait été faite. En outre, elles ont mis en évidence des aménagements primitifs qui n'avaient pas été reconnus jusqu'ici.

\section{HISTORIQUE DES RECHERCHES}

" Au mois de décembre 1704 on découvrit sur la montagne de Fourvière, dans la vigne d'un M. Bourgeat, dont la propriété appartient aujourd'hui à Monsieur M.-Ant. de Nolhac, on découvrit, dis-je, un autel commémoratif d'un sacrifice taurobolique offert pour la santé de l'empereur Antonin le Pieux et pour la prospérité de la colonie lyonnaise. La parfaite conservation de ce monument, sa date qui reculait de quinze ans l'époque présumée de l'invention des tauroboles, enfin un certain nombre d'expressions inconnues jusqu'alors dans les inscriptions, excitèrent la curiosité et provoquèrent les recherches du monde savant. " (Boissieu, 1854), ( $c f$. annexe II, p. 270-273). Cette découverte, qui fit grand bruit à l'époque ${ }^{1}$, fut en effet le point de départ et resta le principal argument de l'identification et de la datation de l'édifice dénommé « sanctuaire de Cybèle » (fig. 1).

Les premiers travaux effectués sur le site le furent par Fabia et Germain de Montauzan qui, en 1925, entreprirent des sondages dans le clos des religieuses de NotreDame (orphelinat de Fourvière), où l'on situait la découverte de l'autel taurobolique. Six tranchées furent

1. L'intérêt soulevé par cette découverte fut tel qu'elle donna lieu à plusieurs publications dans les mois qui suivirent. La première, celle de Gros de Boze, achevée un mois après la découverte et publiée en mars 1705 (permission du 22 février 1705), fut bientôt suivie par celle du R. P. de Colonia (permission du 2 mars 1705) et du Père Daniel, Mémoires de Trévoux, avril 1705.

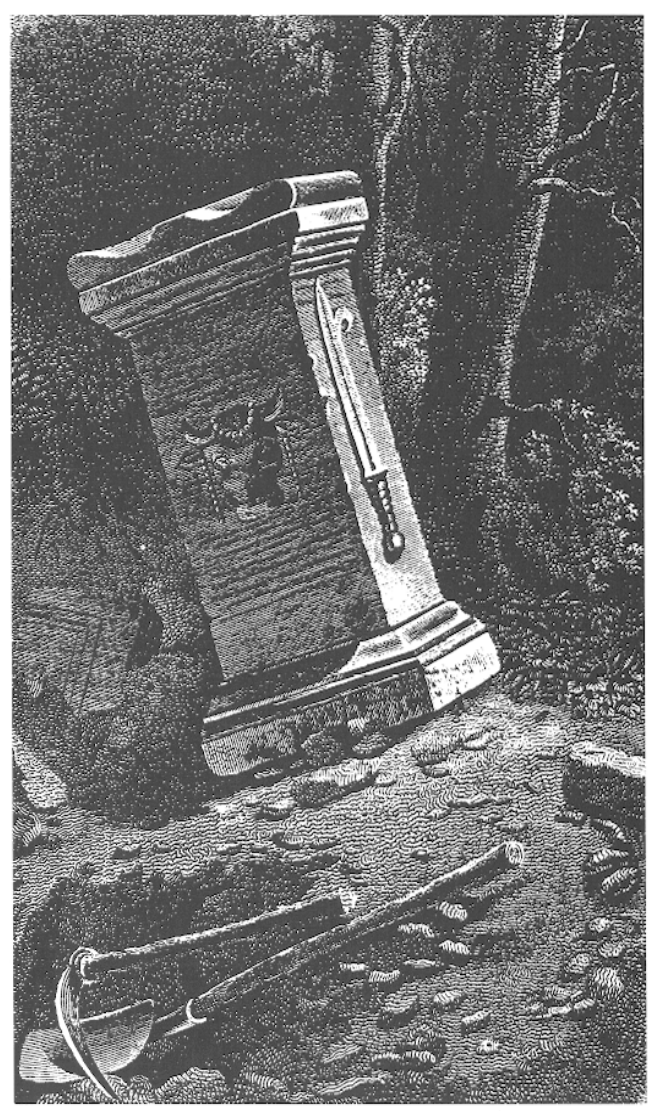

Fig. 1 - L'autel taurobolique au moment de sa découverte (grazure romantique de Richard, Histoire de Lyon de Clerjon, Lyon, 1820).

ouvertes en différents points du terrain ; elles révélèrent toutes des substructions, «certaines atteignant une épaisseur de près de $1,50 \mathrm{~m}$ ", mais « tout cela trop endommagé et discontinu pour que l'on pût en saisir le plan [...] ». Les auteurs n'en conclurent pas moins qu'il s'agissait des vestiges « sans doute d'un édifice public, d'un temple, plutôt que de maisons particulières » (Fabia, Germain de Montauzan, 1926, p. 143).

Il fallut attendre 1943 pour que de nouvelles fouilles dégagent, derrière le théâtre, la façade du monument interprété depuis lors comme le sanctuaire de Cybèle (Wuilleumier, 1951, 1953). Ces dégagements qui se sont poursuivis jusqu'en 1946 ont révélé une façade formée par un mur de soutènement, long de $53 \mathrm{~m}$, avec au centre un massif quadrangulaire, flanqué au sud et au nord d'alvéoles rectangulaires, voûtés, formant les soubassements de l'édifice. La découverte de plusieurs tambours de pierre cannelés avait permis de supposer dix colonnes sur la partie médiane, interprétée comme la 


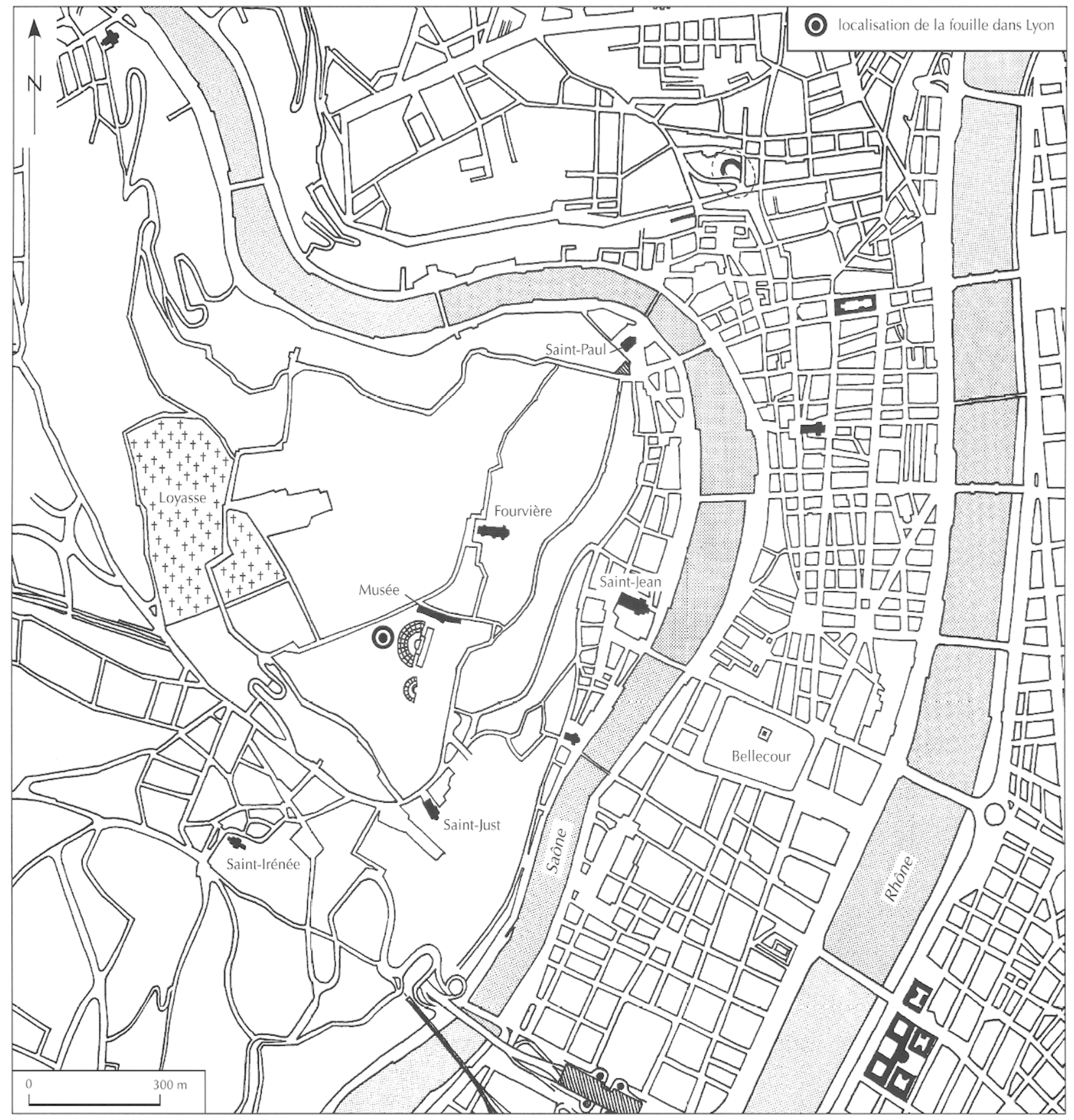

Fig. 2 - Localisation de la fouille dans Lyon.

base de la cella. Dans les alvéoles, apparurent les vestiges d'un édifice antérieur dans lequel furent identifiées des boutiques datées à l'époque du début du $\mathrm{II}^{\mathrm{e}} \mathrm{s}$. (Wuilleumier, 1951, p. 58).
Les choses en restèrent là jusqu'à ce que le projet de reconstruction de l'orphelinat de Fourvière, sur le clos du même nom, contigu au chantier archéologique, suscite une campagne de sondages dans le but de "délimi- 


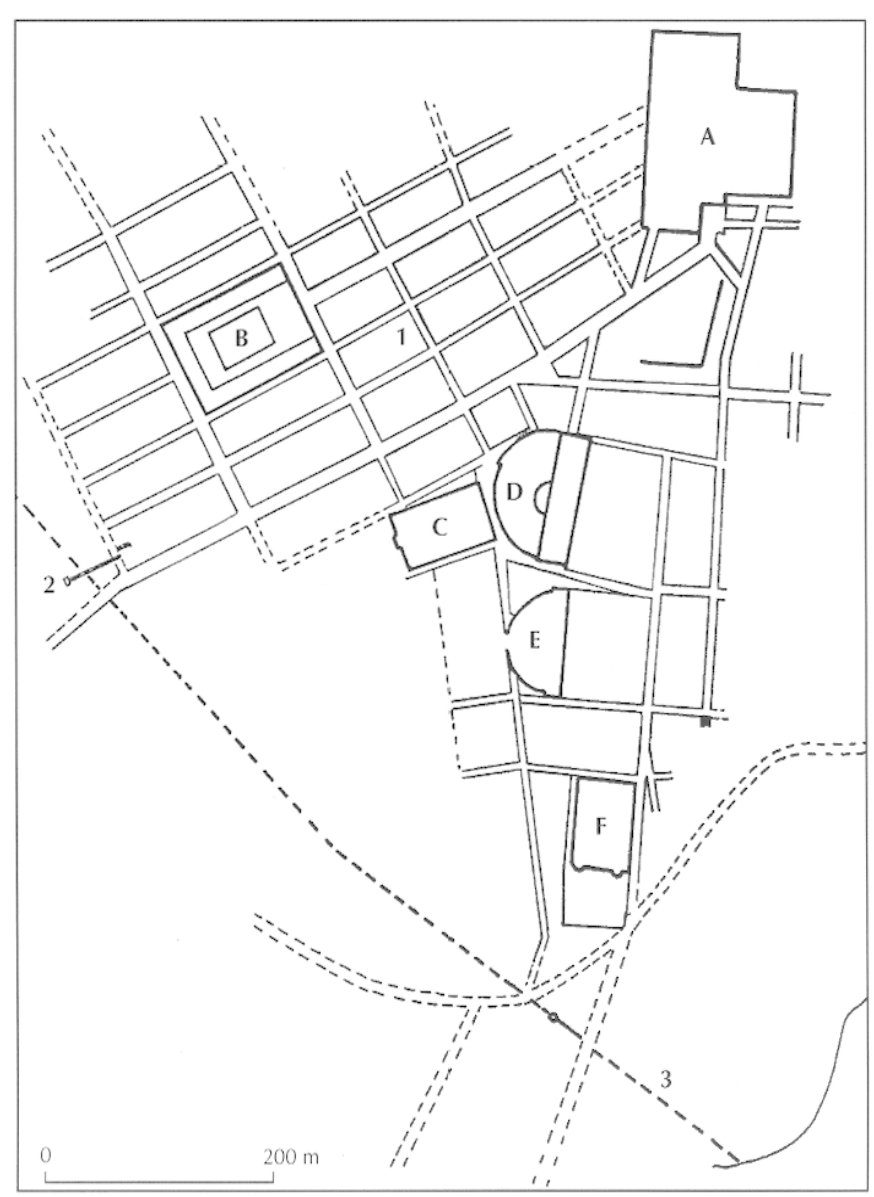

Fig. 3 - Situation dans la ville antique : $A$, forum ; $B$, sanctuaire du culte impérial (Verbe-Incarné) ; $C$, " sanctuaire de Cybèle "; $D$, théâtre; $E$, odéon ; $F$, thermes de la rue des Farges ;

1, fontaine du Verbe-Incarné; 2, aqueduc du Cier;

3, tracé supposé du rempart. ter l'emprise du temple » (Audin, 1965a). Plusieurs tranchées, réalisées entre mars et mai 1965, permirent de reconnaître un bâtiment d'une longueur de $86,60 \mathrm{~m}$, interprété comme le "Campus Matris Deum ». Ces travaux révélèrent également des vestiges antérieurs, considérés comme des restes de demeures privées, remontant au début du II' $s$. (Audin, 1965a, p. 79).

À la suite de ces travaux, une grande partie de la parcelle fut acquise par la ville de Lyon, et à partir de 1973 fut entrepris le dégagement en surface de tout l'édifice, qui devait se poursuivre jusqu'en 1974 (Audin, 1985) et même au-delà, puisque la fouille de la citerne de l'aqueduc du Gier ne fut achevée qu'en 1978 (Boucher, 1980), (fig. 2 à 6).

Les différents travaux conduits sur le site donnèrent lieu à la parution en 1985 d'une synthèse publiée par A. Audin dans la revue Gallia, sous le titre "Dossier des fouilles du sanctuaire lyonnais de Cybèle et de ses abords ». Dans cette étude, l'auteur reprenait les arguments déjà avancés précédemment pour justifier l'interprétation de l'édifice comme un sanctuaire de Cybèle (Audin, 1976, 1978). Outre la découverte de l'autel taurobolique, il s'est appuyé sur la mention, dans les textes médiévaux, reprise à la Renaissance, d'un "Castellum Bucium ", qu'il identifie avec l'édifice, arguant que le nom viendrait sans doute de la présence d'autels tauroboliques qui parsemaient encore le site à l'époque médiévale.

En dehors du «sanctuaire » lui-même, l'article décrit deux édifices qui l'auraient précédé.

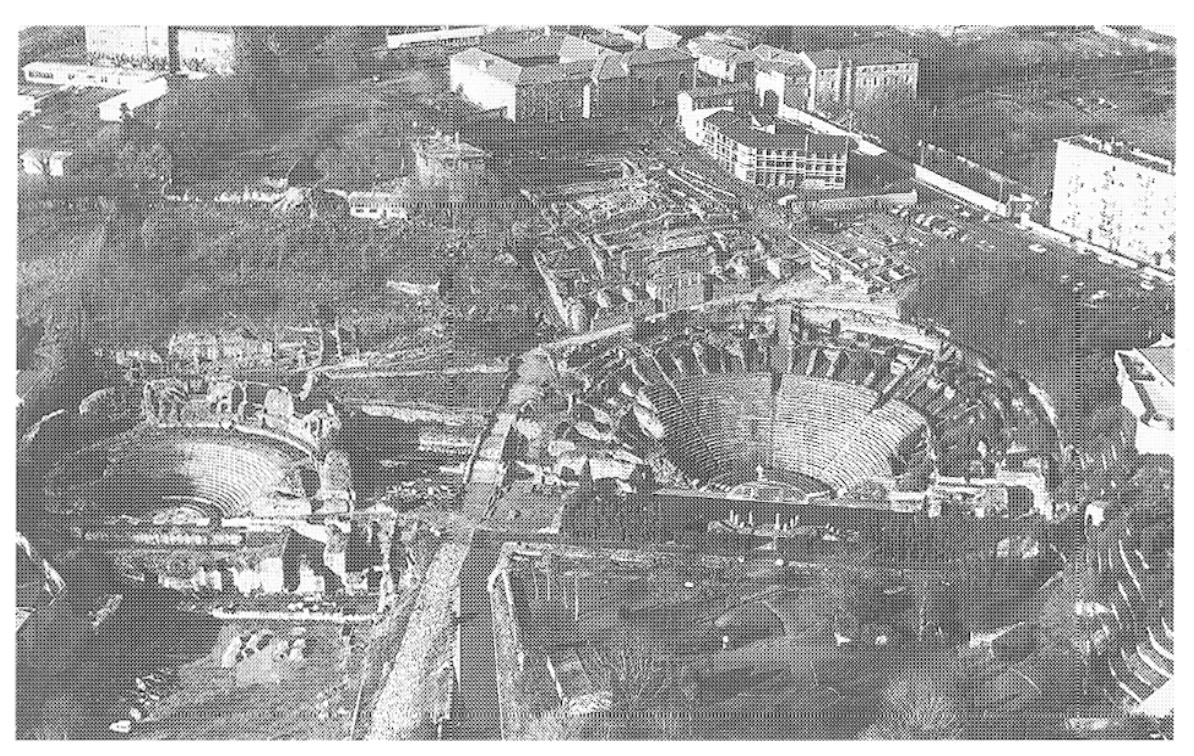

Fig. 4 - Vue aérienne du site en 1981. 


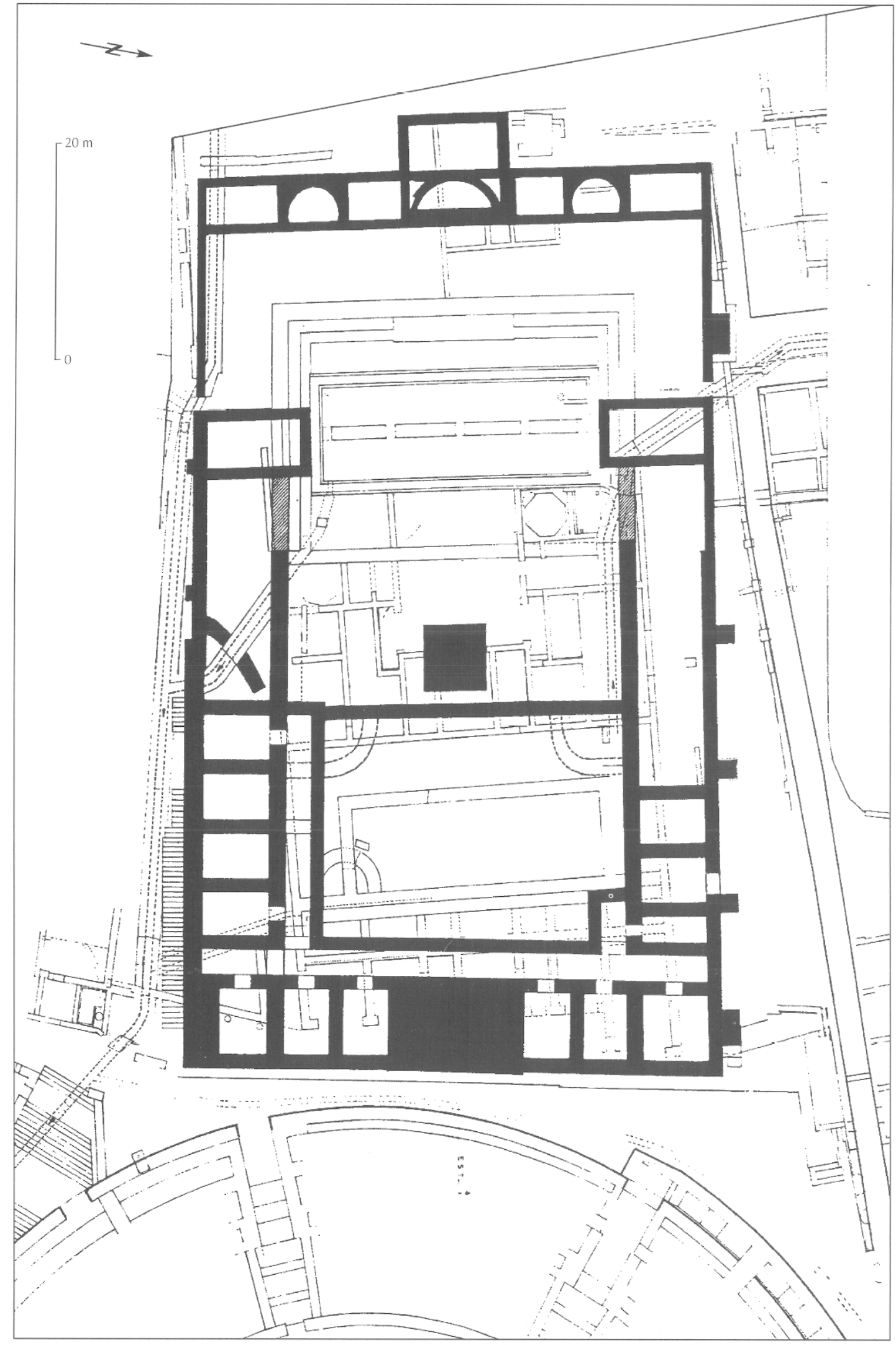

Fig. 5 - Reconstitution du plan du sanctuaire (Audin, 1985). 


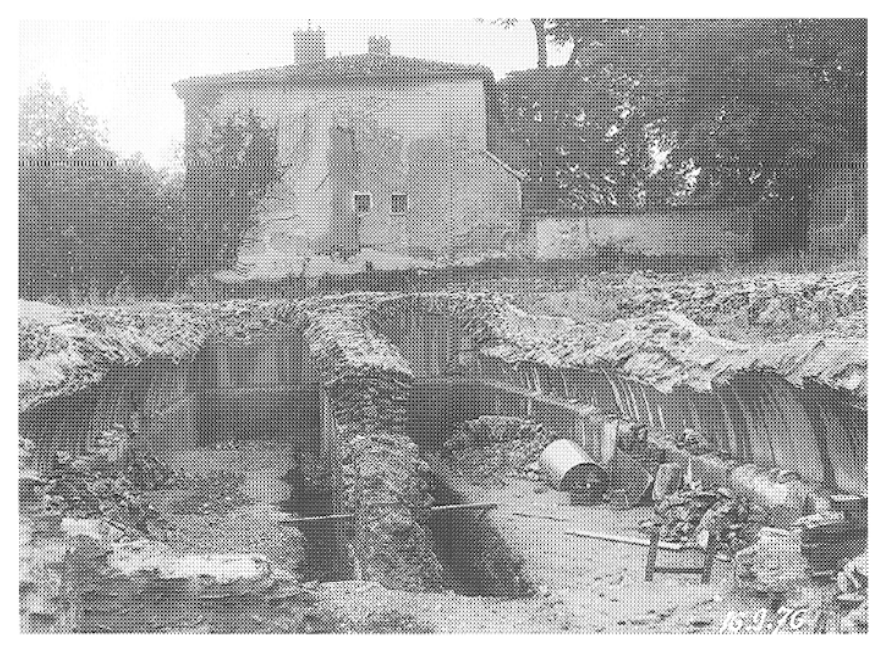

Fig. 6 - Le réservoir de l'aqueduc du Gier durant son dégagement en 1976.

\section{LE RÉSERVOIR TERMINAL DE L'AQUEDUC DU GIER}

Il s'agit d'une vaste citerne à deux nefs, « longue intérieurement de 25,95 m à l'ouest et 26,24 m à l'est, large au nord de 8,66 m, au sud de $8,60 \mathrm{~m}$ ", qui ne constitue que la partie enterrée d'une citerne à deux niveaux et à quatre chambres, selon une disposition connue notamment par le réservoir de l'Aqua Virgo (fig. 6). À cette construction aurait appartenu un ensemble de murs formant un quadrilatère de $35,40 \mathrm{~m}$ du nord au sud et de 23,90 m d'est en ouest, destiné à constituer un glacis pour contrebuter la partie aérienne du réservoir. L'altitude de ce réservoir, dont le radier inférieur est à la cote 288,67 , oblige à l'évidence à mettre l'ouvrage en relation avec l'aqueduc du Gier, seul à pouvoir atteindre une altitude suffisante pour l'alimenter. Selon A. Audin, cet ouvrage aurait donc été détruit lors de la construction du " sanctuaire " en 160 après J.-C. (Audin, 1977, 1985).

\section{L'INSULA « BASILICALE »}

Un autre édifice antérieur au "sanctuaire " a été reconnu et identifié par A. Audin comme une insula «basilicale ». Les vestiges qui présentent une orientation « inclinée de trois degrés plus au nord que celle des édifices postérieurs " forment un quadrilatère auquel
A. Audin restitue $37,20 \mathrm{~m}$ de large, pour une longueur de $62,40 \mathrm{~m}$ (d'est en ouest). Elle est limitée à l'ouest par une voie nord-sud, dont le tracé a été reconnu au nord, à l'extérieur du "sanctuaire ", et à l'est, en contrebas, par la rue qui longe l'hémicycle du théâtre. À cette insula appartiennent les boutiques dégagées en 1946 dans les alvéoles de la façade orientale du " sanctuaire ». Plus à l'ouest, en contre-haut, s'étendent d'autres vestiges dans lesquels $\mathrm{A}$. Audin a cru pouvoir identifier une basilique flanquée à l'ouest de locaux administratifs.

La basilique, reconstituée par A. Audin, de $37,20 \mathrm{~m}$ sur 20,35 $\mathrm{m}$ affecte la forme de deux rectangles emboités (fig. 7). Elle aurait comporté deux niveaux. Un niveau inférieur, formé d'une salle rectangulaire, ceint d'une galerie et couvert en charpente " pouvant supporter des dalles ", et un niveau supérieur, comportant une colonnade, à laquelle il attribue les tambours de colonnes retrouvés " aux abords immédiats » qui avaient été dans un premier temps attribués à la cella du " temple " (Wuilleumier, 1953; Audin, 1956, 1965a et b). Il restitue ainsi un portique comportant « sur les côtés longs, dix colonnes, avec entraxes de $2,80 \mathrm{~m}$, sur les côtés courts, quatre colonnes avec entraxes de 3,10 m ». Dans l'espace s'étendant entre la «basilique » et la rue où s'étalent des plaques de sol en opus signinum blanc, A. Audin distingue une vaste salle de $11,90 \mathrm{~m}$ de large, qualifiée de cour ${ }^{2}$. Entre "cour et basilique ", il distingue également un bâtiment de 7,02 m divisé en trois travées, pour lequel il avance l'hypothèse d'un « tribunal, voire d'une curie ». Il signale en outre, dans l'aile ouest, un petit secteur thermal avec des traces de mosaïque.

En résumé, les recherches d'A. Audin avaient donc conclu à l'existence de trois édifices qui s'étaient succédé, selon la chronologie suivante :

1) l'insula basilicale, édifiée à l'époque d'Auguste ;

2) le réservoir de l'aqueduc du Gier, construit vers 120 après J.-C. ;

3) le sanctuaire de Cybèle édifié en 160 après J.-C., après la destruction du réservoir.

On ne déplorera jamais assez que la documentation concernant les travaux réalisés depuis 1960 dans le parc archéologique de Fourvière soit pratiquement inexis-

2. "Bien que ce nivellement ne joue pas en faveur de telle interprétation, par simplification terminologique, on qualifiera cependant de cour cette vaste salle centrale. " (Audin, 1985, p. 111). 


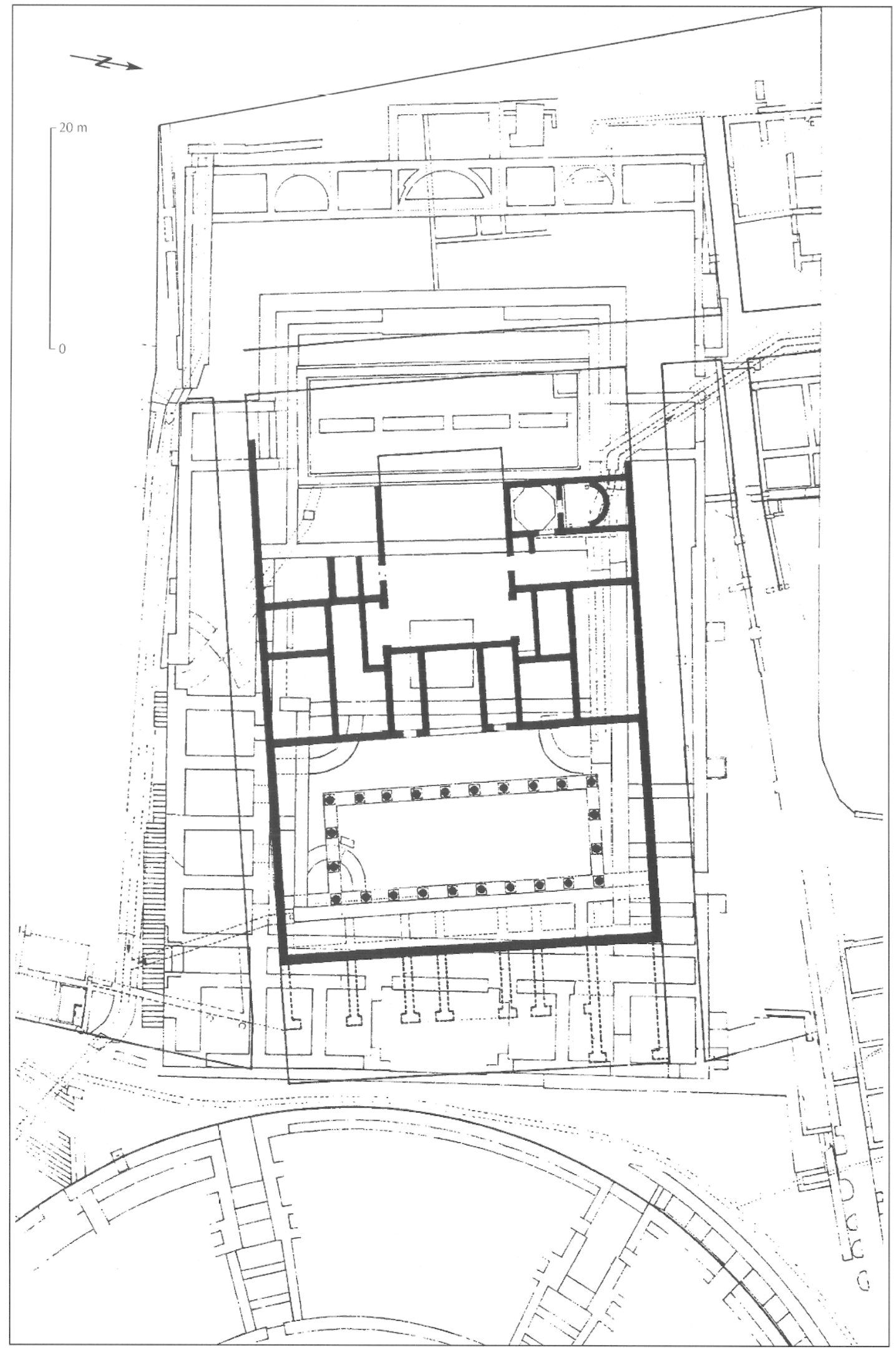

Fig. 7 - Linsula «basilicale»(Audin, 1985). 


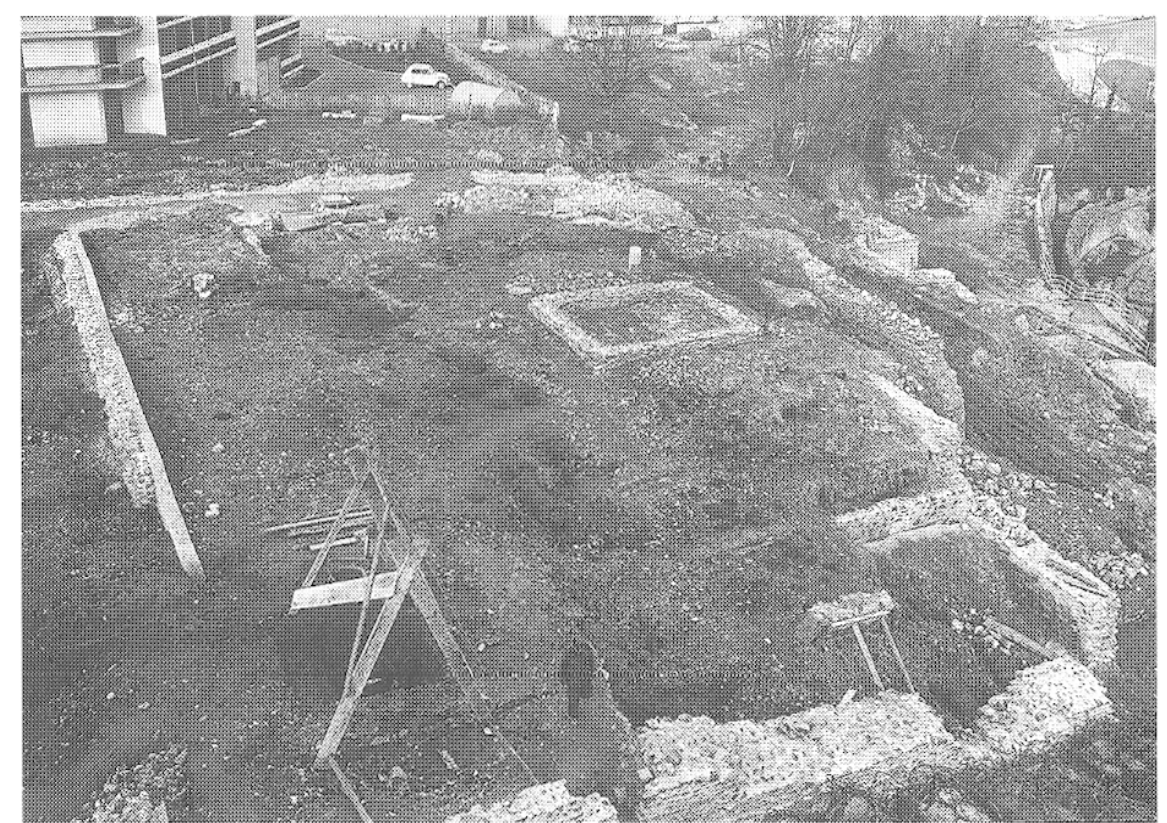

Fig. 8 - Le "sanctuaire de Gybele " en cours de dégagement. On aperçoil des tronçons de murs déjà restaurés bien qu'incomplètement dégagés. tante. Outre l'absence cruelle de cahiers de fouilles, il faut signaler que les rares documents dont nous disposons ont été réalisés en cours de restauration, voire après restauration et que l'on manque de photos ou de relevés de détails donnant l'état des vestiges au moment de la découverte (fig. 8). Il va sans dire que les travaux qui ont consisté en dégagements, suivis de restauration, avant même que les structures aient été dégagées dans leur intégralité, n'ont donné lieu à aucune étude stratigraphique et que la plupart du matériel récolté lors de ces travaux l'a été sans localisation précise. On ne s'étonnera pas dès lors que les nouvelles fouilles réalisées dans ce parc archéologique aient remis en cause bien des hypothèses et considérablement changé certaines datations.

\section{LES NOUVELLES RECHERCHES DEPUIS 1991}

Les premiers sondages réalisés en 1991 avaient pour objectifs de s'assurer qu'il subsistait encore des couches archéologiques en place dans les alvéoles de construction de la façade orientale, mais également de rechercher l'existence éventuelle de traces d'une occupation antérieure. Les résultats, positifs sur ces deux points, nous ont encouragés à poursuivre les investigations. Cinq autres campagnes de fouilles ont été réalisées en 1992, 1993, 1995,1996 et $1997^{3}$. Elles ont été conduites avec la collaboration de E. Bertrand, S. Elaigne et S. Lemaître, avec la participation d'étudiants de l'université de Lyon II ${ }^{4}$. Ces fouilles ont bénéficié en outre de l'assistance technique du Service archéologique municipal, du musée de la Civilisation gallo-romaine et de l'Association lyonnaise pour la promotion de l'archéologie en Rhône-Alpes ${ }^{5}$.

Trente-six sondages ont été réalisés, aussi bien dans la partie basse que sur la terrasse supérieure (fig. 9 et 10). Ces cinq campagnes de fouilles ont confirmé et enrichi les résultats des premiers sondages en mettant au jour des vestiges d'une première occupation jusque-là méconnue, mais surtout en fournissant des données sur la chronologie des édifices et leur interprétation. Ces résultats renouvellent totalement notre connaissance de ces bâti-

3. L'année 1994 a été consacrée à des sondages effectués sur l'esplanade de l'odéon, dans le cadre d'un projet de mise en valeur de l'édifice par la Caisse nationale des monuments historiques. Nous en exposerons prochainement les résultats.

4. Il s'agit pour la plupart d'étudiants effectuant un stage pratique dans le cadre de la licence d'archéologie.

5. Nous remercions pour leur aide précieuse et amicale ces différents organismes, et en particulier M. Jacques Lasfargues, conservateur du musée de la Civilisation gallo-romaine, M. Louis Blanchard, président de l'ALPARA, ainsi que tous les membres du Service archéologique municipal. 


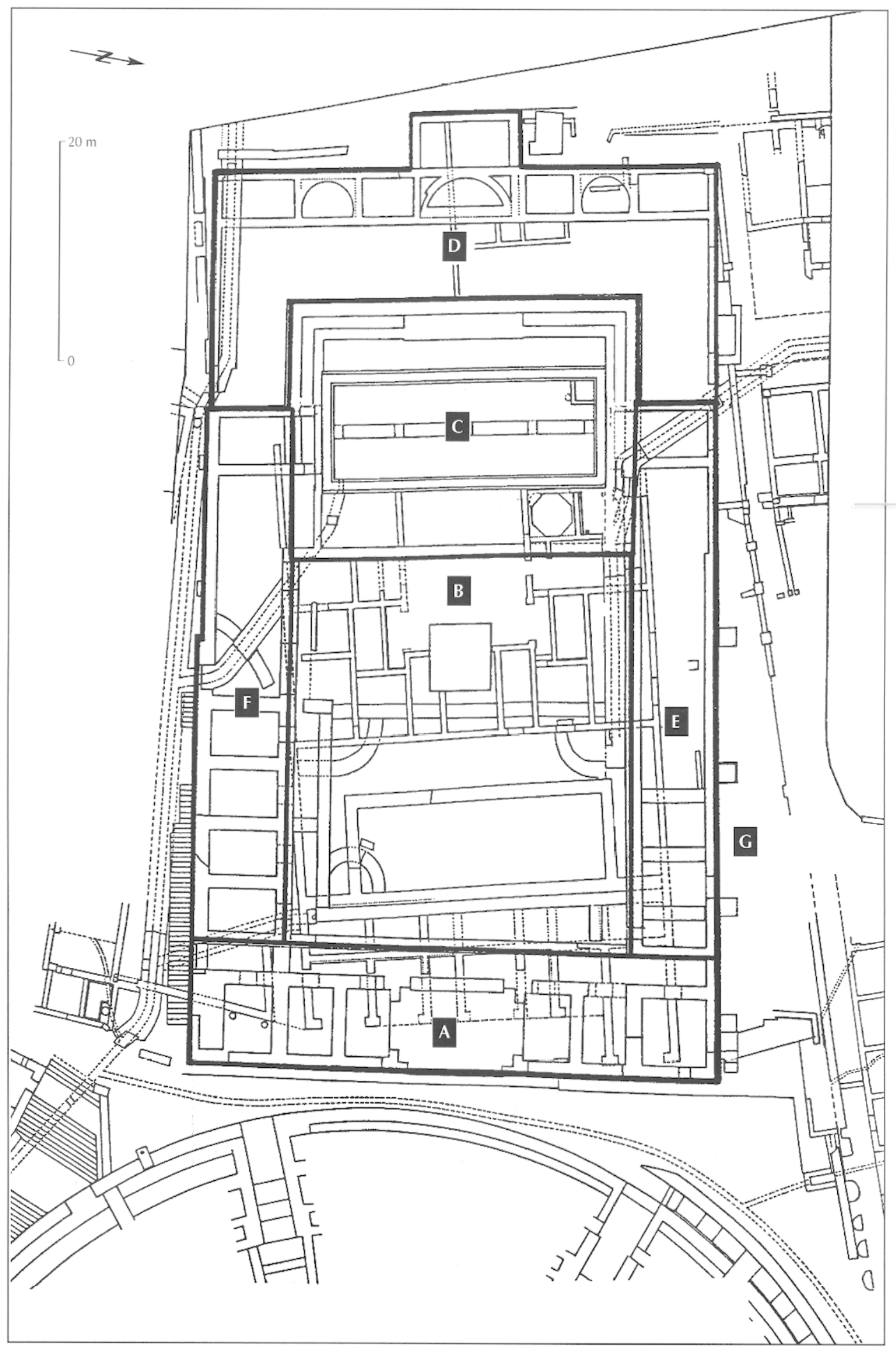

Fig. 9 - Délimitation des zones A à G sur fond de plan Crruyer (1979). 


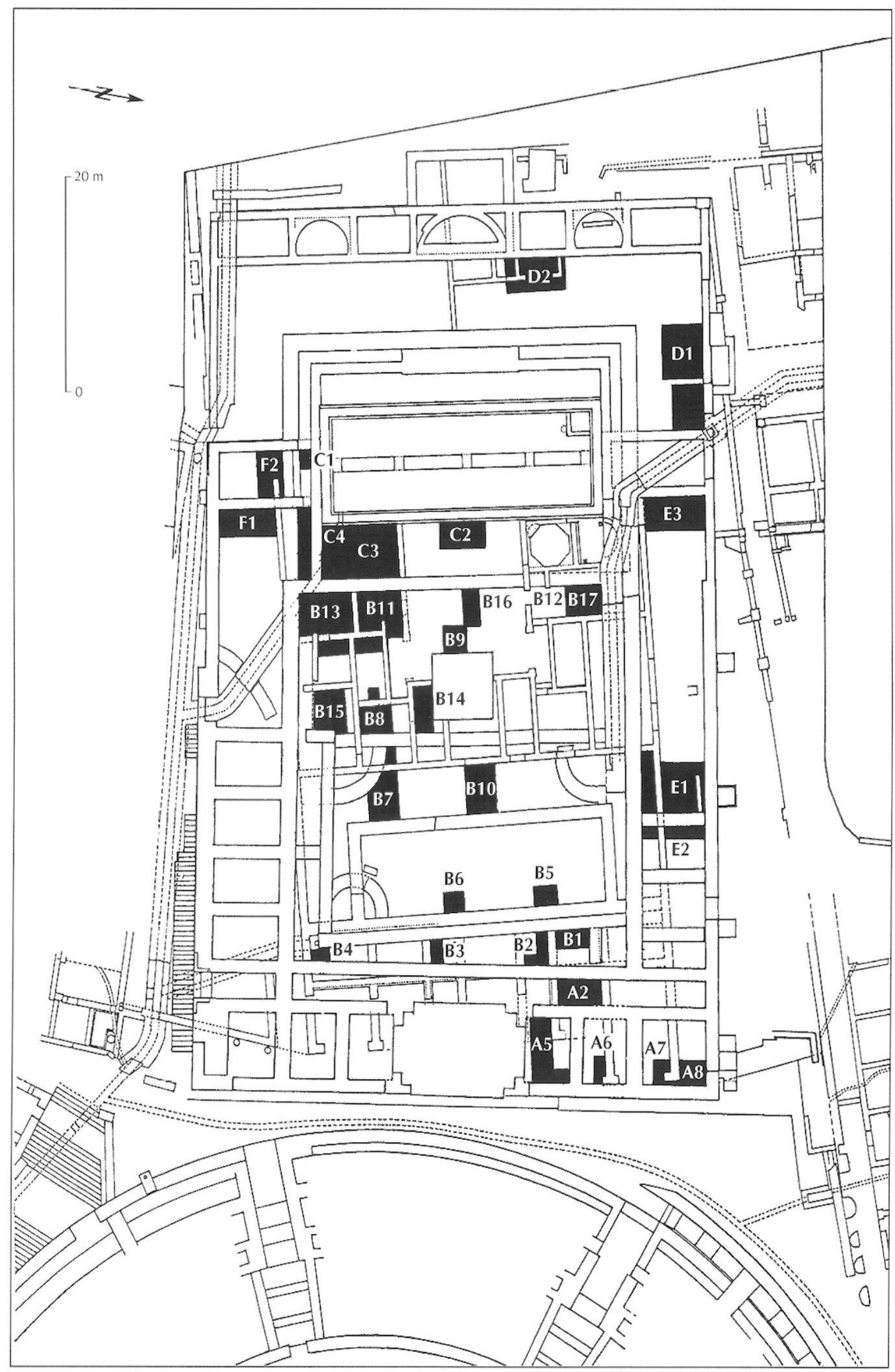

Fig. 10 - Plan des sondages 1991-1997. 
ments mais livrent aussi des éléments nouveaux sur la première urbanisation. C'est pourquoi il nous est apparu indispensable de présenter sans attendre davantage les principaux résultats de ces recherches.

\section{LES PREMIÈRES OCCUPATIONS}

Des vestiges antérieurs aux édifices exhumés par A. Audin et publiés en 1985 sont apparus sur la partie orientale, en façade du supposé sanctuaire de Cybèle et sur la terrasse supérieure. Ces vestiges constituent deux ensembles distincts avec des orientations différentes.

Le premier ensemble, dans la partie basse, n'est figuré que par des négatifs de murs et un mur très arasé, apparus sous les sols des « boutiques" de « l'insula basilicale ». Il s'agit du fantôme d'un mur nord-sud, totalement épierré jusqu'à sa base, repéré dans trois sondages. Ce mur, large de $0,80 \mathrm{~m}$, formait un mur de soutènement contre la moraine. Un second mur, perpendiculaire au premier, est apparu au nord du massif central du prétendu sanctuaire. Large de 0,50 m, il était maçonné en granite et fondé dans le terrain naturel, et se terminait à l'est par une tête en T maçonnée avec des briques. Il se peut qu'il s'agisse d'une ante, mais il est également possible que ce soit l'amorce d'un retour vers le nord. Un autre fantôme de mur est apparu dans le sondage A7, au nord, à $12 \mathrm{~m}$ du précédent.

Ces différents vestiges permettent de reconstituer un bâtiment allongé, d'orientation nord-sud et d'une largeur de 12 m environ, sa longueur étant inconnue. Sa disposition dans le prolongement de la rue, passant derrière l'odéon, rappelle la disposition des boutiques, remblayées lors de la construction de ce dernier. L'orientation de cette construction forme toutefois un léger angle avec l'alignement supposé de la voie primitive. On peut remarquer que la distance entre les murs est et ouest est d'environ $12 \mathrm{~m}$, ce qui correspond à la largeur de deux «boutiques » dans la phase de construction suivante. On peut donc penser qu'il existait un mur intermédiaire. De même on peut supposer l'existence d'un portique de façade. Ainsi reconstitué, ce bâtiment aurait $10 \mathrm{~m}$ de large avec portique, ce qui correspond, là aussi, à la largeur des boutiques à la phase suivante.

Le second ensemble est situé plus haut, à l'ouest sur le rebord du plateau formé par la moraine. Il n'est pas relié au premier et montre une orientation différente. À ce second ensemble appartiennent un certain nombre de murs et de sols installés directement sur le terrain naturel. Les vestiges sont encore trop limités pour permettre d'en reconstituer le plan précis, mais il apparaît que l'ensemble correspond à un îlot rectangulaire (fig. 11).

Du côté ouest, cet îlot était limité par une voie nordsud, dont la partie centrale a été recouverte par la construction de l'ensemble monumental, mais dont le prolongement dénommé " rue de Cybèle »s'est maintenu jusqu'à la fin de l'occupation. Il s'agit d'une rue importante puisqu'elle aboutit au nord en façade du sanctuaire du culte impérial mis au jour sur le site du Verbe-Incarné (Mandy, 1983). Les niveaux de cette rue ont été endommagés par le creusement de la citerne mais une portion a pu être fouillée dans l'angle nordouest de l'ensemble monumental (sondage D1), à l'emplacement d'un carrefour avec une voie est-ouest. La rue est constituée de couches de graviers et de galets compactés.

Sur les côtés sud et nord, les limites de l'îlot primitif paraissent avoir été reprises par la construction postérieure. Sur la façade sud, un sondage a fait apparaître le sol de galets d'une ruelle est-ouest qui longeait l'îlot. Sur la façade nord également on a reconnu la rue primitive en galets.

Sur la base des données actuelles on peut donc reconstituer un îlot rectangulaire de $45 \mathrm{~m}$, d'est en ouest, sur $37 \mathrm{~m}$ du nord au sud, ce qui correspond à peu près à 120 pieds. Cet îlot était divisé dans le sens longitudinal par un mur médian, dont un tronçon a été retrouvé dans le sondage C2, installé contre la citerne. Plus à l'est, les sondages B16 et B10 ont livré la trace d'un mur, sur le même axe. Cette division longitudinale se retrouve dans l'îlot situé plus à l'ouest de l'autre côté de la rue, mais aussi dans le découpage primitif en parcelles des îlots du Verbe-Incarné, dont la largeur est identique (Mandy, 1983).

L'existence du mur divisant l'îlot dans le sens longitudinal comme l'étagement formé par les sols suggèrent l'existence d'un découpage en plusieurs lots, comme au Verbe-Incarné, mais cette hypothèse demandera à être vérifiée par les travaux ultérieurs. Les murs périmétraux des parcelles étaient probablement en galets liés à l'argile comme le mur médian.

La terrasse supérieure, sur la façade ouest, a livré les traces d'habitats les mieux conservées. Les vestiges de 


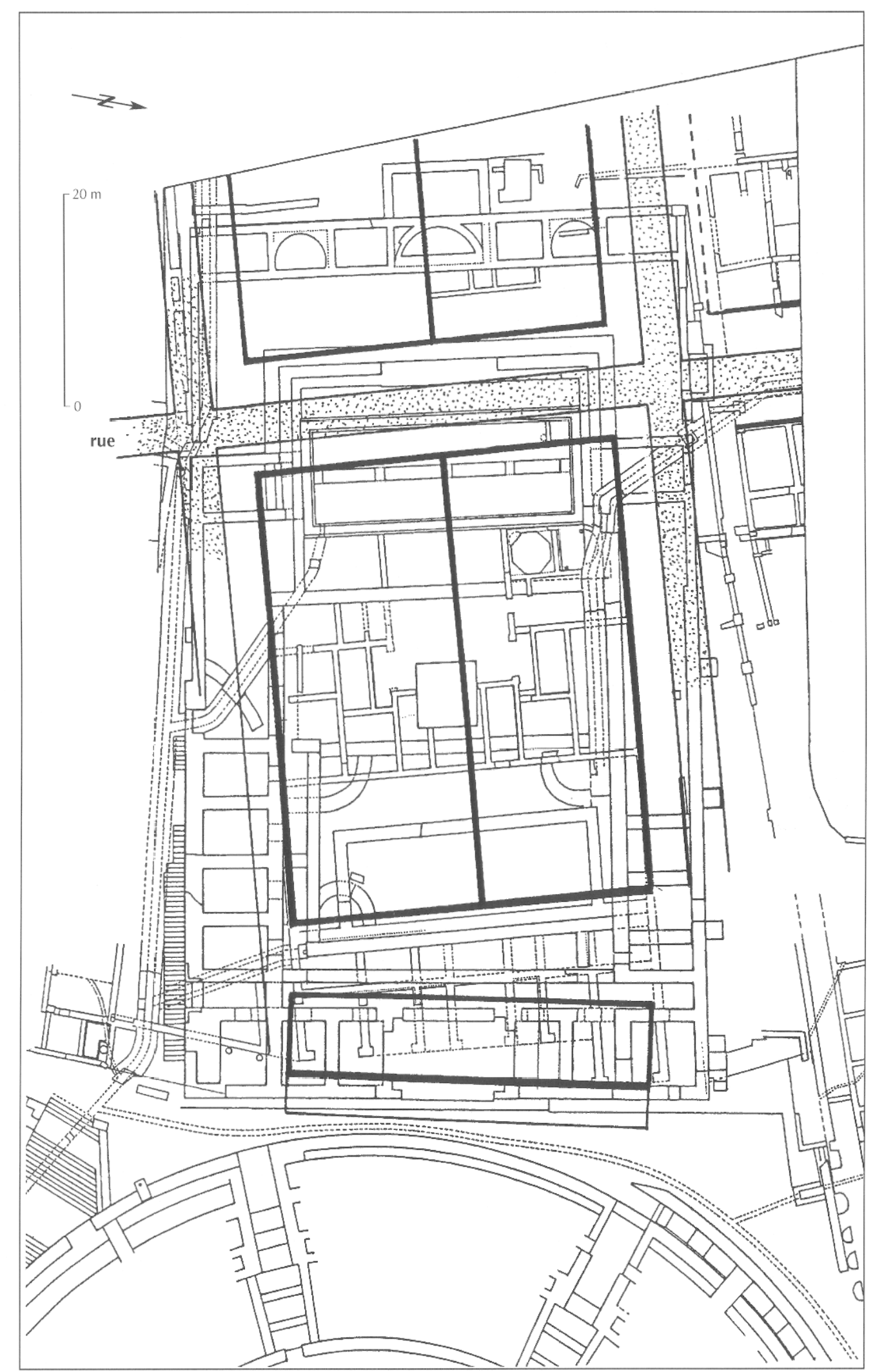

Fig. 11 - Hypothèse de restitution du parcellaire primitif sur fond de plan Gruyer (1979). 
plusieurs pièces au sol de terre battue ont été mis au jour. Elles étaient limitées par des cloisons à pan de bois, matérialisées par des négatifs de sablière. Plusieurs de ces cloisons avaient reçu de très belles peintures du deuxième style pompéien, qui indiquent l'existence d'un habitat de qualité dès la première période. Malheureusement les vestiges sont encore trop restreints pour permettre de reconstituer le plan de cet habitat. On peut toutefois penser qu'il ne s'agit pas de maisons de type italique mais plutôt de maisons comparables à celle de Sulla à Glanum ou à celles du lotissement de Saint-Florent à Orange (Mignon, 1996). Sur ce dernier site les maisons correspondent à des lots de 60 pieds par 40 , voire pour les plus grandes (qui associent deux lots) à 60 pieds par 80, soit $12 \mathrm{~m} \times 24 \mathrm{~m}$. De tels modules seraient tout à fait adaptés à la largeur des lots qui correspondent précisément à 60 pieds.

\section{LA CHRONOLOGIE \\ DES PREMIÈRES OCCUPATIONS}

Les premières constructions étant installées directement sur le terrain naturel, aucun élément de datation pouvant fournir un terminus post quem n'a été recueilli sous les sols, ni dans les boutiques ni dans les habitats de la partie haute. Cette première phase de construction ne peut donc être située chronologiquement que par rapport à son abandon. Celui-ci est matérialisé par des couches de destruction et des remblais mis en place pour la construction de l'édifice postérieur.

Le matériel recueilli dans ces couches est abondant. Il comprend de la céramique sigillée, dans laquelle les formes précoces dominent largement, alors que le service $1 \mathrm{C}$ de Haltern est très minoritaire et le service 2 totalement absent. Les céramiques à paroi fine sont également abondantes et comprennent des gobelets cylindriques et des gobelets à lèvre concave, associés à des gobelets d'Aco, notamment des gobelets de l'atelier de Loyasse. Les amphores comprennent des Dressel 1, mais on note la présence d'autres types : Dressel 2/4 italiques ou orientales, Pascual 1, Dressel 7/11, Dressel 20, etc. Tout ce matériel traduit un faciès antérieur à l'horizon Dangstetten-Oberaden-Rödgen et permet de dater la destruction des constructions primitives vers 20 avant J.-C.

En dehors de l'habitat les sondages ont livré un matériel pouvant correspondre à l'occupation de la première phase, voire à son installation. Il s'agit en premier lieu du sondage A8 réalisé contre le mur nord des boutiques (fig. 12 à 14 et annexe I, p. 268) mais surtout de celui effectué sur la rue ouest en D1. Ce dernier a fourni des niveaux installés sur le terrain naturel, qui correspondent à l'aménagement de la rue et à ses recharges successives, contemporaines de la première installation. Ces couches ont livré un matériel plus ancien, dans lequel on note la présence de campanienne $\mathrm{A}$ et de sigillée précoce : plat Goudineau 1, estampilles radiales de L.TETTI (fig. 15 à 18 et annexe I, p. 268-269). Le mobilier n'est pas très abondant mais présente un faciès plus ancien que les niveaux d'abandon. Tous ces éléments convergent pour proposer une installation de la phase 1 vers 40 avant J.-C. et sa destruction vers 20 avant J.-C.

\section{UN ÉDIFICE REMARQUABLE : LE « PRÉTOIRE » D'AGRIPPA ?}

La deuxième phase est marquée par la construction du très vaste ensemble qui avait été dénommé « insula augustéenne " ou «insula basilicale» (Audin, 1985). En effet, la majeure partie du bâtiment, avec ses niveaux de sols, avait déjà été dégagée lors des fouilles dirigées par A. Audin et l'ensemble constitue l'insula augustéenne dans laquelle il avait reconnu une basilique et des locaux administratifs. L'étude des structures contredit cette hypothèse et permet de proposer une nouvelle interprétation.

Le nouveau bâtiment conserve l'orientation des structures précédentes, mais il occupe à lui seul plus que la surface de l'îlot primitif, puisqu'il reprend ses limites au nord, au sud et à l'ouest mais le prolonge vers l'est, audelà de la rupture de pente constituée par le front de la moraine (fig. 19). Les substructions de ce nouveau bâtiment s'étagent donc d'ouest en est sur un dénivelé important, les sols de la partie ouest se situant autour de $291,50 \mathrm{~m}$, alors que ceux de la façade orientale se placent autour de $279 \mathrm{~m}$ (fig. 20 à 22).

Le bâtiment se compose en fait de deux parties, l'une ouvrant à l'ouest sur la rue dite « de Cybèle », l'autre à l'est sur la rue du théâtre.

Dans la partie ouest, la construction du grand réservoir a détruit irrémédiablement la façade du bâtiment sur une profondeur de 7 à $8 \mathrm{~m}$, et son aménagement demeure hypothétique, en dehors du vestibule d'entrée 

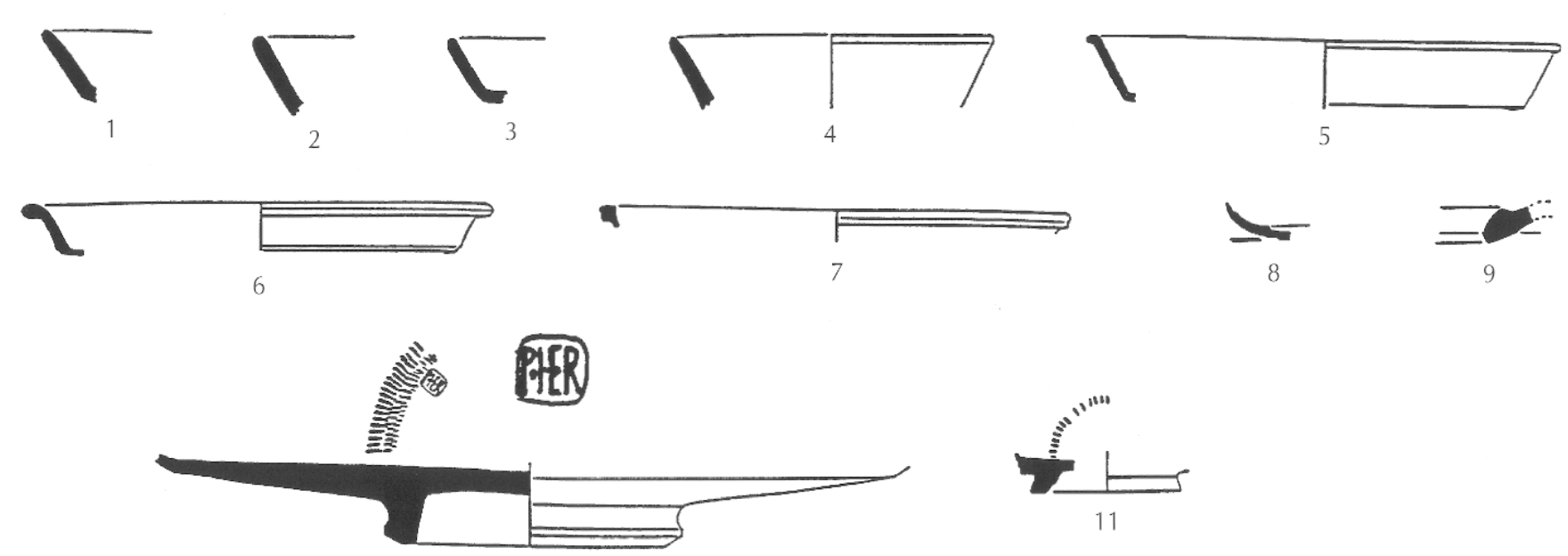

10
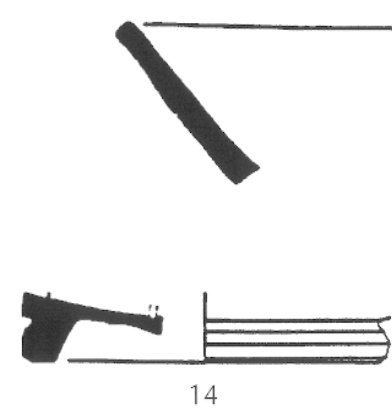

14

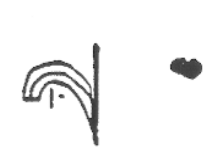

18

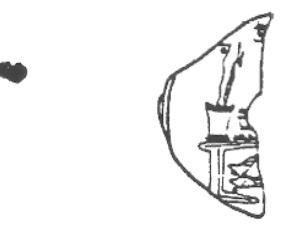

19

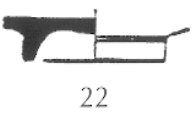

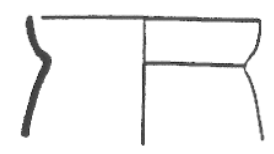

15
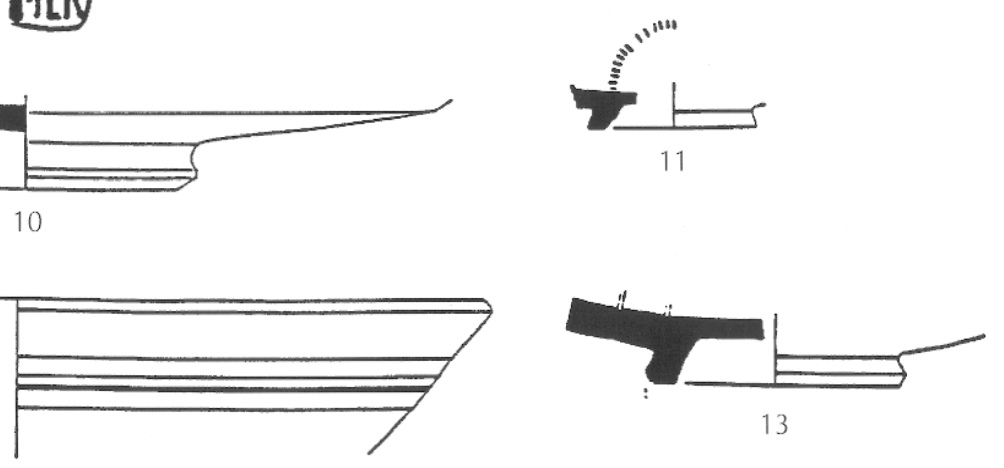

12
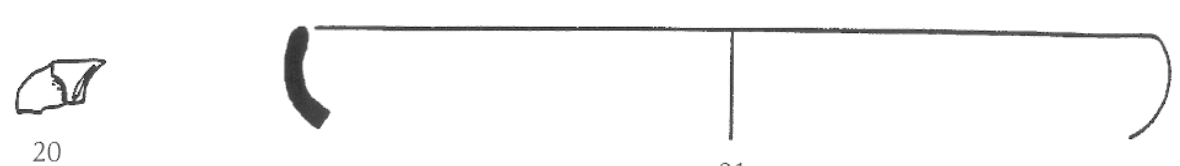

21

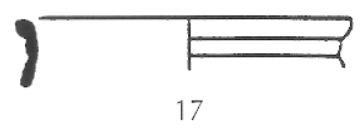

16

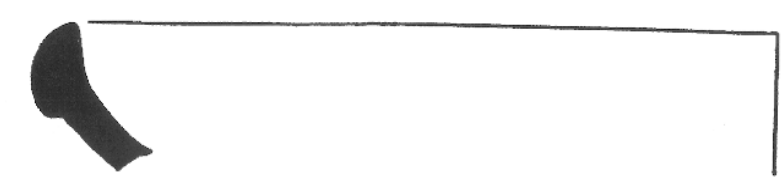

23
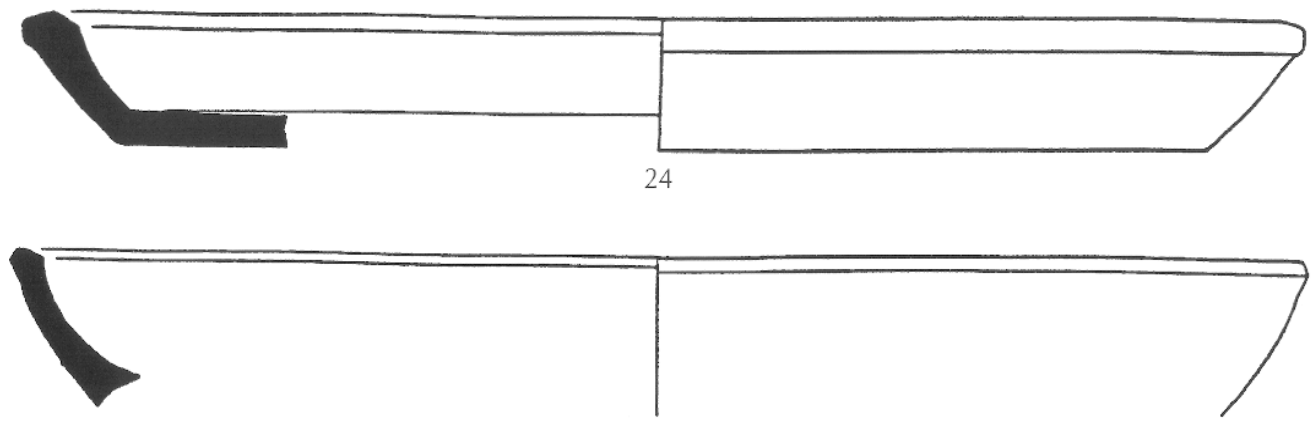

25

Fig. 12 - Sondage A8, céramique des niveaux d'occupation de l'état 1 (cf. annexe I) : 1-10, sigillée ; 11-14, imitation à vernis rouge ou noir ; 15-18, céramique à paroi fine; 19, 20, lampes ; 21, 22, céramique grise fine ;23-25, céramique à vernis rouge " pompéien ". 

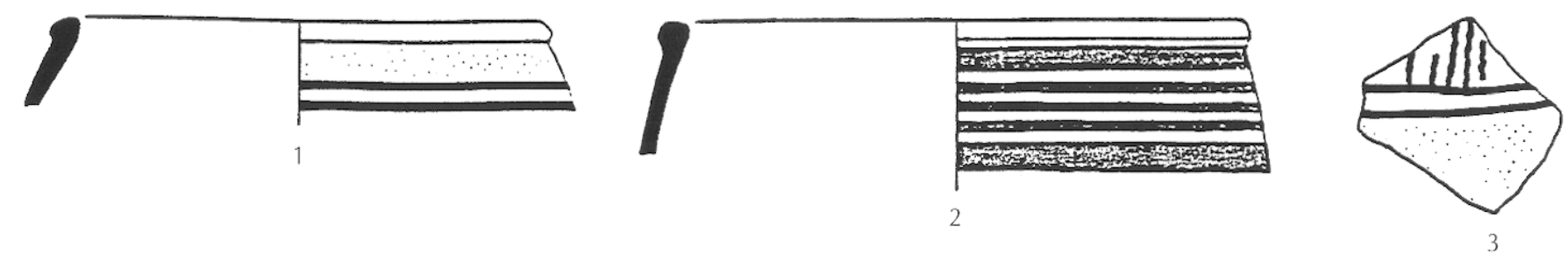

1
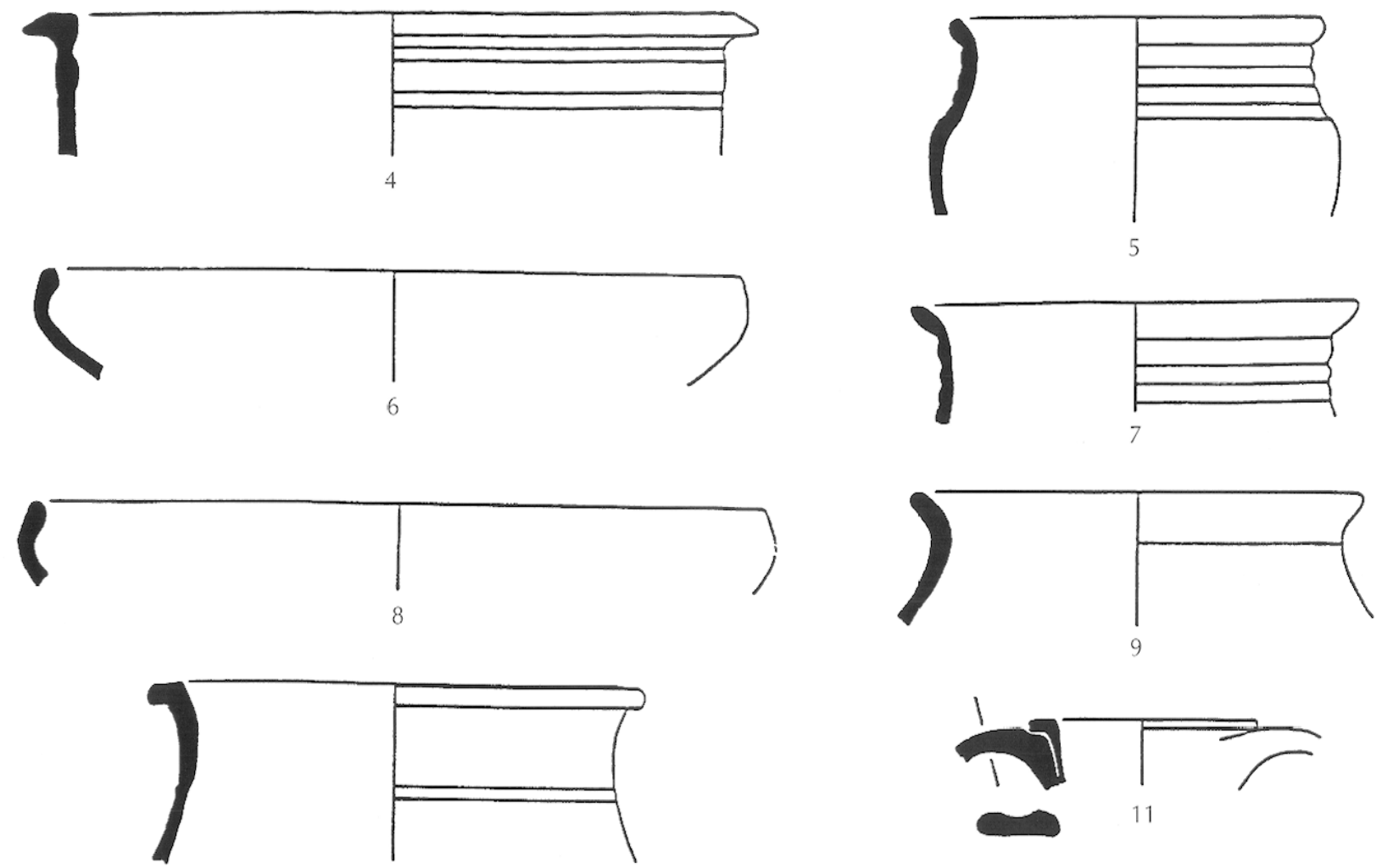

10

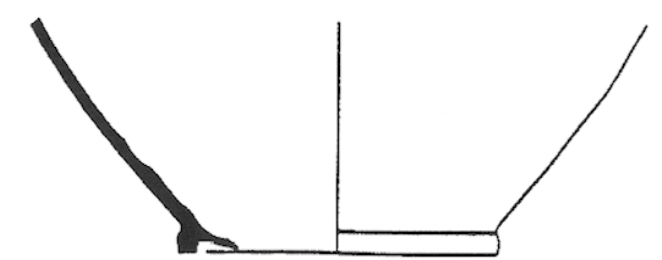

12
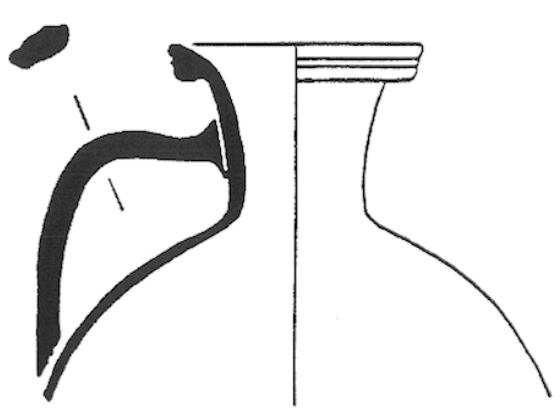

13

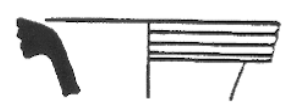

14
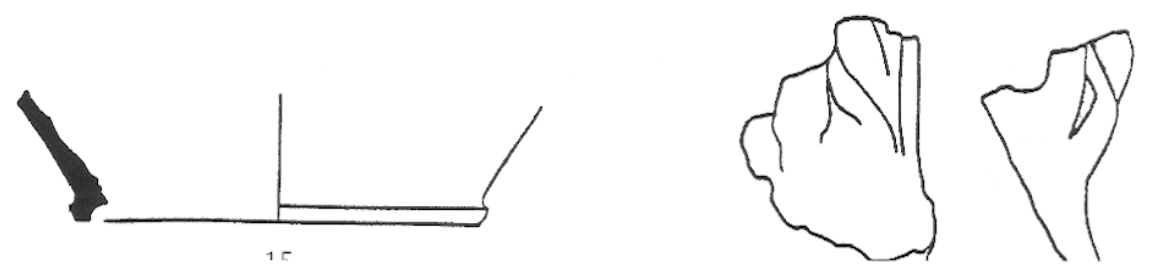

Fig. 13 - Sondage A8, céramique des niveaux d'occupation de l'état 1 (cf. annexe I) : 1-3, céramique peinte ; 4, céramique commune sombre rouge ; 5-9, céramique commune sombre grise ; 10-16, céramique commune claire. 

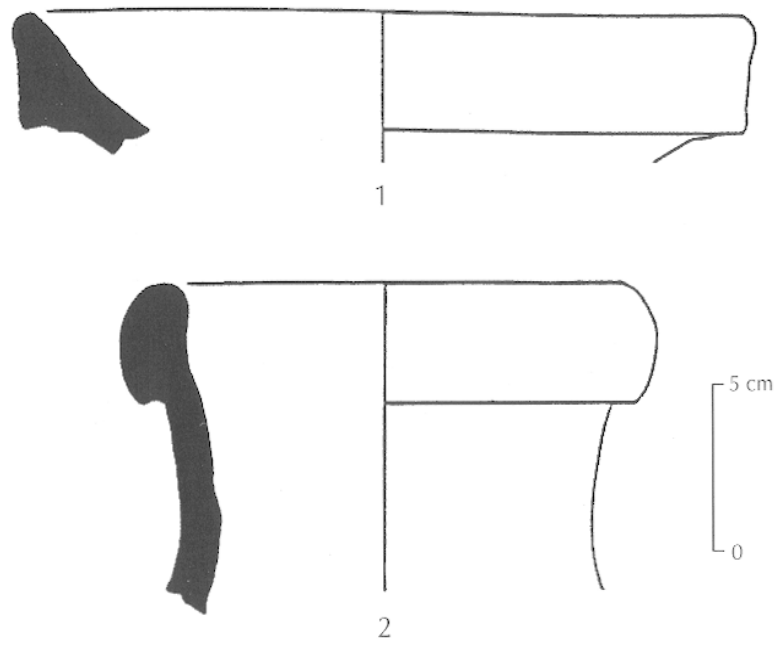

Fig. 14 - Sondage A8, amphores des niveaux d'occupation de l'élal 1 (cf. annexe I).

qu'il faut situer à cet emplacement. En revanche, le plan du reste du bâtiment est presque intégralement restituable (fig. 19). Il est centré autour d'une vaste salle (A), de $12 \mathrm{~m}$ de large, à laquelle on peut attribuer une longueur de $16 \mathrm{~m}$. Cette salle dont Audin avait fait une cour (cf. note 2, p. 242) était certainement couverte ${ }^{6}$ et correspondait à un grand atrium. Elle ouvre à l'ouest sur le tablinum $(\mathrm{T})$ flanqué de deux couloirs.

De part et d'autre de l'atrium se développent deux ailes d'égale largeur. L'aile nord, déjà entièrement dégagée par les travaux anciens, comporte un petit secteur thermal, formé de deux pièces (B) dont l'une conserve les traces d'un pavement en mosaique ${ }^{7}$. Ce secteur thermal, probablement voisin des cuisines $(\mathrm{Cu})$, communique à l'est par un couloir avec un autre ensemble de pièces desservies par une antichambre. Cette antichambre ouvre à la fois sur une grande chambre carrée et sur une plus grande pièce $(\mathrm{O})$ de $12 \mathrm{~m}$ x $6 \mathrm{~m}$ (40 pieds par 20), qui correspond sans doute à un grand triclinium ou oecus. L'aile sud, dont les fouilles récentes ont largement complété le plan, montre une disposition complexe avec une succession de couloirs et d'antichambres desservant des chambres de taille variable $(C)$. Cette aile

6. I.e sol constitué de terrazzo ne présente pas d'impluvium en son centre, ni aucun système d'évacuation des caux pluviales.

7. Ces thermes sont aujourd'hui très restaurés et il est regrettable que nous ne possédions ni photo ni dessin de l'état au moment de la découverte. semble avoir été directement accessible depuis la rue par un long couloir longeant l'atrium.

Si dans le détail on observe des différences, on remarque, notamment dans le schéma de construction d'ensemble, une grande symétrie : la largeur des ailes est pratiquement la même que celle de l'atrium; la partie orientale de ces deux ailes présente une symétrie presque parfaite : de part et d'autre du tablinum et des deux couloirs d'accès au portique, on retrouve une grande chambre carrée donnant sur le portique, précédée d'une antichambre donnant accès, du côté sud, à deux pièces tandis que sur la façade nord l'espace de ces deux pièces est occupé par l'oecus. Les deux couloirs encadrant le tablinum permettent d'accéder à un péristyle en U largement ouvert à l'est, dans lequel Audin avait cru reconnaître une basilique (fig. 7). La disposition de ce péristyle en rebord du plateau permet en effet d'ouvrir sur une large perspective à l'instar des maisons de Pompéi ou d'Herculanum construites sur les remparts. Le portique lui-même recouvrait une galerie, constituant non pas un véritable cryptoportique, mais une galerie jouant le rôle de vide sanitaire et de réserve ou de cave, à laquelle on accédait par l'extérieur sur les côtés sud et nord. Sous l'aile sud du portique a été aménagée une grande pièce au sol de terre battue, décorée de peintures, dont un panneau subsistait encore en place (Audin, 1985, fig. 17). Rappelons que c'est l'existence de cette peinture qui avait amené $\mathrm{A}$. Audin à reconstituer une basilique à deux niveaux.

Un fort mur de terrasse limite à l'est le péristyle et le sépare de la partie orientale en contrebas.

La partie orientale comporte deux niveaux :

- le niveau inférieur, adossé à un premier mur de soutènement, est constitué par les boutiques mises au jour dès 1943. Il s'agit de sept cellules ouvrant largement à l'est. La dernière au nord, en saillie par rapport aux autres, donne l'alignement du portique dont le négatif d'une base de pilier a été retrouvé ;

- le niveau supérieur déborde vers l'ouest au-delà du premier mur de soutènement et vient s'appuyer contre un second mur soutenant la terrasse du péristyle. Cette terrasse intermédiaire entre les boutiques et le péristyle était divisée par des murs situés dans le prolongement de ceux des boutiques. La découverte d'un sol de terrazzo en place nous donne le niveau de cet étage qui devait s'étendre à $5 \mathrm{~m}$ au-dessus du sol des boutiques (fig. 21). 

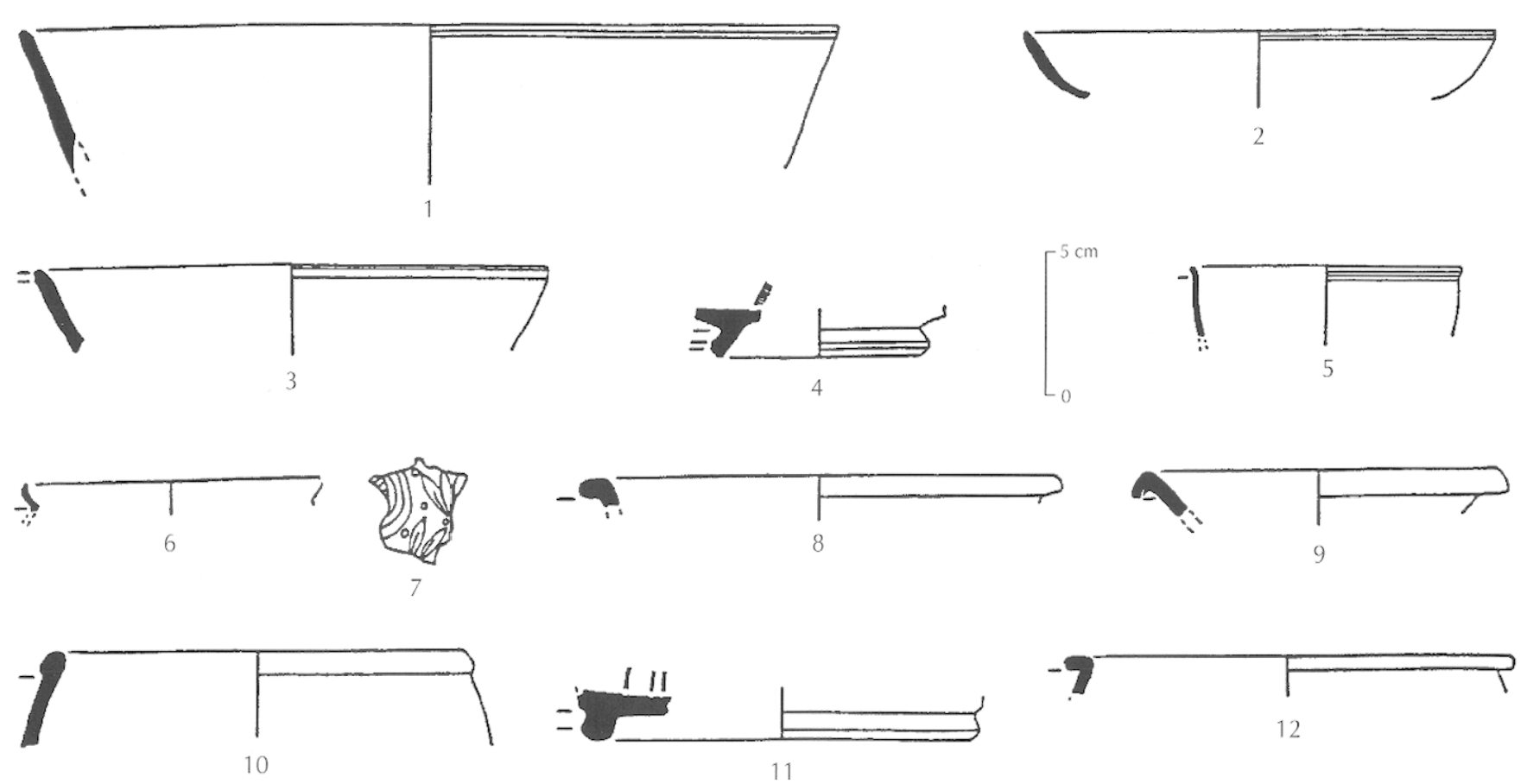

10

11
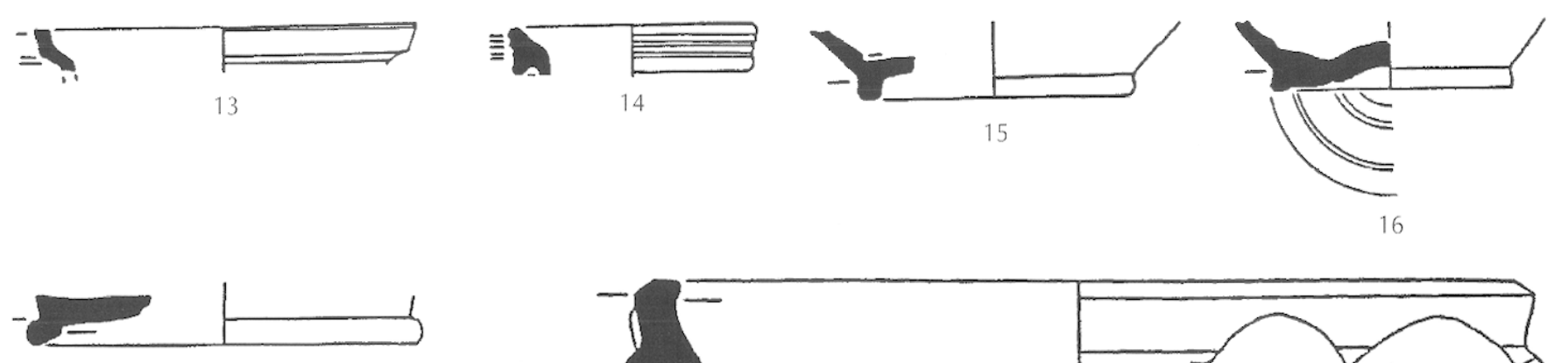

17
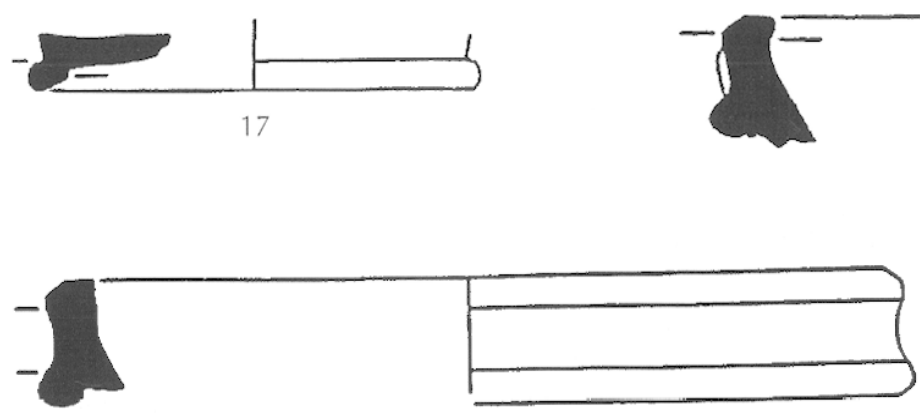

19

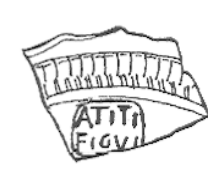

20

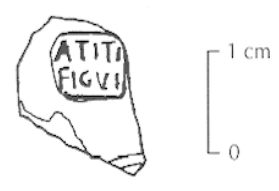

21

Fig. 15 - Sondage D1, céramique du niveau d'installation de la rue, élat 1 (cf. annexe I) : 1, campanienne; 2-4, 20, 21, sigillée ; 5 , 6, céramique à paroi fine; 7 , lampe; 8, 9, céramique grise fine; 10 , céramique peinte; 11 , imitation à vernis noir;

12-19, céramique commune claire.

L'ensemble se caractérise par une construction de très bonne qualité. Les fondations sont constituées de murs de moellons liés au mortier. Dans la partie ouest, ces murs sont larges de $0,60 \mathrm{~m}$ mais l'angle sud-ouest de la façade a montré une fondation de $0,80 \mathrm{~m}$ profondé- ment ancrée dans le terrain naturel. Les murs ont été édifiés à partir des sols de l'habitat précédent ou à partir d'un sol de travail installé sur un léger remblai. La fondation parementée a été enșuite remblayée pour l'installation du sol de circulation. Au-dessus des sols l'élévation 

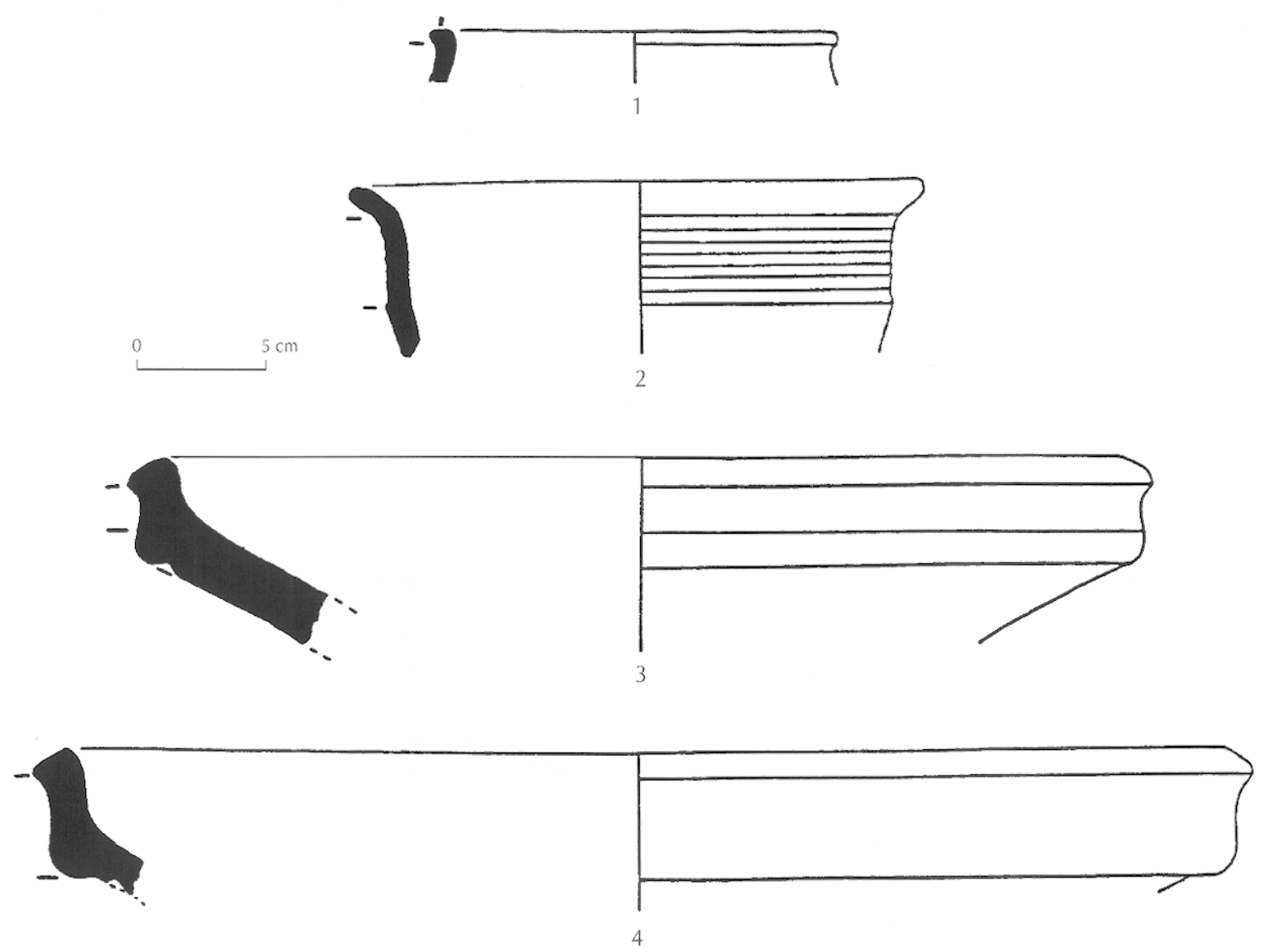

Fig. 16 - Sondage D1, céramique du niveau d'installation de la rue, état 1 (cf. annexe I) : 1, céramique commune sombre rouge; 2, céramique commune sombre noire; 3, 4, céramique commune claire.

était toutefois en briques crues comme l'ont révélé les couches de démolition conservées à l'extérieur de l'édifice ou dans les boutiques du niveau inférieur. Plusieurs sols subsistent dans la partie centrale. Il s'agit pour la plupart de sols de terrazzo; cependant deux espaces ont livré les restes d'un béton avec tuileau qui paraît correspondre au lit de pose d'une mosaique. Dans une des pièces des bains demeure encore un fragment d'opus tessellatum. Dans l'autre, les travaux de restauration ont fait disparaître les traces éventuelles.

La partie orientale correspondant aux boutiques présente une construction encore plus soignée avec un dispositif remarquable jusqu'ici inconnu à Lyon : les murs de $0,75 \mathrm{~m}$ de large sont profondément fondés. Ils sont constitués de blocs de granite, alternant dans les antes des murs avec des rangs de briques (fig. 23) et avec des poutres disposées horizontalement. Ces poutres se retrouvent dans les parements des murs des boutiques, ainsi que dans les deux murs de soutènement. Elles formaient des chaînages horizontaux disposés tous les $0,80 \mathrm{~m}$.

La disposition générale des pièces, telle qu'elle apparaît à la lecture du plan, évoque une maison de type italique. Celle-ci se distingue par sa très grande régularité, son axialité et le souci de la symétrie. Il s'y ajoute le soin apporté à sa construction, son ampleur ainsi que la richesse des aménagements, tout à fait inhabituels en Gaule, à une époque aussi ancienne et jusqu'ici inconnus dans la région lyonnaise. Aucune mosaïque ni aucun balnéaire n'était connu jusqu'ici à Lyon pour cette période. L'atrium a une taille comparable aux plus grands atria pompéiens, comme celui de la maison des Noces d'argent, et correspond au plus grand type défini par Vitruve. Le caractère vitruvien de la construction se retrouve dans la proportion des pièces. Ainsi, côté nord, la grande pièce $(\mathrm{O})$, qui correspond sans aucun doute au triclinium, pré- 

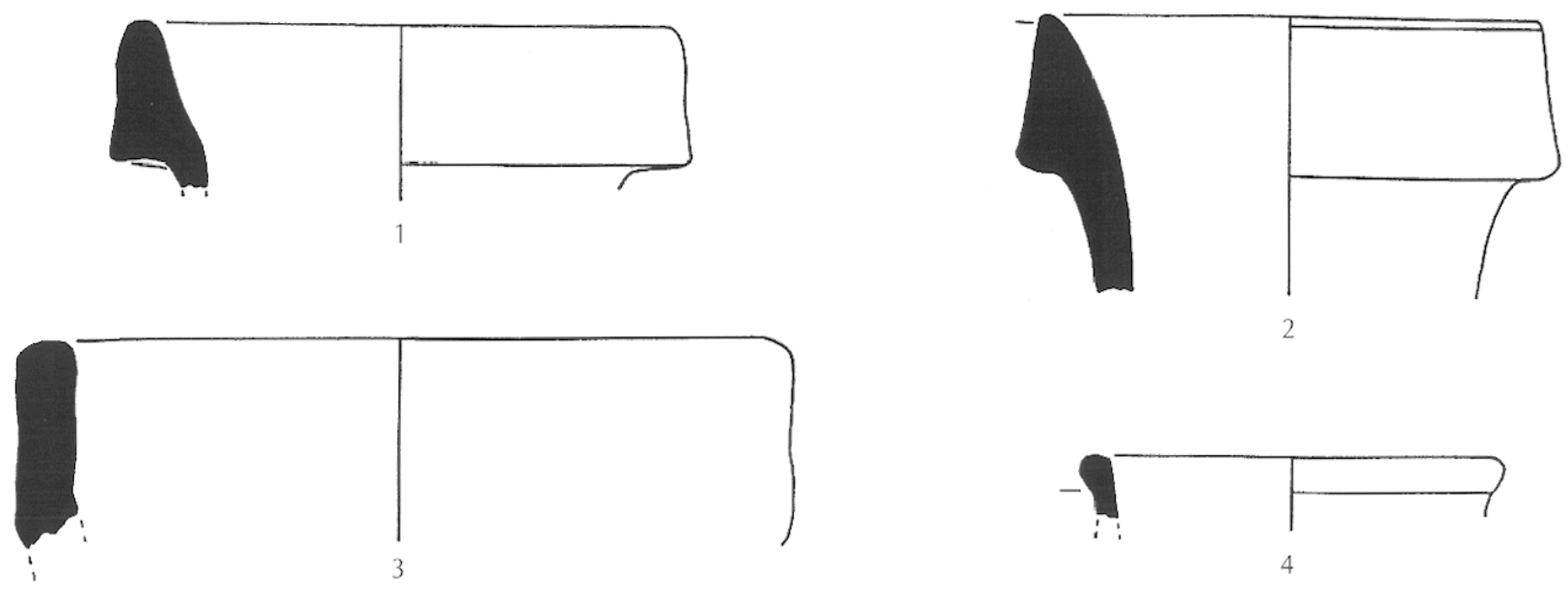

2
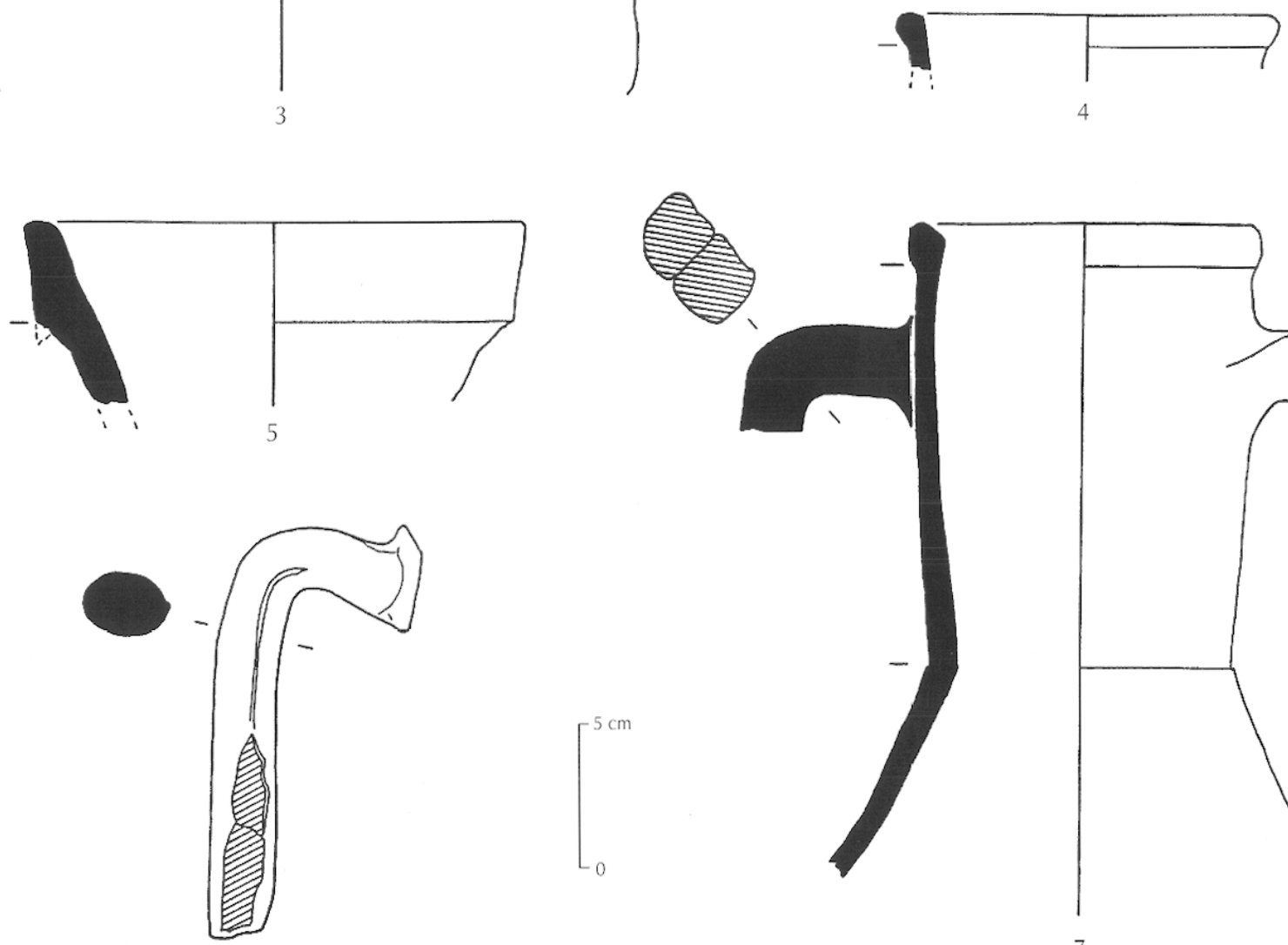

6

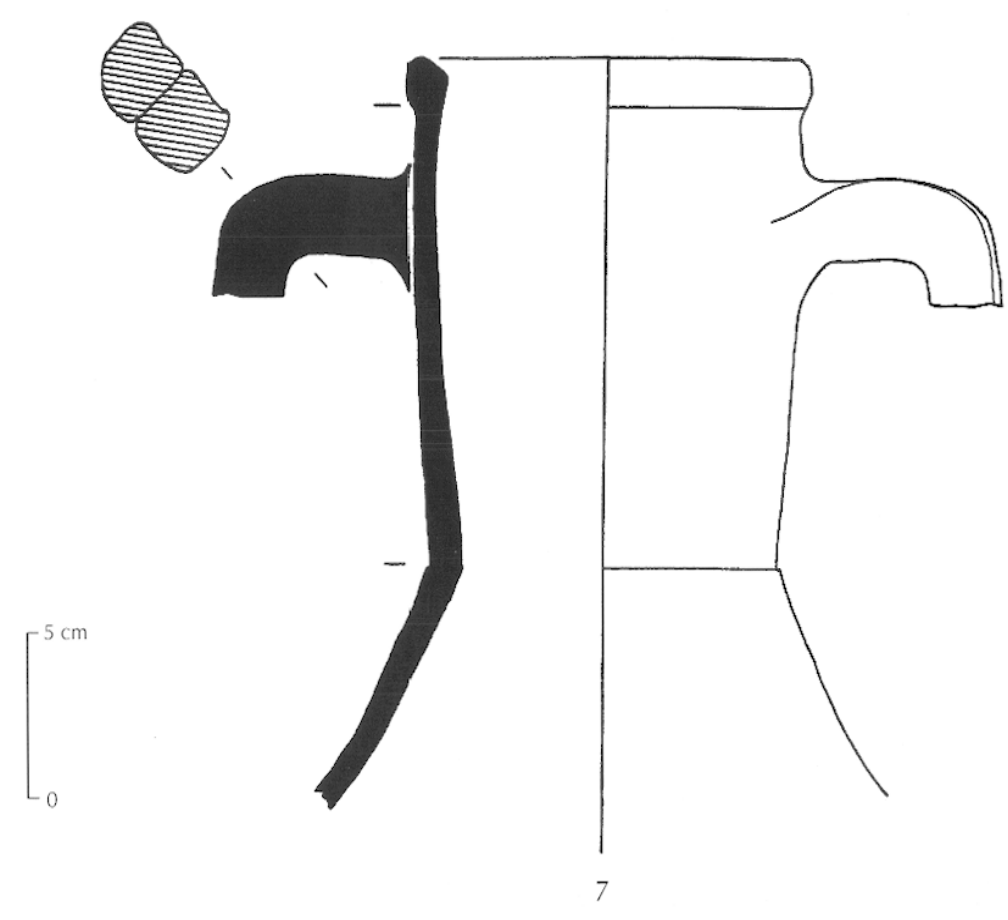

Fig. 17 - Sondage D1, amphores du niveau d'installation de la rue, état 1 (cf. annexe I).

sente-t-elle une longueur double de la largeur, proportion proposée par Vitruve pour les triclinia (Vitruve, De architectura, VI, V). Ces éléments autorisent à reconstituer la longueur de l'atrium à $16 \mathrm{~m}$ en appliquant la règle de Vitruve pour les atria de 40 pieds $(12 \mathrm{~m}$ ) de large (longueur calculée en abaissant la diagonale du carré ayant pour côté la largeur de l'atrium). Tout cela, comme sa situation privilégiée, au-dessus du théâtre, sur un des points les plus hauts de la colline de Fourvière, jouissant d'une vue imprenable sur la vallée du Rhône et la chaîne des Alpes, concourt à faire de ce bâtiment un édifice exceptionnel. Cet aspect est encore renforcé par le fait que la construction s'est accompagnée d'un rehaussement important des sols par rapport à l'état précédent (1,50 m environ), surélevant ainsi le bâtiment par rapport aux rues environnantes et soulignant son importance.

Le plan axial et la symétrie de l'ensemble, inhabituelles pour les habitations urbaines de l'époque, offrent au contraire des analogies avec des constructions militaires, notamment avec les praetoria des camps, en parti- 


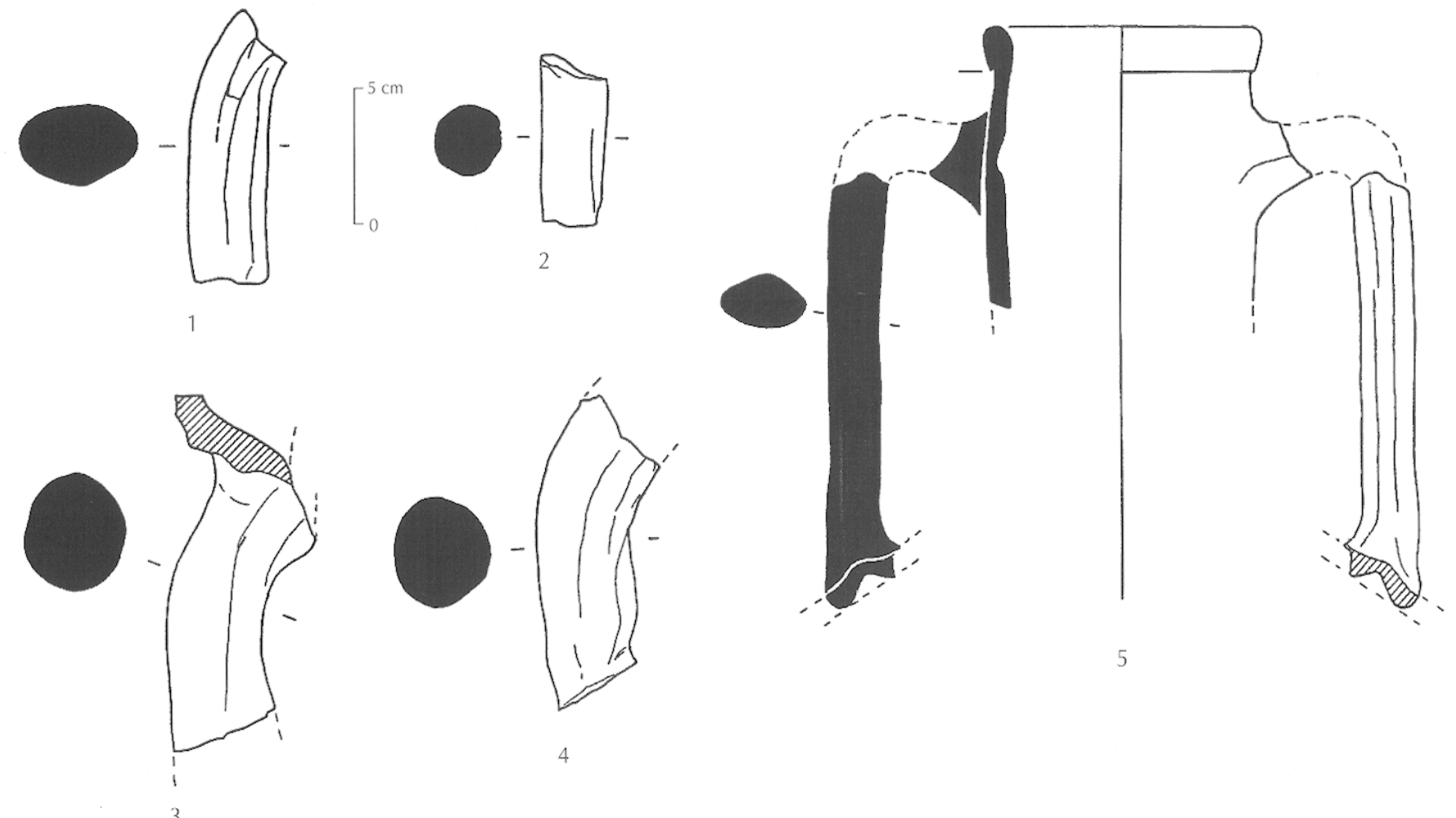

Fig. 18 - Sondage D1, amphores du niveau d'installation de la rue, élat 1 (cf. annexe I).

culier avec celui d'Oberaden ${ }^{8}$ (fig. 24), mais aussi avec des palais comme ceux de la Plate-Forme ou de la Butte Saint-Antoine à Fréjus, interprétés comme la résidence du préfet de la flotte et du gouverneur de la province (Février, 1977). Il est donc plus que probable qu'il ne s'agit pas de la demeure d'un riche particulier, mais du palais d'un des principaux dignitaires de la colonie. Il nous semble alors possible que cette construction remarquable à tout point de vue ait été le palais ("prétoire ») $\mathrm{du}$ gouverneur. Sa date de construction, vers 20 avant J.-C. ( $c f$. infra), à l'époque où Agrippa est gouverneur de la Gaule et séjourne à Lyon ${ }^{9}$, nous amène à formuler l'hypothèse qu'il s'agirait du " prétoire " de ce dernier. Cette hypothèse, que l'on ne peut démontrer de manière formelle en l'absence de documents épi-

8. Le prétoire d'Oberaden présente notamment un grand atrium, que l'on peut supposer couvert et dont les dimensions sont voisines et les proportions identiques. À partir de cet atrium, deux couloirs qui encadrent une grande salle occupant la place du tablinum donnent accès à une cour arrière, peut-être à portiques. Les dimensions de l'ensemble, environ $40 \mathrm{~m}$ x $60 \mathrm{~m}$ se rapprochent également de l'édifice lyonnais.

9. Après un premier séjour entre 40 et 37 avant J.-C., Agrippa séjourna en Gaule entre 20 et 19 ou 18 avant J.-C. (Roddaz, 1984, p. 357 et 384 ). graphiques, expliquerait le caractère exceptionnel du bâtiment.

\section{LA CHRONOLOGIE DE LA DEUXIÈME PHASE}

L'abondant matériel céramique issu des couches de démolition du premier état et des remblais d'installation de l'état 2 permet de dater la destruction des premières constructions et, par voie de conséquence, l'installation du deuxième état vers 20 avant J.-C. (cf. supra, p. 249). Concernant la date d'abandon de l'édifice, les éléments sont plus épars. Sur la terrasse supérieure, les dégagements opérés dans les années 70 ont fait disparaître toutes les couches de démolition qui recouvraient les sols de terrazzo. La majeure partie du mobilier correspondant à ces couches a disparu. Seul subsiste un petit lot de matériel provenant de tranchées exploratoires réalisées en 1965 (Audin, 1965a), mais non localisé stratigraphiquement. Toutefois, les sondages réalisés dans la partie nord des boutiques, où les remblais de démolition étaient encore en place, ont livré des éléments pour dater la destruction de ces boutiques. On signalera en 


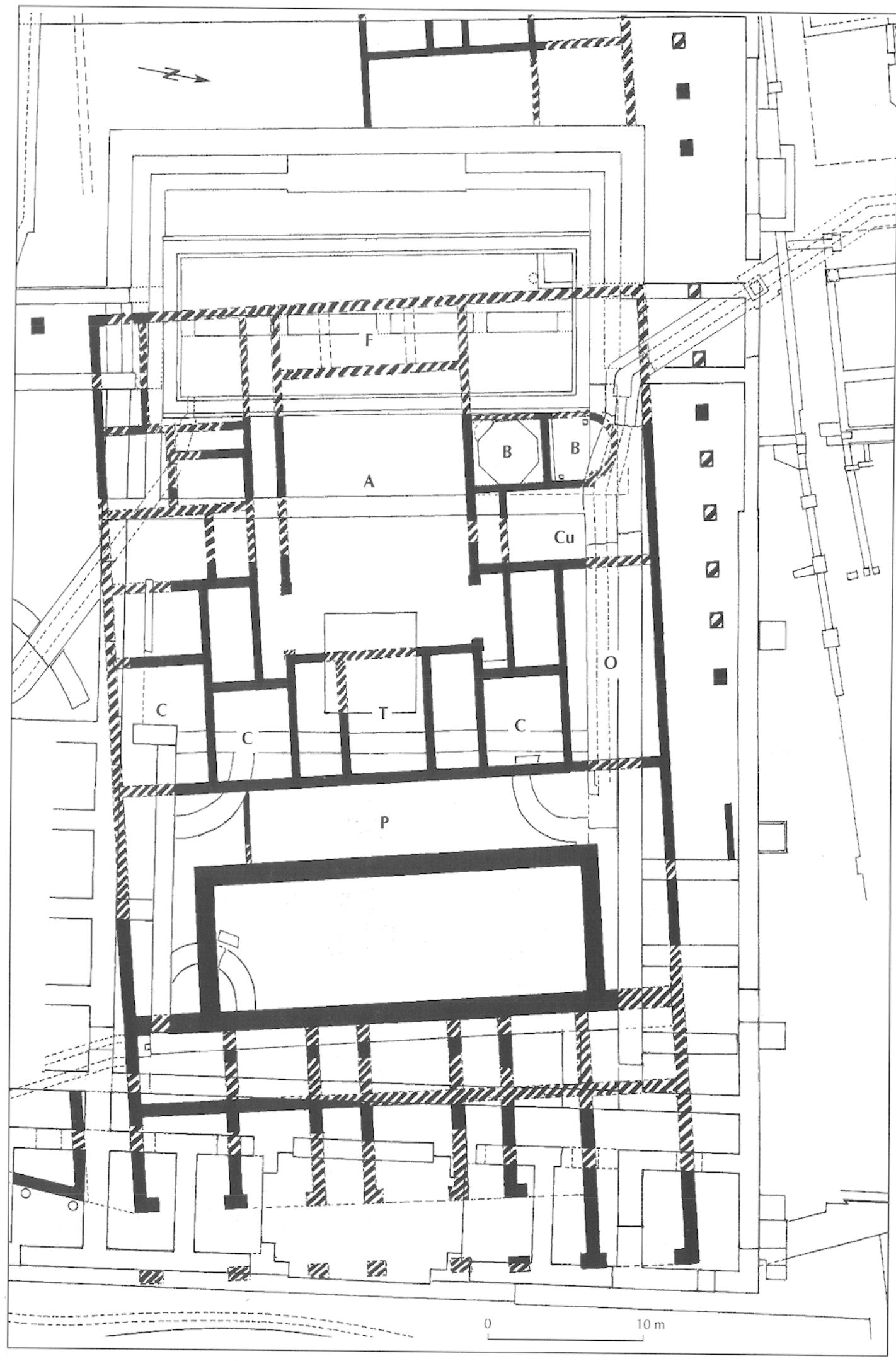

Fig. 19 - Plan $d u$ "prétoire » : A, atrium ; $B$, balneum ; $C$, cubiculum ; $C u$, culina ; $F$, fauces ; $O$, oecus ; $P$, péristyle ; $T$, tablinum. 


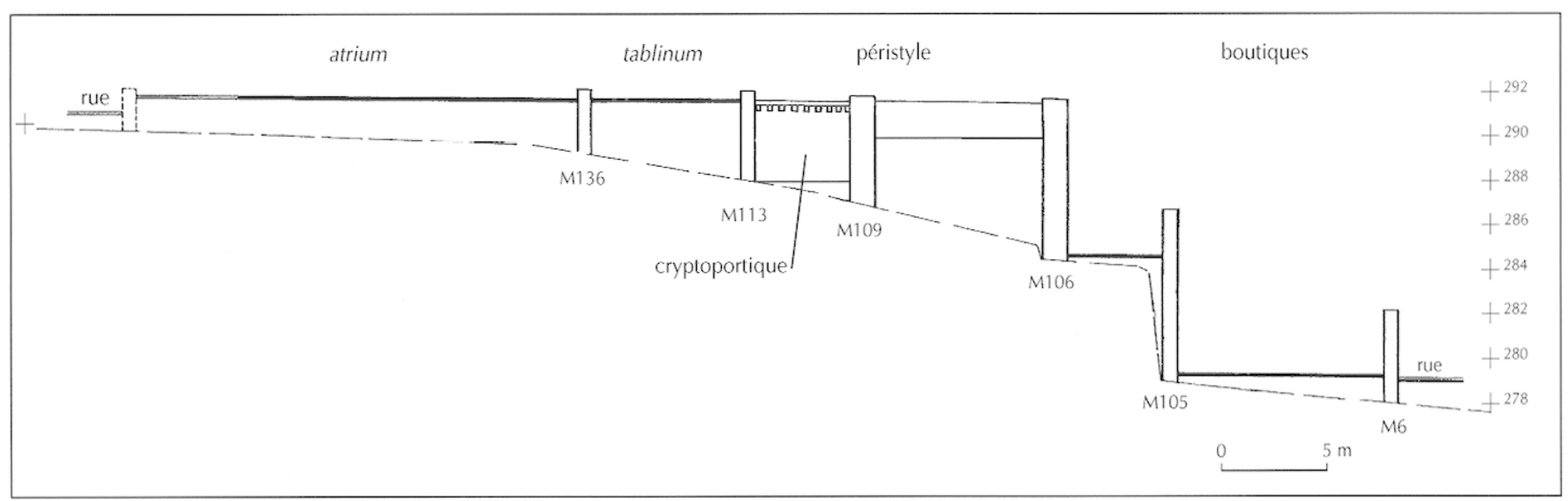

Fig. 20 - Coupe ouest-est des substructions du « prétoire ».

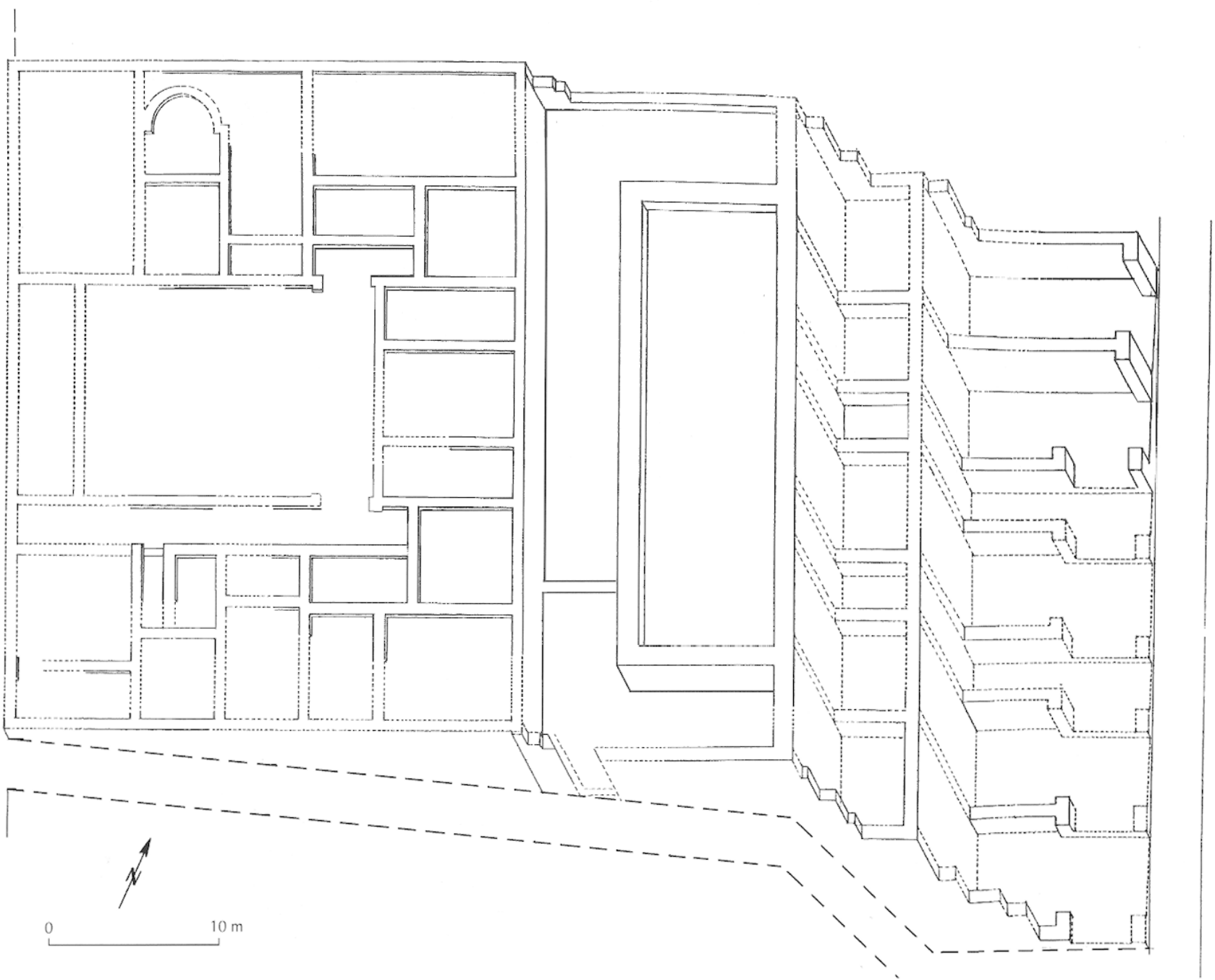

Fig. 21 - Axonométrie sélective des vestiges du "prétoire " (état 2) (I. Parent). 
OUEST B8
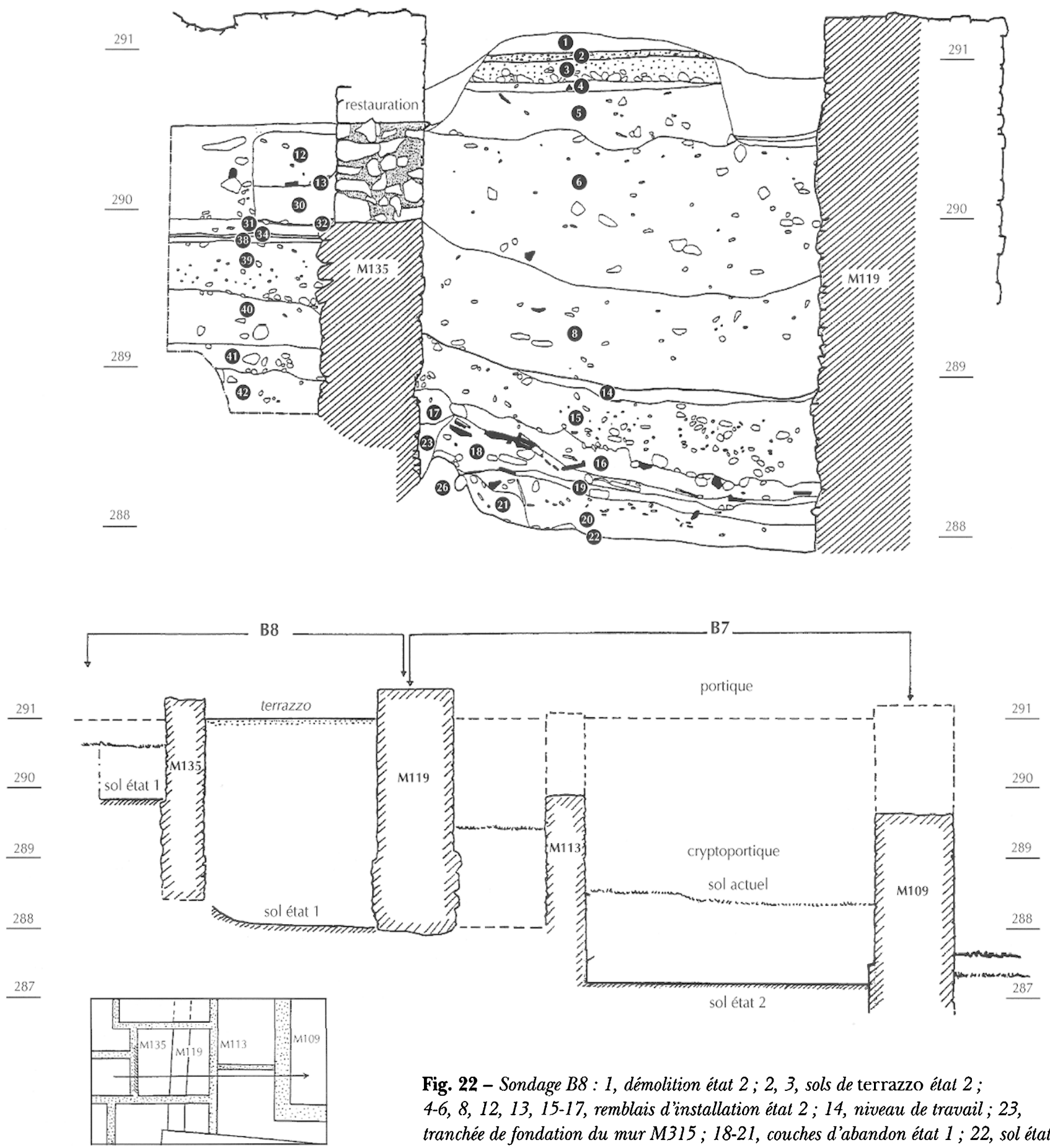

Fig. 22 - Sondage $B 8: 1$, démolition état $2 ; 2,3$, sols de terrazzo étal 2 ; $4-6,8,12,13,15-17$, remblais d'installation état $2 ; 14$, niveau de travail ; 23, tranchée de fondation du mur $M 315 ; 18-21$, couches d'abandon état $1 ; 22$, sol état $1 ; 26$, moraine ; 30-32, installation état $2 ; 34,38$, sol état $1 ; 39-42$, remblais d'installation état 1 . Sondages $B 7$ et $B 8$, coupe ouest-est avec les différents niveaux de terrasse: M135, M113 et M109, murs de l'état 2; M119, mur de l'état 3. 


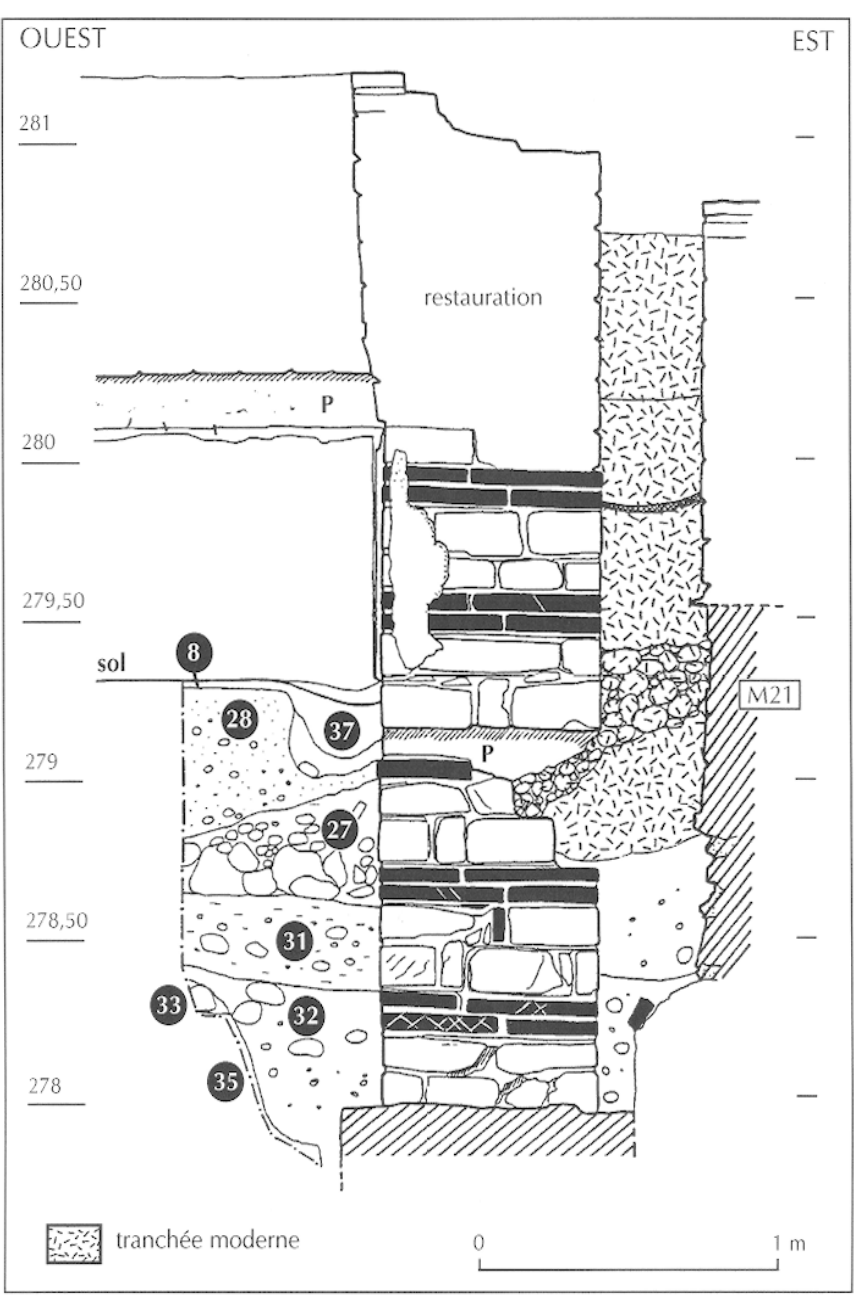

Fig. 23 - Sondage A7, coupe stratigraphique ouest-est et élévation de l'ante (M8) d'une boutique de l'état $2: 8$, sol de la boutique; 28, 27, 31 , remblais d'installation du niveau des boutiques; 32 , comblement de la tranchée de fondation de $M 8 ; 33,35$, radier de galets du mur M24 de l'état $1 ; 37$, petite fosse sous le sol.

particulier un petit dépotoir ménager, lié à un foyer installé sur le sol du portique en avant d'une boutique en A6. Ce dernier a livré une vingtaine de vases (fig. 25 à 27 et annexe I, p. 269-270) presque complets pour la plupart. Le lot comprend surtout des vases culinaires mais compte aussi plusieurs gobelets à paroi fine, un plat en sigillée de l'atelier de la Muette estampillé L. TYRS(us) et deux bols peints. Ce dépotoir était lié à un foyer installé directement sur le sol du portique. Sur le sol reposaient également plusieurs tambours de colonnes rudentées en calcaire (fig. 28).

Le reste du mobilier exhumé dans les boutiques, bien que plus fragmentaire, présente un faciès identique,

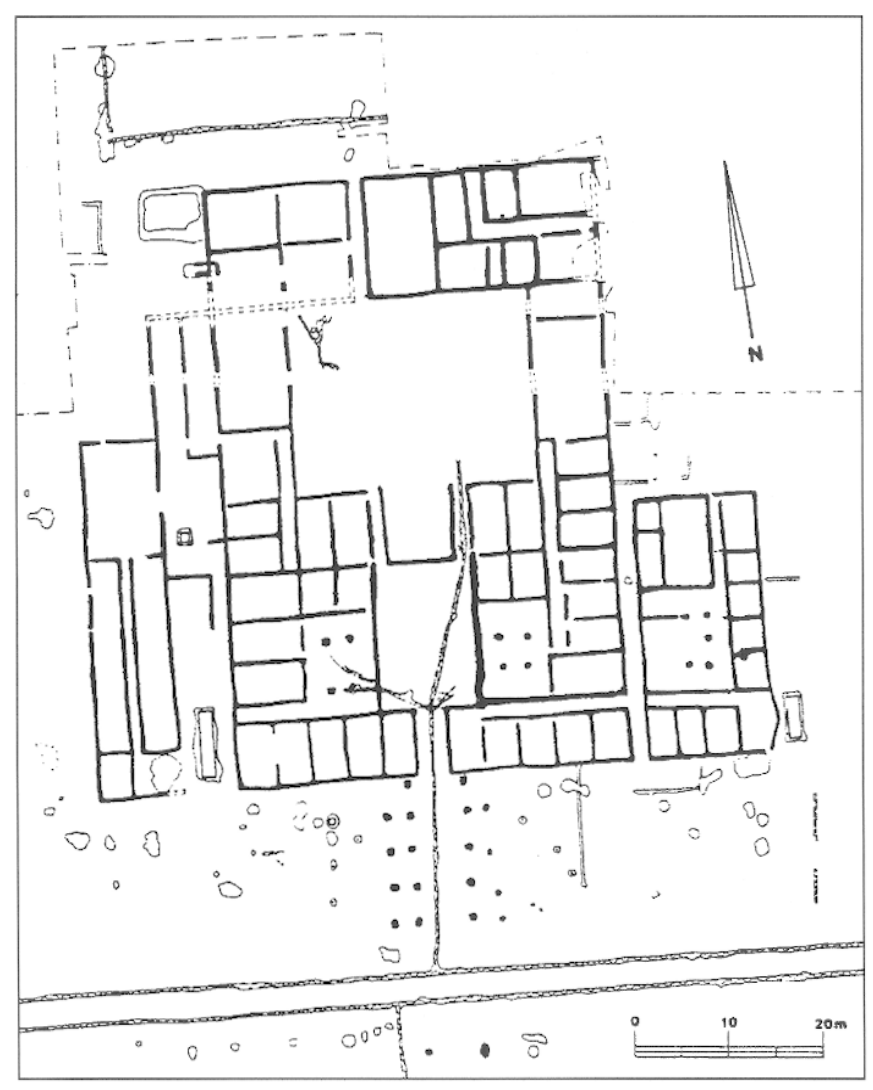

Fig. 24 - Plan du praetorium d'Oberaden (d'après Kühlborn, 1989).

augustéen classique que l'on peut rapprocher de celui de Haltern. On note en effet la présence majoritaire des vases du service 2 de Haltern et l'absence, en revanche, des productions sud-gauloises. On notera également la présence de quatre monnaies sur le sol des boutiques ou dans les remblais installés lors de la construction des fondations du grand édifice; il s'agit de trois as de Nîmes et d'un as d'Auguste. Ce faciès est comparable à celui du matériel recueilli dans les tranchées réalisées en 1965. Bien que peu abondant, ce dernier fournit en effet des éléments chronologiques comparables : dominante du service 2 de Haltern et absence des productions sud-gauloises.

Un dernier élément pour l'abandon du " prétoire » est fourni par le sondage effectué au carrefour formé par la rue nord-sud, dite « de Cybèle » et la rue est-ouest longeant la façade nord du "prétoire " (sondage D1). Il faut rappeler que la rue nord-sud est partiellement condamnée par la construction du grand édifice monumental dit « sanctuaire de Cybèle ». Or les niveaux supérieurs de la 

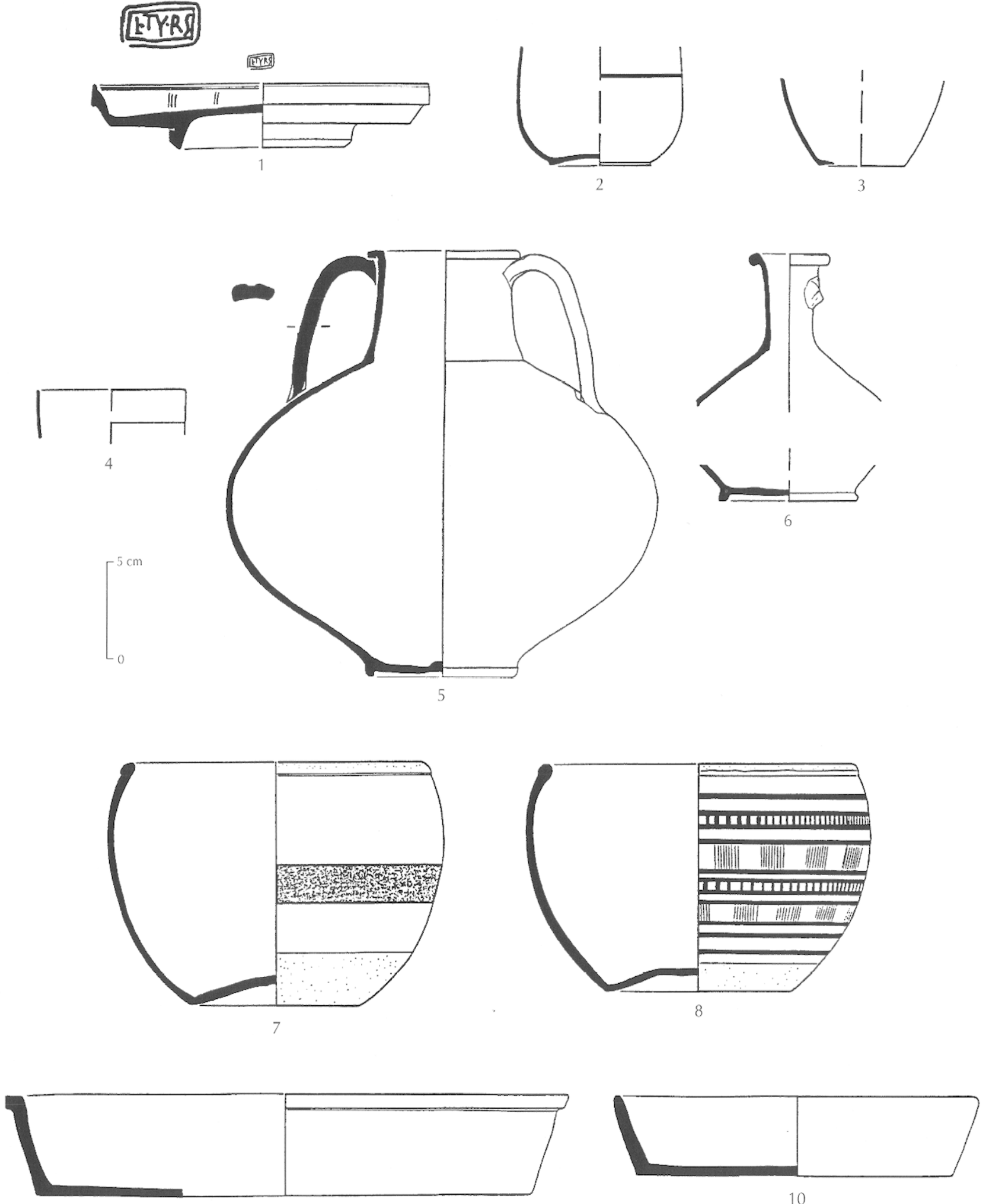

Fig. 25 - Sondage A6, céramique du foyer, abandon de l'état 2 (cf. annexe I) : 1, sigillée; 2-4, céramique à paroi fine; 5, 6, céramique commune claire; 7, 8, céramique peinle; 9, 10, céramique commune sombre. 

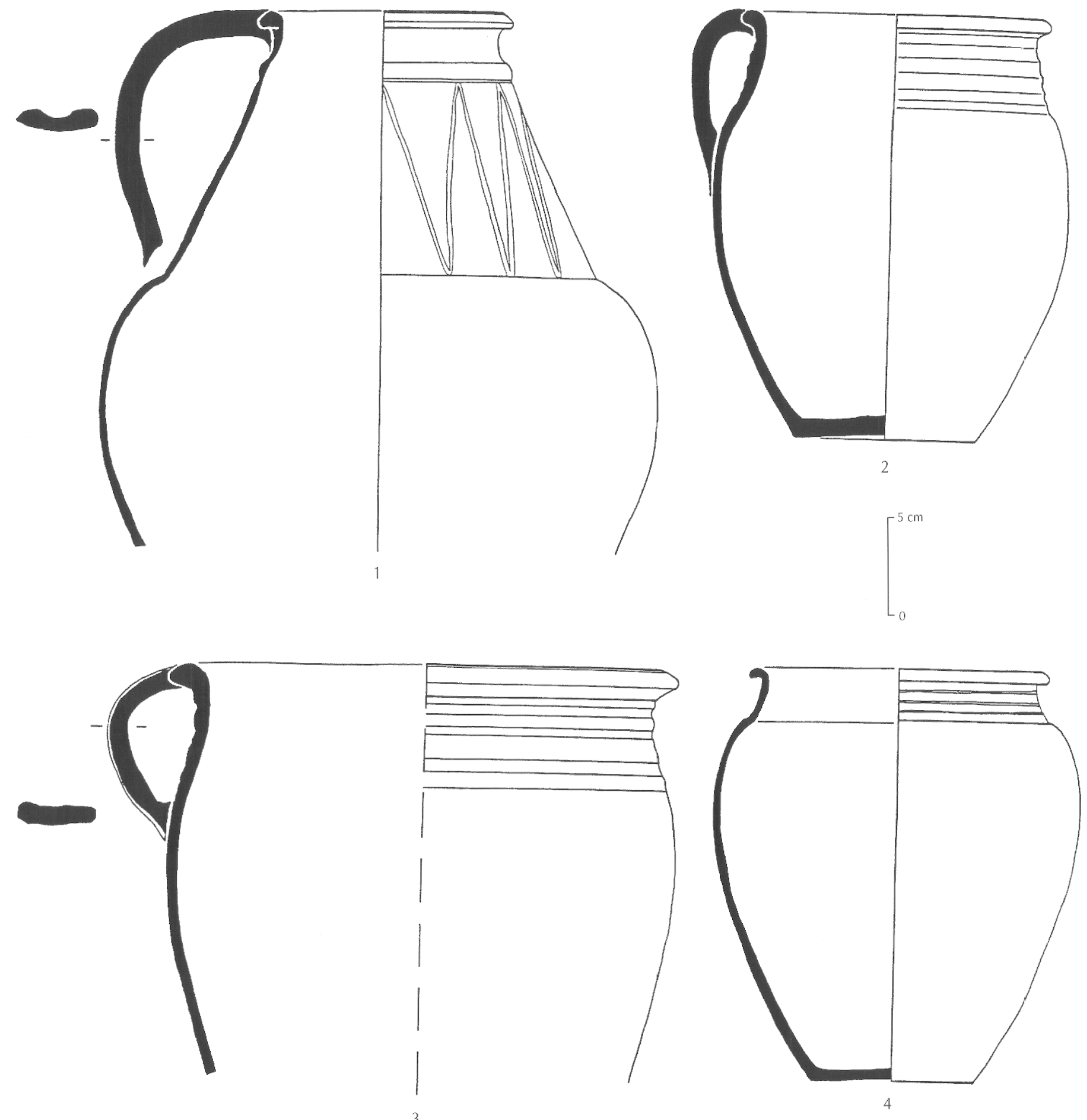

Fig. 26 - Sondage A6, céramique du foyer, abandon de l'état 2 (cf. annexe I). Céramiques communes sombres grises. 

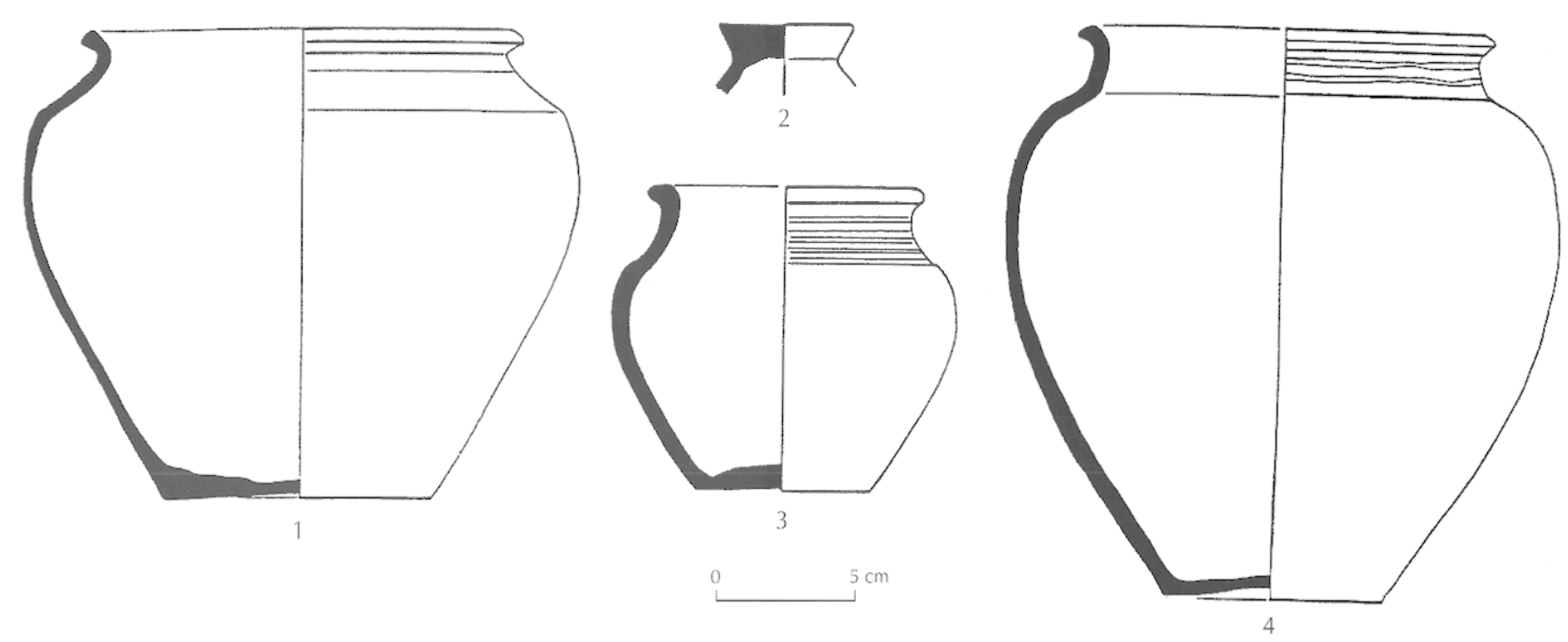

Fig. 27 - Sondage A6, céromique du foyer, abandon de l'état 2 (cf. annexe I). Céramiques communes sombres grises.

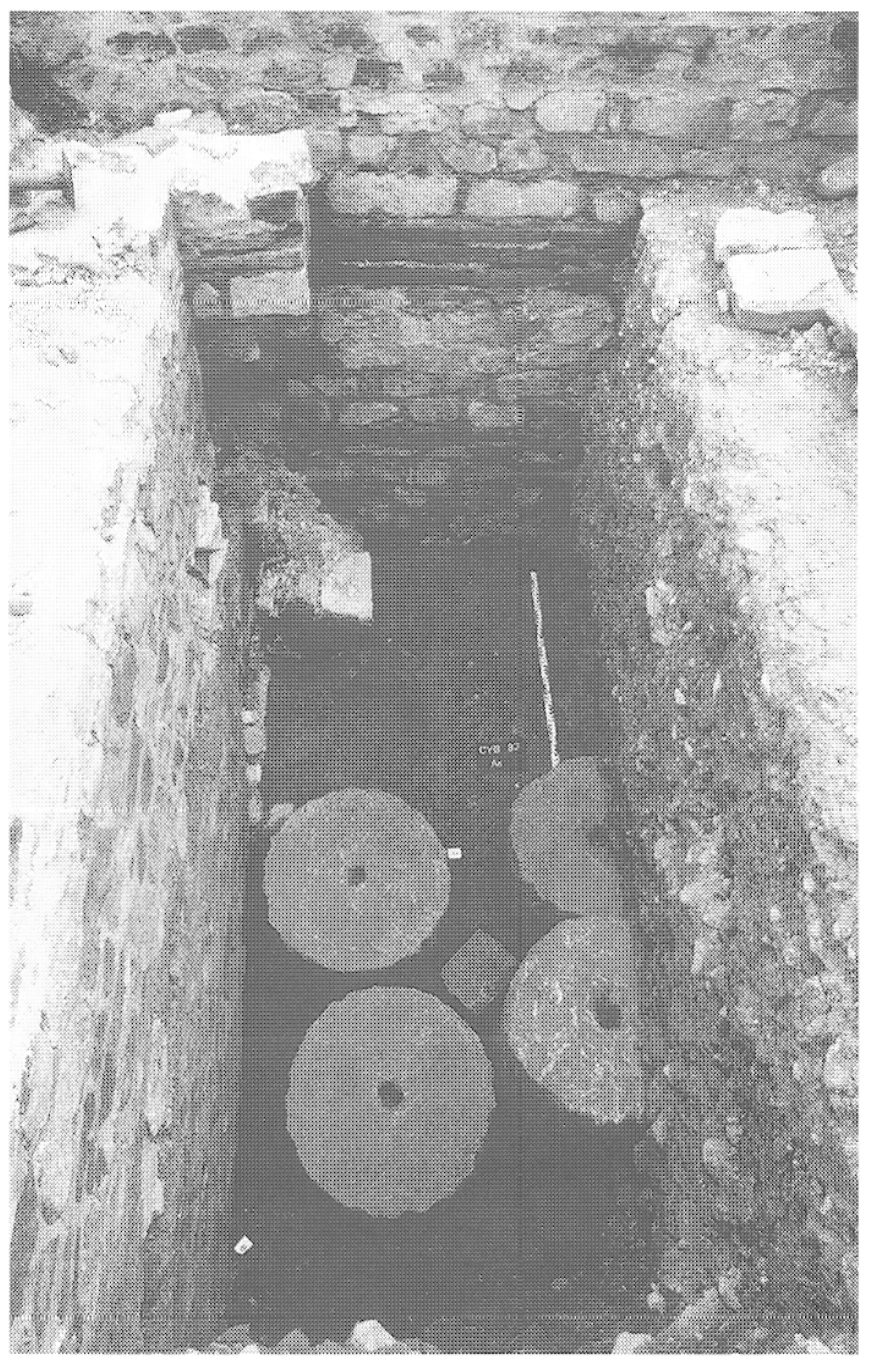

chaussée et le comblement des égouts ont livré un abondant matériel céramique augustéen classique que l'on peut mettre en relation avec la dernière utilisation de la rue ou son abandon. Le comblement de l'égout a livré à lui seul plus de 7000 tessons dont environ 500 fragments de sigillée, qui appartiennent à une écrasante majorité au service $\mathrm{lC}$ et au service 2 . Les mêmes couches ont livré une quinzaine de monnaies dont les plus récentes sont trois as à l'autel de Lyon et quatre as de Nîmes.

Tous ces éléments concourent à démontrer que le "prétoire " a été désaffecté dans son ensemble au tout début $d u I^{\text {er }} s$. de notre ère. On peut donc à l'heure actuelle fixer sa création vers 20 avant J.-C. et sa destruction vers 10 après J.-C.

\section{LE PRÉTENDU SANCTUAIRE DE CYBÈLE}

La troisième phase de construction est matérialisée par le grand édifice dénommé « sanctuaire de Cybèle ». Ce dernier forme un quadrilatère de $50 \mathrm{~m}$ sur sa face ouest pour $52,70 \mathrm{~m}$ sur sa face est, et de $81,66 \mathrm{~m}$ sur son côté sud pour $84 \mathrm{~m}$ au nord. Cette nouvelle construction déborde les limites des îlots précédents et englobe

Fig. 28 - Sondage A6, fûts de colonnes disposés sur le sol du portique de l'état 2. 
une portion de la rue primitive nord-sud, mais mord également sur les rues est-ouest. Elle présente en outre une orientation différente des constructions précédentes, mais aussi des autres vestiges aux alentours.

Les dégagements opérés dans les années 70 ont fait disparaître tous les niveaux supérieurs et il ne reste aujourd'hui aucun témoin des couches liées à l'occupation de l'édifice. Les fouilles réalisées jusqu'aux sols de terrazzo du "prétoire ", voire à un niveau inférieur là où aucun sol bétonné n'apparaissait, ont de même fait disparaître les sols de travail liés à la construction du bâtiment, excepté en de rares endroits. Il faut ajouter qu'une grande partie des murs est fondée en tranchée étroite (bourrage de maçonnerie dans une tranchée de la largeur du mur). Pour ces raisons, les sondages effectués depuis 1991 n'ont apporté que très peu d'éléments nouveaux pour l'interprétation de l'édifice. Parmi les éléments nouveaux on peut signaler la découverte d'un égout nord-sud venant se jeter dans l'égout de l'aile nord ; la destruction totale de cet égout au niveau de sa jonction avec l'égout nord et la restauration poussée de ce dernier interdisent de déterminer si les deux égouts ont été construits simultanément ou si l'égout nouvellement découvert est un ajout postérieur. En revanchc, sur le côté sud, l'égout nord-sud chevauche un égout perpendiculaire dont il a obstrué le canal. On aurait donc bien là deux états distincts qui témoignent des remaniements subis par l'édifice. Parmi les modifications postérieures il faut ajouter la construction de contreforts couchés, en quart de cercle, que l'on doit très certainement mettre en rapport avec la construction de la citerne. Ces contreforts, ajoutés après coup, étaient sans doute destinés à contenir la poussée exercée par la masse de la citerne.

On peut cependant proposer aujourd'hui une autre restitution du plan que celle proposée par A. Audin en 1985. Le bâtiment se compose en fait de deux parties (fig. 29).

- À l'est un grand quadrilatère de $63 \mathrm{~m} \times 53 \mathrm{~m}$. La moitié orientale de ce quadrilatère, construite à la rupture de pente, est établie sur le système d'alvéoles de construction constituant des caissons et des couloirs voûtés. Ces caissons construits en élévation à partir des sols de l'état 2 ont été remblayés volontairement au moins dans leur partie basse, mais il est probable que les caissons des niveaux supérieurs étaient vides, sans que l'on sache si les parties supérieures constituaient des salles souterraines accessibles. La moitié orientale en revanche, installée à partir de la terrasse supérieure, présente des fondations bâties presque entièrement en tranchée étroite. Le plan des fondations permet de reconstituer, au niveau du sol, un espace presque carré de $38 \mathrm{~m} \times 35 \mathrm{~m}$, entouré sur quatre côtés (et non trois) par une galerie de $10 \mathrm{~m}$ de large sur les côtés sud, nord et est, et de seulement $9 \mathrm{~m}$ sur le côté ouest. La galerie ouest est doublée par une seconde galerie de $6 \mathrm{~m}$ de large. Il s'avère en effet que les deux pavillons reconstitués par Audin, à l'extrémité des galeries nord et sud (fig. 5), correspondent en fait aux deux extrémités d'une galerie unique interrompue par la citerne. L'espace central semble avoir été divisé postérieurement par un mur nord-sud. On ignore encore si la base quadrangulaire dont $\mathrm{A}$. Audin faisait le socle de l'autel appartient au plan initial ou aux remaniements postérieurs.

- Côté ouest, la seconde partie est constituée par un vaste espace de $16 \mathrm{~m}$ de large sur $49 \mathrm{~m}$ de long (du nord au sud), accolé à la double galerie du secteur oriental. Cette grande aire est bordée sur son côté ouest par un système de deux murs parallèles incluant des niches alternativement rectangulaires et semi-circulaires. Ce secteur semble avoir fait, lui aussi, l'objet de transformations. Une exèdre rectangulaire en saillie sur la façade correspond peut-être à une modification postérieure, à moins qu'il ne s'agisse au contraire de l'état initial. Il s'agit là d'un point important que devront vérifier les prochaines campagnes.

À l'extérieur de la façade nord, au débouché de la portion de rue conservée, est accolé un massif rectangulaire, constituant probablement un socle de fontaine plutôt que le socle d'un escalier.

Tel qu'il vient d'être décrit, le bâtiment évoque davantage un petit forum qu'un temple, bien que les fora à quadriportique soient peu courants. Le secteur ouest suggère une basilique, et la largeur de $16 \mathrm{~m}$ est compatible avec une couverture en charpente. La dimension de l'ensemble parait toutefois trop restreinte pour imaginer qu'il puisse s'agir du forum de la colonie et il faut rechercher d'autres hypothèses. Une des questions est de savoir si ce nouvel édifice a un rapport avec celui qui l'a précédé. La durée de vie relativement courte du "prétoire" pourrait s'expliquer par la construction au début du ${ }^{\text {er }} s$. du palais impérial dont nombre d'archéologues ont situé 


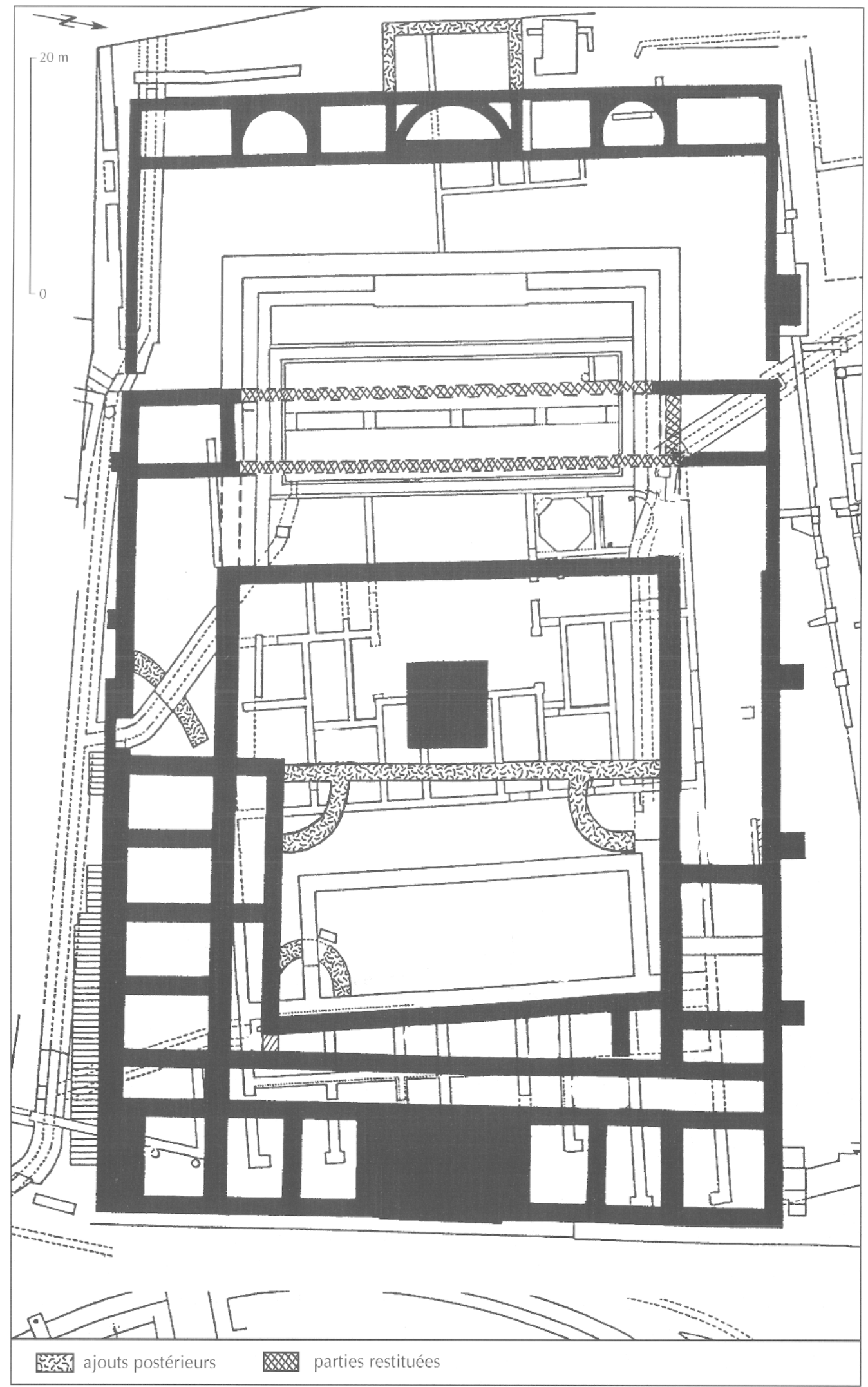

Fig. 29 - Nouvelle hypothèse de restitution des substructions du grand édifice, dit " sanctuaire de Cybèle ». 
la localisation à Fourvière ${ }^{16}$. Faut-il voir dans le nouvel édifice un simple bâtiment administratif ayant remplacé le «prétoire»dont la fonction résidentielle était désormais assurée par le palais, ou faut-il y voir un bâtiment commémorant l'emplacement du palais ayant hébergé Agrippa et peut-être Auguste lors de son séjour à Lyon entre 16 et 13 avant J.-C. ? On y aurait bien vu dès lors un sanctuaire du culte impérial, si ce dernier n'était connu à l'emplacement du Verbe-Incarné à $100 \mathrm{~m}$ à peine.

Une autre possibilité serait de voir dans cet édifice un collège des Augustales, mais on n'en connaît pas d'équivalent dans le monde romain. Les collèges connus à Ostie, Misène ou Herculanum sont de taille beaucoup plus réduite (à Ostie $35 \mathrm{~m}$ x $30 \mathrm{~m}$ ). Seul le site de Sarmizegetusa a livré un bâtiment comparable, avec une cour à quadriportique et une basilique à une nef, identifié par le fouilleur comme l'aedes Augustalium, mais cette hypothèse a été critiquée par Balty (1991) pour qui il s'agit ni plus ni moins du forum!

L'hypothèse d'un collège des Augustales d'une ampleur inusitée pourrait toutefois s'expliquer par l'importance à Lyon du culte impérial et des sévirs augustaux. On connaît en effet plus de 70 inscriptions, dans leur majorité plus tardives il est vrai, qui se rapportent aux sévirs et on continue à en trouver régulièrement ${ }^{11}$. La proximité du temple du culte impérial irait dans le même sens. De plus cette hypothèse serait compatible avec la découverte de l'autel taurobolique de 160 (si l'on conserve l'hypothèse que la découverte eut bien lieu à cet emplacement), dont rien ne dit qu'il fut érigé dans un sanctuaire de Cybèle ${ }^{12}$, mais dont le dédicant était sévir augustal. En revanche on s'expliquerait très mal l'installation de la citerne dans un tel édifice. Peut-être faut-il voir plus simplement une schola comparable à celle de Velia (Gros, 1996, p. 379), sorte de bourse de commerce et de marché spécialisé réservé à une corporation particulière, comme l'édifice d'Eumachia à Pompéi ou la pseudo-basilique

10. I.e point le plus complet sur la question du palais impérial se trouve dans Fabia, 1933.

11. En 1995, la fouille d'une nouvelle partie de la nécropole de la rue Pierre-Audry a livré plusieurs inscriptions mentionnant des sévirs.

12. Cf. Allmer, Dissard, 1888, I, p. $25:$ : [...] autel dressé sur un lieu public, vraisemblablement le forum de Lyon et peutêtre devant le temple municipal de Rome et d'Auguste qu'il devait certainement y avoir à I.yon. ”
d'Herculanum, que Balty (1991, p. 208) ${ }^{13}$ interprète dans le même sens.

Comme on le voit, l'interprétation de ce bâtiment reste problématique et on en est réduit aux conjectures dont beaucoup restent gratuites faute de pièces épigraphiques. Il faudra attendre la poursuite des recherches pour en savoir plus. Il faudra notamment établir la chronologie relative des murs (fortement restaurés), afin de progresser dans l'établissement de plans sélectifs, dans la mesure où il est certain que le bâtiment a subi des transformations.

La seule certitude est la datation de l'édifice pour laquelle les sondages ont fourni des données nouvelles.

\section{LA DATATION DU GRAND ÉDIFICE}

Jusqu'ici la datation de ce bâtiment reposait sur la découverte de l'autel taurobolique dédié en 160 après J.C.C., sans que cette datation n'ait été validée par d'autres critères. Or l'étude du mobilier exhumé des remblais installés pour constituer la terrasse sur la façade orientale contredit cette hypothèse. En effet, les remblais qui comblent les alvéoles de la partie est et recouvrent les sols des boutiques n'ont livré que du matériel augustéen. On a vu par ailleurs qu'un foyer, installé sur le sol du portique, a livré un matériel à mettre en relation avec l'abandon des boutiques, voire avec le chantier de construction du nouveau bâtiment (fig. 25 à 27 et annexe I, p. 269-270).

La fouille en plusieurs points de la tranchée de fondation du mur de terrasse limitant le couloir nord-sud, en arrière des alvéoles de façade, a livré un matériel en tout point comparable. De même les éléments fournis par la fouille de la rue désaffectée lors de la construction du nouvel édifice donnent un terminus post quem qui s'accorde avec les données fournies par les autres sondages. Tous ces éléments concordent parfaitement pour placer la destruction du "prétoire " et la construction du pseudo-sanctuaire de Cybèle vers 10 après J.-C.

13. Il s'agit dans les trois cas de bâtiments d'ampleur comparable : Velia $36 \mathrm{~m} \times 71 \mathrm{~m}$, Eumachia $40 \mathrm{~m}$ x $75 \mathrm{~m}$, Herculanum $40 \mathrm{~m}$ x $65 \mathrm{~m}$ environ. À propos de la « basilique " d'Herculanum, Balty écrit : "c'est dans le sens d'une bourse de commerce, d'un portique particulièrement luxueux mais affecté à une corporation particulic̀rc de marchands que je chercherais la destination de l'édifice. " (Balty, 1991, p. 208). 


\section{LE PROBLÈME DU RÉSERVOIR DE L'AQUEDUC DU GIER}

Dans sa synthèse parue en 1985, A. Audin situait la construction du réservoir de l'aqueduc du Gier antérieurement à celle du "sanctuaire ». Cette antériorité ne reposait pas sur l'analyse des vestiges mais résultait de la chronologie admise pour la construction de l'aqueduc (vers 120) et de celle proposée pour le "sanctuaire " (160). Les nouveaux résultats concernant la chronologie des édifices contredisent cette hypothèse. L'absence d'hiatus entre la destruction du «prétoire » et l'édification du grand édifice ne permet pas de situer la construction du réservoir dans une phase intermédiaire. Un autre indice milite dans le même sens : l'orientation du réservoir coincide parfaitement avec celle du "sanctuaire ». Dans l'hypothèse d'une construction antérieure, le réservoir non seulement s'inscrirait au milieu d'un vaste espace non bâti, mais encore présenterait une orientation différente de celle de toutes les constructions avoisinantes, mais préfigurant celle de l'édifice postérieur. Il faut donc admettre que l'installation de ce réservoir est soit contemporaine de la construction du pseudo-sanctuaire de Cybèle, soit postérieure.

Deux sondages implantés contre le réservoir ont permis de fouiller une portion de la tranchée de fondation $\mathrm{du}$ mur est. Cette dernière n'a malheureusement livré aucun matériel datable, permettant de situer avec précision la date de construction de la citerne. En revanche, l'étude des maçonneries permet de trancher pour la deuxième hypothèse. L'installation de la citerne est bien postérieure et vient bouleverser l'agencement primitif du grand édifice.

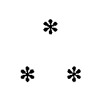

Le bilan des recherches conduites depuis 1991 sur un édifice que l'on pouvait croire, à tort, bien connu, est donc très riche et notre connaissance du site a été totalement renouvelée. On connaît maintenant une première phase d'occupation remontant à l'origine de la colonie. Malgré la vision très partielle que l'on possède aujour- d'hui, il s'avère qu'il s'agit d'habitations privées construites en terre et en bois, mais qui possèdent cependant une décoration soignée. La fouille de ces niveaux précoces a livré en outre un matériel abondant qui fournit des ensembles de références faisant jusque-là défaut pour la période $40-20$ avant J.-C.

Tout aussi nouveaux sont les résultats concernant la deuxième phase de construction. Là où les recherches antérieures avaient cru reconnaître une basilique et ses annexes, les fouilles récentes permettent de conclure à l'existence d'un "palais " construit vers 20 avant J.-C. L'ampleur du bâtiment, la grande qualité de sa construction ainsi que sa situation privilégiée nous conduisent à émettre l'hypothèse qu'il pourrait s'agir de la résidence du gouverneur. En tout état de cause, il s'agit d'un bâtiment exceptionnel pour l'époque qui ne peut qu'être la résidence d'un personnage très important.

Un autre résultat important est la remise en cause de la chronologie de l'aqueduc du Gier ( $c f$. annexe III, p. 273), dont la construction pourrait être contemporaine de celle du " prétoire » et être l'œuvre d'Agrippa. Dans un autre domaine, on notera la confirmation du caractère erroné de la chronologie de l'usage des arases de briques établie par A. Audin, à partir de la datation supposée de l'aqueduc et du "sanctuaire de Cybèle », et la démonstration de l'introduction précoce de cette technique en Gaule (Desbat, 1993).

Concernant enfin l'édifice qui avait été interprété comme un sanctuaire de Cybèle, les recherches conduites depuis 1991 ont montré qu'il s'agissait d'un bâtiment construit à la fin de l'époque augustéenne, vers 10 après J.-C. Cet énorme décalage avec la chronologie jusqu'ici admise (160 après J.-C.) rend caduque l'interprétation qui reposait sur la découverte de l'autel taurobolique. Cet autel constitue la plus ancienne attestation du culte de Cybèle en Gaule et la construction d'un temple de Cybèle à Lyon, à l'époque d'Auguste, est plus qu'improbable. L'état des recherches n'est pas assez avancé pour proposer aujourd'hui une nouvelle interprétation de l'édifice. Ce sera l'objet des recherches futures sur ce site majeur de l'archéologie lyonnaise. 


\section{ANNEXE I}

\section{CATALOGUE DES PLANCHES DE CÉRAMIQUE}

Fig. 12

Sondage A8, céramique des niveaux d'occupation de l'état 1.

Sigillée

1, CYB. 93. A8. 16.1 : bord de plat Goudineau 1;

2, CYB. 93. A8. 15.15 : bord de plat Goudineau 1;

3, CYB. 93. A8. 29.2 : bord Goudineau 1;

4, CYB. 93. A8. 29.1 : bord Goudineau 1 ;

5, CYB. 93. A8. 24.7 : bord Conspectus 2 ;

6, CYB. 93. A8. 10.10 : bord Conspectus 2 ;

7, CYB. 93. A8. 10.11 : bord sigillée arétine ;

8, CYB. 93. A8. 5.5 : forme ouverte sigillée arétine ;

9, CYB. 93. A8. 15.14 : fragment de lèvre ;

10, CYB. 93. A8. 24.1 : fond de plat à estampille radiale P.HER(TORIUS), O.C.788.

Imitation à vernis rouge ou noir

11, CYB. 93. A8. 10.8 : pied à décor guilloché interne à vernis rouge ;

12, CYB. 93. A8. 1311 : coupe à bord oblique à vernis rouge ;

13, CYB. 93. A8. 24.2 : pied à vernis noir ;

14, CYB. 93. A8. 24.3 : pied mouluré à vernis rouge.

\section{Céramique à paroi fine}

15, CYB. 93. A8. 24.4 : bord gobelet à lèvre concave ;

16, CYB. 93. A8. 9.5 : bord gobelet cylindrique à engobe micacé ;

17, CYB. 93. A8. 27.1 : bord gobelet à lèvre moulurée ;

18, CYB. 93. A8. 24.5 : anse de gobelet.

Lampes

19, CYB. 93. A8. 6.3 : fragment de disque à décor moulé ;

20, CYB. 93. A8. 24.10 : fragment de bec.

Céramique grise fine

21, CYB. 93. A8. 4.7 : jatte à bord rentrant ;

22, CYB. 93. A8. 24.7 : pied.

Céramique à vernis rouge "pompéien "

23, CYB. 93. A8. 14.1 : plat à lèvre en bourrelet ;

24, CYB. 93. A8. 13.6 : plat ;

25, СYB. 93. A8. 13.7 : plat.
Fig. 13

Sondage A8, céramique des niveaux d'occupation de l'état 1.

\section{Céramique peinte}

1, CYB. 93. A8. 13.9 : bord de bol, type Roanne;

2, CYB. 93. A8. 10.9 : bord de bol ;

3, CYB. 93. A8. 24.16 : fragment de panse, type Roanne.

Céramique commune sombre rouge

4, CYB. 93. A8. 15.4 : bord de marmite.

Céramique commune sombre grise

5, CYB. 93. A8. 24.12 : vase ovoïde à col côtelé ;

6, CYB. 93. A8. 24.8 : jatte à bord rentrant ;

7, CYB. 93. A8. 29.4 : vase à col côtelé ;

8, CYB. 93. A8. 13.12 : jatte à bord rentrant ;

9, CYB. 93. A8. 4.4 : vase à col lissé.

Céramique commune claire

10, CXBB. 93. A8. 13.14 : col de vase à pâte claire et engobe rouge ;

11, CYB. 93. A8. 29.3 : col de cruche à deux anses ;

12, CYB. 93. A8. 10.4 : fond de cruche ;

13, CYB. 93. A8. 16.12 : cruche monoansée à lèvre striée :

14, CYB. 93. A8. 15.8 : cruche à lèvre striée ;

15, CYB. 93. A8. 16.3 : fond de cruche ;

16, CXB. 93. A8. 24.9 : fragment d'anse avec torsade centrale.

Fig. 14

Sondage A8, amphores des niveaux d'occupation de l'ćtat 1 .

1, CYB. 93. A8. 4.2 : amphore à garum de Bétique ;

2, CYB. 93. A8. 4.8 : lèvre Dressel 20 précoce.

Fig. 15

Sondage D1, céramique du niveau d'installation de la rue (état 1).

Campanienne

1, CYB. 95. D1. 73/15 : fragment d'un grand bol Lamboglia 8. 


\section{Sigillée}

2, CYB. 95. D1. 73/11 : fragment d'assiette Conspectus 4.1 ;

3, CYB. 95. D1 73/18 : fragment de bord Goudineau 1;

4, CYB. 95. D1. 73/7 : fragment de fond de bol ;

20, CYB. 95. Dl. $73 / 9$ : fond estampillé

A. TITI. FIGU(LI) ;

21, CYB. 95. D1. $73 / 10$ : fond estampillé A. TITI. FIGU(LI).

Céramique à paroi fine

5, CYB. 95. D1. 73/17 : fragment de bord de gobelet;

6, CYB. 95. D1. 72/8: lèvre de gobelet à lèvre concave.

Lampe

7, CYB. 95. D1. 72/12 : fragment de disque de lampe républicaine Dressel 1.

Céramique grise fine

8, CYB. 95. D1. 72/6 : lèvre aplatie ;

9, CYB. 95. D1. 73/20: coupe à lèvre pendante.

\section{Céramique peinte}

10, CYB. 95. Dl. 73/13 : lèvre de bol, type Roanne.

Imitation à vernis noir

11, CYB. 95. Dl. 73/4 : fond de plat avec pied annulaire.

\section{Céramique commune claire}

12, CYB. 95. D1.72/6 : lèvre aplatie de vase ovoïde ;

13, CYB. 95 . D1. $73 / 38$ : lèvre de pot ;

14, CYB. 95. D1. 73/41: cruche à lèvre striée ;

15, CYB. 95. D1. 73/36, fond de cruche ;

16, CYB. 95. D1. 74/1 : fond de cruche ;

17, CYB. 95. D1. 74/5 : fond de cruche ;

18, CYB. 95. D1. 74/6 : mortier à lèvre en bandeau, à décor de festons ;

19, CYB. 95. D1. 73/45: mortier à lèvre en bandeau.

\section{Fig. 16}

Sondage $\mathrm{Dl}$, céramique du niveau d'installation de la rue (état 1).

Céramique commune sombre rouge

1, CYB. 95. D1. 73/35 : pot ovoïde.

Céramique commune sombre noire

2, CYB. 95. D1. 73/21 : marmite à col côtelé.

Céramique commune claire

3, CYB. 95. D1. 74/7 : mortier à lèvre en bandeau ;

4, CYB. 95. D1. 72/13 : mortier à lèvre en bandeau.
Fig. 17

Sondage D1, amphores du niveau d'installation de la rue (état 1).

1, CYB. 95. D1. 73/2 : amphore Dressel 1 ;

2, CYB. 95. D1. 74/1 : amphore Dressel 1 ;

3, CYB. 95. D1. 72/15 : amphore indéterminée ;

4, CYB. 95. D1. 72/14 : amphore orientale de Chios ;

5, CYB. 95. D1. 73/51 : amphore Dressel 9 ;

6, CYB. 95. D1. 73/49 : anse d'amphore orientale ;

7, CYB. 95. D1. 73/50 : amphore italique Dressel 2/4.

Fig. 18

Sondage D1, amphores du niveau d'installation de la rue (état 1).

1, CYB. 95. D1. 74/10 : anse d'amphore Dressel 1;

2, CYB. 95. D1. 74/8 : anse d'amphore Dressel 2/4 ;

3, CYB. 95. D1. 74/11 : anse d'amphore de Brindes?;

4, CYB. 95. D1. 74/9 : anse d'amphore de Brindes? ;

5, CYB. 95 . D1. $73 / 47$ et 73/48: amphore orientale.

Fig. 25

Sondage A6, céramique du foyer, abandon de l'état 2. Sigillée

1, CYB. 92. A6. 6.4 : assiette de La Muette signée L. TYRS(US).

Céramique à paroi fine

2, CYB. 92. A6. 9.11 : gobelet hémisphérique ;

3, CYB. 92. A6. 9.12 : fond de gobelet "tonneau ";

4, CYB. 92. A6. 9.13 : gobelet hémisphérique.

Céramique commune claire

5, CYB. 92. $\Lambda 6.9 .15$ : cruche à deux anses et à col cylindrique ;

6, CYB. 92. A6. 9.16 : cruche à une anse et à lèvre en bourrelet.

Céramique peinte

7, CYB. 92. A6. 9.10 : bol type Roanne, décor de bande rouge sur fond blanc;

8, CYB. 92. A6. 6.2 : bol type Roanne, décor brun sur fond blanc.

Céramique commune sombre

9, CYB. 92. A6. 9.7 : plat à cuire ;

10, CYB. 92. A6. 9.22 : plat à cuire. 
Fig. 26

Sondage A6, céramique du foyer, abandon de l'état 2.

Céramiques communes sombres grises

1, CYB. 92. A6. 9.4 : pichet à col tronconique ;

2, CYB. 92. A6. 9.3 : pot ovoïde à col côtelé et une anse ;

3, CYB. 92. A6. 9.8 : pot ovoïde à col côtelé et une anse ;

4, CYB. 92. A6. 9.6 : pot ovoïde à col lissé.
Fig. 27

Sondage A6, céramique du foyer, abandon de l'état 2. Céramiques communes sombres grises

1, CXB. 92. A6. 9.5 : pot à épaule carénée ;

2, CYB. 92. A6. 9.14 : bouton de couvercle ;

3, CYB. 92. A6. 9.1 : pot ovoïde à col côtelé ;

4, CYB. 92. A6. 9.2 : pot ovoïde à col lissé.

\section{ANNEXE II}

\section{LA LOCALISATION DE LA DÉCOUVERTE DE L'AUTEL TAUROBOLIQUE}

Les premières publications consacrées à l'autel taurobolique (Gros de Boze, 1705; Colonia, 1705) et les ouvrages parus les années suivantes (Brossette, 1711) ne mentionnent pas le lieu exact de la découverte qui est situé sans plus de précision "sur la montagne de Fourvière ». Ce n'est qu'en 1728 que Colonia précise en note la localisation "dans la vigne de M. Bourgeat", reprise par la suite par Artaud (1846), Boissieu (1854) et bien d'autres. Artaud, qui dans un premier temps avait placé la découverte " en 1705 [sic], près de l'église de Fourvières [sic] " (Artaud, 1808, p. 24), la situe bien quelques années plus tard, dans son "Lyon souterrain ", dans la propriété Bourgeat en ajoutant les précisions suivantes : «c'est vis-à-vis la partie méridionale du Forum, et au-dessus du théâtre, dans la maison qui a appartenu à M. Bourgeat et que possède Marc-Antoine de Nolhac, qu'on a découvert, en 1704, le fameux taurobole d'Antonin » (Artaud, 1846, p. 71).

La localisation de la propriété dont il est question ne semble pas poser de problème. La maison Bourgeat est figurée en effet sur le plan de Delamonce de 1767, d'ailleurs reproduit par Audin (1985). Sur ce plan la maison est figurée avec la légende «maison où est l'inscription du taurobole antique, chez M. Bourgeat ». La localisation de la maison semble toutefois approximative si on la compare avec une autre source : le plan terrier de Chavallard, dressé en 1737 (archives municipales de Lyon 2S.57). Sur ce plan le clos Bourgeat est figuré avec sa maison, limité à l'est par la ruelle des Belettes, qui subsistait encore en 1971 et permettait d'accéder à la maison qui accueille aujourd'hui le Service archéologique municipal (baptisée depuis Maison aux Cèdres). Ce plan terrier nous confirme l'identification, proposée par Germain de Montauzan et Fabia, du clos Bourgeat avec le terrain de l'orphelinat de Fourvière qui conservait les mêmes limites (fig. 30).

Le lieu de la découverte de l'autel paraît donc parfaitement assuré. Et pourtant le doute subsiste : en effet le plan terrier de Chavallard comporte la légende "verger " à l'emplacement du clos Bourgeat, mais surtout il nous apprend que M. Bourgeat possédait une autre vigne à Fourvière, située plus à l'ouest, dans le clos que limite au sud la rue Roger-Radisson et à l'est la rue Pauline-Jaricot (autrefois rue des Quatre-Vents). Clos qui correspond à une partie de la propriété Bouchaudy, dans laquelle Germain de Montauzan entreprit en 1924 des sondages malheureusement stériles (Fabia, Germain de Montauzan, 1925) (fig. 31).

Il n'est donc pas exclu que l'autel ait pu être trouvé dans la vigne de Bourgeat et transporté dans sa maison, où il est resté visible plusieurs années. Cela peut avoir été source d'erreurs dans la mesure où les contemporains de la découverte n'ont accordé que peu d'importance au lieu exact de la trouvaille et où Artaud peut avoir été influencé par le plan de Delamonce. On peut remarquer que la version du plan, datée de 1767 , conserve la localisation de l'autel alors que celui-ci a été vendu depuis 1742 aux échevins de Lyon ${ }^{14}$.

14. Le plan de 1767 constitue la 3 édition du plan dont l'original a été publié en 1740, mais que l'on suppose avoir été gravé quelques années plus tôt. En revanche, la date de 1701 proposée par quelques ourrages s'avère erronée puisque l'autel découvert en 1704 y est mentionné. 


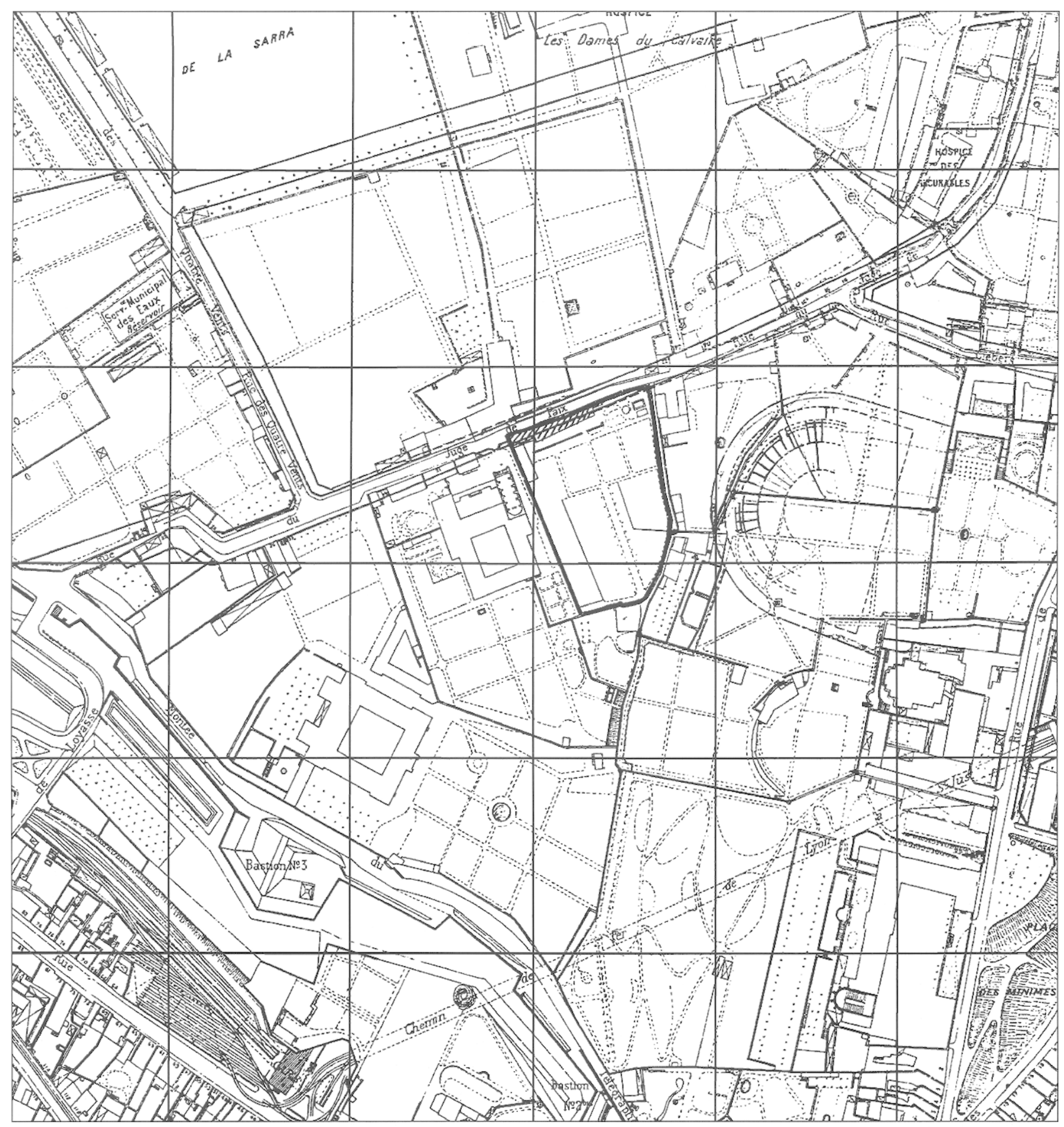

Fig. 30 - Plan cadastral du secteur vers 1930 : trait gras, la parcelle correspondant au clos Bourgeat et en hachures, l'ancienne maison devenue orphelinat. 


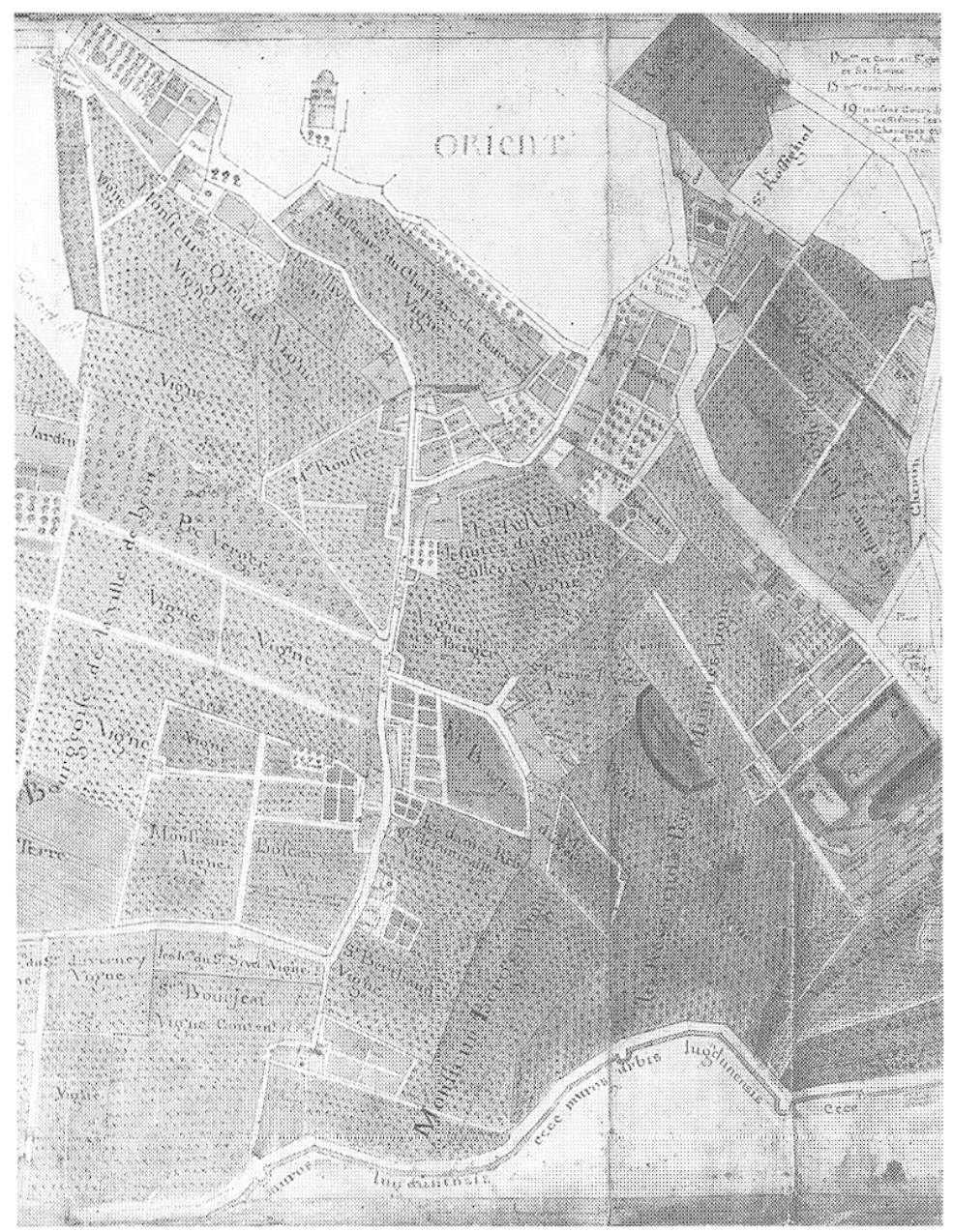

Fig. 31 - Détail du plan terrier de Chavallard (XVIIY s.), avec la maison Bourgeal et son verger, et au sud la vigne du Sieur Bourgeat (archives municipales 2S.57).

On s'aperçoit d'autre part, à la lecture des différentes mentions, que la plupart des précisions sur la localisation ont été apportées beaucoup plus tard, à partir des données d'Artaud qui identifiait le lieu cité par Colonia avec la propriété Bourgeat. Les discussions ou les objections soulevées par la mention " au-dessus du théâtre », nom donné à l'époque à l'odéon, n'ont donc aucune valeur, dans la mesure où Artaud situe la découverte dans la propriété Bourgeat, qui correspond bien au terrain occupé au début du siècle par l'orphelinat de Fourvière et donc à l'emplacement du prétendu sanctuaire de Cybèle. Toute la question est de savoir si l'autel a bien été trouvé dans ce terrain ou dans l'autre vigne appartenant à M. Bourgeat. Rien ne permet de trancher à l'heure actuelle. Seule la découverte d'autres sources apportant des précisions supplémentaires le permettrait, mais il ressort de tout cela que le lieu de découverte de l'autel qui paraissait ne poser aucun problème est lui-même sujet à discussion.

On notera encore que Comarmond a fait une confusion en plaçant le lieu de la trouvaille « dans la propriété de M. Gautier, marchand de sel », alors qu'il s'agit en fait du personnage qui fit don de l'autel aux échevins en $1742{ }^{15}$. Lequel personnage, au demeurant Gaultier du Fel, ou du Sel, trésorier de France au bureau des finances de la généralité de Lyon, avait dû acquérir l'autel auprès de $M$. Bourgeat. Cette erreur, qui peut sembler surprenante, a malheureusement été reprise dans le CIL.

Reste le problème du Castellum Bucium ou Castellum Buci, dans lequel Audin a cru retrouver une allusion aux autels tauroboliques, justifiant l'identification avec les ruines du sanctuaire de Cybèle. Les arguments mis en avant par Audin sont pour le moins discutables. Les citations de Paradin ne sont pas suffisamment précises, mais surtout elles peuvent s'appliquer aussi bien au théâtre qu'au fameux mur Cléberg.

"Ces antiques masures d'admirables estoffe et structure, qui s'estendent par toutes ces vignes de cette montagne, sont nommées es pancartes Castellum Bucium: combien que l'on tienne aujourd'huy que c'estait l'amphithéâtre, duquel parle Eusèbe en l'histoire Saincte, les autres disent que c'estait le palais de l'empereur Severus. Tant y a qu'en une pancarte sont ces mots : Sita est namque ipsa plantada, in pago, vel agro Lugdunensi, prope forum vetus, ad castellum scilicet Bucium. [...] En une autre pancarte est une terre confinée en ces mots : A mane, via publica, a medio die, et circio plantada Belloni, de terra Sancti Stephani, a sero est Castellum Buci. " (p. 255).

«Semblablement j'ay monstré, ces admirables masures, et vieilles murailles qui sont vers la croix Decolle, et s'étendent par tout Forvière (montrans bien un bastiment y avoir été, de structure merveilleuse) estre nommées es pancartes des églises, Castellum Bucium, et Castellum Buci. Le commun tient que c'estait

15. En échange de ce " don", le consulat offrit 3000 livres au susdit Iéonard Gaultier du Fel! (Allmer, Dissard, 1888, I, p. 16). 
un amphithéâtre, d'autres le disent avoir été le palais de Severus : mais il ne s'en trouve rien es escrits antiques " (p. 270).

Audin s'appuie surtout sur la seconde citation pour localiser le "Castellum Bucium " à l'emplacement du chantier archéologique mais sa situation, entre la voie d'Aquitaine et l'odéon, s'applique aussi bien au mur Cléberg, qu'il avait d'ailleurs identifié dans un premier temps avec le Castellum Bucium. La référence de Paradin à l'amphithéâtre et au palais de Sévère permet en effet de penser que le vocable s'appliquait soit à l'odéon, comme le propose Steyert (1895), soit au mur Cléberg, seuls vestiges à être encore visibles au XVI ${ }^{\mathrm{e}}$ s., et pour lesquels ces interprétations ont été souvent avancées.

\section{Les diverses mentions de la découverte de l'autel taurobolique découvert en 1704 par ordre chronologique}

Gros de Boze, 1705, p. 2 : «Il y a près d'un mois qu'on la déterra à Lyon, dans cet endroit de la haute et ancienne ville qu'on nomme Fourvière. »

Colonia, 1705 : «Ce curieux monument fut découvert à Lyon, ce mois de décembre dernier, sur la montagne de Fourvière par des païsans qui y travaillaient la terre.. "

Brossette, 1711 (p. 47) : " [...] fut découvert à Lyon, sur la montagne de Fourvière en l'année 1704 (le 12 décembre) par des païsans qui fouillaient la terre. "

Colonia, 1728 (p. 181) : "L'an 1704, au mois de décembre dans la vigne de $\mathrm{M}$. Bourgeat. »
Artaud, 1808 (p. 24) : "Ce monument remarquable fut trouvé en 1705 près de l'église de Fourvières [sic]. "

Artaud, 1816 (p. 49) : « L'autel taurobolique de Lyon découvert, en 1705, près de l'église de Fourvières [sic]. "

Artaud, 1846 (p. 11) : " C'est vis-à-vis la partie méridionale du forum, et au-dessus du théâtre, dans la maison qui a appartenu à $M$. Bourgeat, et que possède aujourd'hui M. Marc-Antoine de Nolhac, qu'on a découvert, en 1704, le fameux taurobole d'Antonin. »

Comarmond, 1846-1854 (p. 204) : "Ce magnifique monument, le premier des tauroboles découverts à Lyon, fut trouvé au mois de décembre 1704, sur le versant oriental de la colline de Fouvière, non loin de l'ancien forum, dans la propriété de M. Gautier, marchand de sel, qui en fit hommage au corps des échevins de la ville. "

Boissieu, 1854 (p. 23) : "Au mois de décembre 1704, on découvrit sur la montagne de Fourvière, dans la vigne d'un M. Bourgeat, dont la propriété appartient aujourd'hui à Monsieur M.-Ant. de Nolhac, on découvrit dis-je, un autel commémoratif d'un sacrifice taurobolique offert pour la santé de l'empereur Antonin le Pieux et pour la prospérité de la colonie lyonnaise. »

Allmer, Dissard, 1888 (p. 15-16) : « [...] fut découvert en 1704, sur le versant oriental de la colline de Fourvière, dans la vigne d'un sieur Bourgeat, [...] dont la propriété appartient aujourd'hui à M. Marc-Antoine de Nolhac (de Boissieu), derrière les ruines du théâtre antique qui se voient chez les dames de la Compassion. »

CIL, XIII, 1751 : "in fundo Gaultier du Fel, qui a 1742 urbi dedit."

\section{ANNEXE III}

\section{NOUVELLES DONNÉES SUR LA GHRONOLOGIE DE L'AQUEDUC DU GIER}

Dans sa thèse consacrée aux aqueducs antiques de Lyon, Germain de Montauzan (1909) avait proposé une chronologie des aqueducs lyonnais qui a fait autorité pendant plusieurs décennies. L'aqueduc du Gier y était daté du règne d'Hadrien, en s'appuyant sur la découverte quelques années plus tôt, en 1887 , de « la pierre de Chagnon ", inscription rappelant, de l'autorité de l'empereur Hadrien, l'édit d'Auguste interdisant de construire ou de labourer à proximité de la conduite
(CIL, XIII, 1623). La datation fournie par ccttc inscription et admise pour la construction de l'aqueduc modifiait considérablement la datation jusque-là proposée pour cet ouvrage que l'on avait attribué à l'empereur Claude. La datation claudienne proposée dès le XVIII s. par le père Menestrier et reprise par Allmer et Dissard (1888) s'appuyait sur la découverte de tuyaux de plomb marqués du nom de Claude, dans le secteur de Fourvière (Colonia, 1728). L'absence de localisation précise pour ces trouvailles et la découverte de la pierre de Chagnon amenèrent Steyert (1895, p. 266), puis Germain de Montauzan, à mettre ces tuyaux en rapport avec l'aque- 


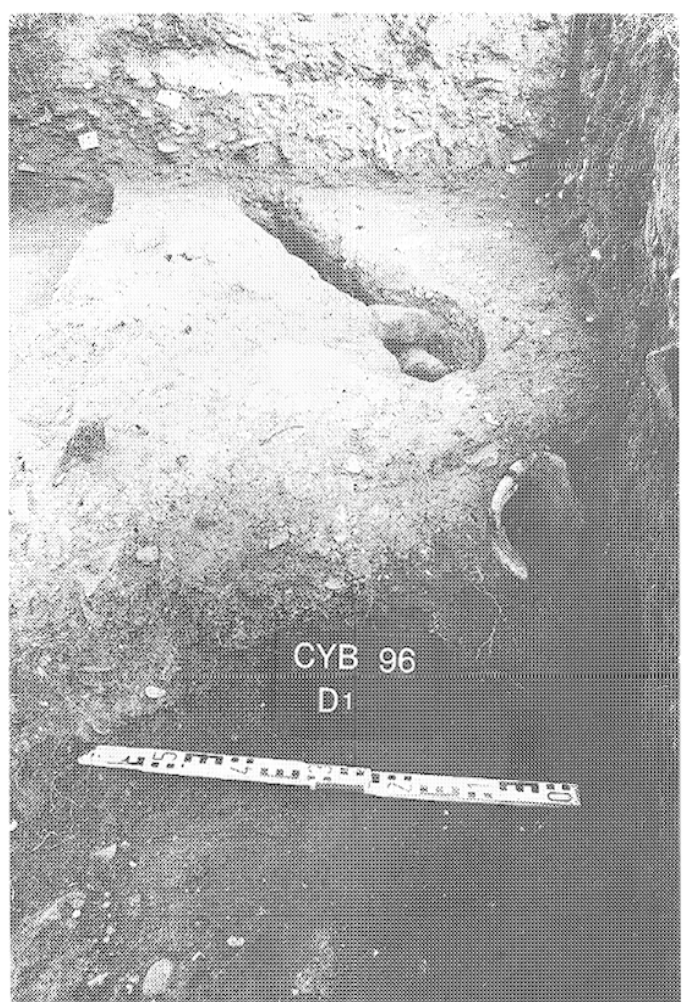

Fig. 32 - Détail du négatif de tuyau traversant la rue. avec le col d'une amphore Hallern 70 installé pour aménager le passage du tuyau dans l'égout.

duc de la Brévenne et non plus avec celui du Gier. Par la suite, les travaux de différents chercheurs ont repris la question en soulevant certains doutes mais sans trancher définitivement (Jeancolas, 1978, 1983; Turcan, 1978a et $\mathrm{b}$; Jeancolas et al., 1986).

En 1982, la découverte d'une fontaine publique dans le clos du Verbe-Incarné a réactualisé la datation claudienne, qui semblait désormais définitivement acquise (Lavrut, 1984; Mandy, 1986 ; Delaval, 1989) ${ }^{16}$. Ccttc fontaine située à un carrefour de rue comportait une borne que devait surmonter un chapiteau trouvé à proximité immédiate. Celui-ci était orné de lettres de bronze, aujourd'hui disparues, formant l'inscription

16. "Il cn résulte que seul l'aqueduc du Gier a pu jouer ce rôle. Ainsi cette découverte fournit un argument péremptoire qui rend surannées les discussions sur l'éventuelle datation hadrienne de cet aqueduc." (Mandy, 1986, p. 93). "L'attribution de ce monument à l'empereur Claude, prudemment évoquée par plusieurs auteurs, trouve ici une confirmation éclatante qui rend caduque la datation hadrianique faisant foi jusqu'ici. "(Delaval, 1989, p. 240).
CLAVD AVG (Mandy, 1986 ; Delaval, 1989). Cette fontaine recouvrait le socle d'une fontaine plus ancienne, situé à la cote 280,90, qui permet de supposer l'arrivée de l'eau sur la fontaine primitive à l'altitude de $283 \mathrm{~m}$, si l'on admet l'existence d'une borne semblable à celle de la seconde fontaine. Cette altitude de $283 \mathrm{~m}$ paraissait démontrer que seul l'aqueduc du Gier pouvait alimenter la fontaine. L'attribution de l'aqueduc à Claude, admise par la tradition ancienne, a donc été considérée comme acquise, malgré la pierre de Chagnon. En effet, celle-ci a été trouvée à proximité de la boucle de Chagnon, qui constitue une dérivation de l'aqueduc, pouvant appartenir à un réaménagement postérieur (Burdy, 1996).

Les découvertes récentes effectuées lors des fouilles à l'emplacement du prétendu sanctuaire de Cybèle apportent aujourd'hui de nouveaux éléments et obligent à envisager d'autres possibilités. La fouille des niveaux de rue contemporains du " prétoire » a livré l'empreinte de tuyauteries qui supposent un réseau de distribution de l'eau (fig. 32). L'existence d'un tel réseau de distribution semble être confirmée par la présence dans le "prétoire » d'un secteur thermal et a contrario par l'absence de toute trace de citerne et d'impluvium dans l'atrium. L'altitude du "prétoire » de même que celle du négatif de tuyau interdit de les mettre en rapport avec un autre aqueduc que celui du Gier. Ces éléments obligent à considérer l'hypothèse de la création de cet ouvrage dès le règne d'Auguste, probablement par Agrippa.

D'autres arguments militent en faveur d'une telle hypothèse :

- l'appareil réticulé utilisé pour les parements des piles de l'aqueduc est d'un emploi courant à l'époque tardorépublicaine ;

- le calcaire utilisé pour cet appareil est un calcaire oolithique, rarement employé à Lyon, mais qui est précisćment mis cn ocuvrc pour lc soclc de la fontainc primitive du Verbe-Incarné ${ }^{17}$;

17. L'usage du calcaire oolithique à Lyon cst maintenant attesté dès l'époque d'Auguste. Une des plus ancienne stèle funćraire lyonnaise utilise cn effet ce matériau (Tarpin, 1994), mais surtout de nombreux blocs ou éclats de ce calcaire ont ćté retrouvés sur le site, associés à du mobilier augustéen, dans des fosses correspondant à l'état 3. Bien que l'on ne puisse déterminer à l'heure actuelle s'il s'agit d'éléments provenant de la démolition du "prétoire " ou de la construction du pseudo-sanctuaire, il n'en demeure pas moins que ces éléments démontrent que ce matériau est utilisé à une date plus ancienne qu'on ne le supposait jusqu’ici (Savay-Guerraz, Desbat, 1992). 
- l'aqueduc est l'un des rares à appliquer à la lettre les préceptes de Vitruve (De architectura, VIII, VI, 3) concernant la construction des regards tous les 240 pieds, comme l'a mis en évidence J. Burdy (1990). Ce point est peut-être un indice de l'ancienneté de l'aqueduc.

On ajoutera que la présence d'arases de briques n'est en rien un élément de datation basse pour la construction de l'aqueduc du Gier. Non seulement la datation hadrienne de ce mode de construction reposait sur la datation supposée de l'aqueduc, mais encore la fouille $\mathrm{du}$ " prétoire " confirme l'utilisation d'arases de briques dès l'époque augustéenne précoce et l'emploi en Gaule à haute époque d'un mode de construction qui apparaît en Italie dès l'époque républicaine (Desbat, 1993).

L'objection la plus couramment avancée pour rejeter l'idée de l'antériorité de cet ouvrage par rapport aux autres aqueducs est que l'on a dû aller chercher d'abord l'eau au plus près. C'est ce raisonnement qui fait attribuer à Agrippa, par Germain de Montauzan et à sa suite par tous les auteurs, la construction de l'aqueduc des Monts d'Or. Or cet aqueduc ne peut alimenter les quartiers hauts de la colonie. Le seul aqueduc à pouvoir alimenter le sommet de Fourvière où se développe le cour de la nouvelle capitale d'Auguste est précisément l'aqueduc du Gier. De ce fait le point le plus près pour pouvoir alimenter la colline en eau est le Gier.
Agrippa, premier curateur des eaux de Rome, et constructeur de l'Aqua Virgo et de l'Aqua Iulia, était mieux placé que quiconque pour entreprendre un tel ouvrage, dont la difficulté même augmentait l'impact politique.

Les arguments que l'on a pu invoquer pour attribuer l'aqueduc à Claude s'appliquent pour la plupart à Agrippa : Claude fut sans conteste un grand constructeur d'aqueducs et Rome lui doit l'Aqua Claudia et l'Anio Novus. Natif de Lyon, il doit avoir comblé sa ville natale de bienfaits mais Auguste décidant d'ériger Lugdunum en capitale des trois Gaules peut tout aussi bien avoir confié à Agrippa la construction d'un ouvrage destiné à marquer la force de l'empire naissant. La découverte de tuyaux marqués à son nom confirme que Claude a doté sa ville d'un aqueduc, mais il peut avoir également restauré un ouvrage construit par Agrippa, comme il l'a fait à Rome pour les deux aqueducs construits par ce dernier. Le deuxième état de la fontaine du Verbe-Incarné, auquel on doit attribuer le chapiteau à son nom, pourrait être l'indice de cette restauration. $\mathrm{La}$ restauration de l'aqueduc du Gier, mais aussi l'aménagement d'une nouvelle citerne, pourrait être mise en relation avec la construction du grand édifice thermal de la rue des Farges, construit précisément à l'époque de Claude. 


\section{BIBLIOGRAPHIE}

Allmer A., Dissard P.

1888 : Inscriptions antiques du musée de Lyon, 5 vol., Lyon, Imprimerie Delaroche.

ARTALID F.

1808: Notice des antiquités el des tableaux du musée de Lyon, Lyon, Imprimeric Ballanche.

1816: Nolice sur les inscriptions antiques $d u$ musée de Lyon, Lyon.

1846: Lyon souterrain, Lyon, Montfalcon.

Audin A.

1956 (le éd.) : Essai sur la lopographie de Lugdunum, Lyon, Audin.

1964 ( $3^{c}$ éd.) : Essai sur la topographie de Lugdunum, Lyon, Audin.

1965a : Le sanctuaire lyonnais de Cybèle, Bulletin des Musées et Monuments Lyonnais, 4, p. 65-75.

1965b : Lyon miroir de Rome dans les Gaules, Paris, Fayard.

1976 : Cybèle à Lugdunum, Latomus, XXXV, 1, p. 55-70.

1977 : Le réservoir terminal de l'aqueduc du Gicr à Lyon, Journées d'études sur les aqueducs romains, Lyon.

1978 : I.e sanctuaire de Cybèle et les autels tauroboliques de I.yon, Revue du Lyonnais, 4, p. 193-200.

1979 : Ljon miroir de Rome, Paris, Fayard.

1985 : Dossier des fouilles du sanctuaire lyonnais de Cybèle et de ses abords, Gallia, 43, 1, p. 81-126.

BALTY J.-CH.

1991 : Curia ordinis, Bruxelles.

BOISSIEU A. DE

1854 : Inscriptions antiques de Lyon, Lyon, L. Perrin.

Borgard PH. (Éd.)

1996 : la maison urbaine d'époque romaine, en Gaule Narbonnaise et dans les provinces voisines, in: Actes du Colloque d'Avignon, 11-13 nov.
1994, Documents d'Archéologie Vauclusienne, 6, Avignon, 2 vol.

\section{BOUCHER J.-P}

1977 : Rhône, in : Informations archéologiques, Circonscription de RhôneAlpes, Gallia, 35, 2, p 482-483.

1980 : Rhône, in : Informations archéologiques, Circonscription de RhôneAlpes, Gallia, 38, 2, p. 519.

\section{BROSSETTE}

1711 : Éloge historique en histoire abrégée de la ville de Lyon ancienne et moderne, Lyon, J.-B. Girin.

BurdY J.

1990 : La normalisation dans la construction de l'aqueduc du Gier, in : Mélanges d'archéologie offerts à A. Audin, Iyon, Association des Amis du Musée de la Civilisation galloromaine, p. 30-52.

1996 : L'aqueduc romain du Gier, Préinventaire des monuments et richesses artistiques, département du Rhône, IV.

BURIYY., BugNOI. H.

1986a : Mille regards sur l'aqueduc du Gier, Bulletin des Musées et Monuments Lyonnais, VII, 2, p. 353-379.

1986b : Mille regards sur l'aqueduc du Gier, Bulletin des Musées et Monuments Lyonnais, VII, 3, p. 381-400.

Chauffin J., Audin A.

1972 : Essai de stratigraphie archéologique à Fourvière, Revue Archéologique de l'Est et du Centre-Est, XXIII, 1-2, p. 89-95.

\section{COLONIA J. DE}

1705 : Dissertation sur un monument antique découvert à Lyon, sur la montagne de Fourvière au mois de décembre 1704, Lyon, T. Amaulry Libraire.

1728 : Hisloire lilléraire de la ville de Lyon,
2 vol., Lyon, F. Rigollet Libraire.

Comarmond A.

1854 : Description du musée lapidaire de la ville de Lyon, 1846-1854, Lyon, F. Dumoulin impr.

Delaval É.

1989 : Une fontaine gallo-romaine alimentée par l'aqueduc du Gier découverte à Lyon (clos du Verbe-Incarné, Fourvière), Rerue Archéologique de l'Est et du Centre-Est, 40, 2, p. 229-242.

\section{Desbat A.}

1993 : Note sur l'apparition des constructions à arases de briques dans la région lyonnaise, Gallia, 49, 1992, p. $45-50$.

Fabia $\mathrm{P}_{\mathrm{H}}$.

1933 : Pierre Sala, sa vie, son cuvre, Lyon, Audin.

fabia Ph., Grimain de Montauzan C.

1925 : Les fouilles de Fourvière en 1924, Comptes rendus des séances de l'Académie. des Inscriptions et Belles-Lettres, p. 119124.

1926 : Les fouilles de Fourvière en 1925 , Comples rendus des séances de l'Académie des Inscriptions el Belles-Lettres, p. 140145.

\section{FÉVRIER P.-A.}

1977 (2 éd.) : Fréjus (Forum Iulii), llinéraires Ligures, 13.

Germain de Montauzan C.

1909 : Les aqueducs antiques de Lyon, Paris, E. Leroux.

1931 : Les fouilles archéologiques de Fourvière à Lyon, depuis la guerre, Bulletin de l'Association Guillaume Budé, p. 11-24.

GROS P.

1996 : L'archilecture romaine -1- Ies monu- 
ments publics, Manuels d'art et d'archéologic antique, Paris, Picard.

\section{GROS DF. BO7F.}

1705 : Explication d'une inscription antique trouvée depuis peu à Lyon où sont décrites les particularités des sacrifices que les anciens appelaient Tauroboles, Paris, Chez P. Cot.

JEAVCOLAS L.

1978 : Présentation des aqueducs antiques de Lyon; problemes anciens, observations nouvelles, p. 3-77.

1983 : Présentation des aqueducs antiques de Lyon, in: Journées d'études sur les aqueducs romains, Paris 1983, p. 179-205.

JeANCOlas L., GrLyer J., Lutrin C.

1986 : Les aqueducs antiques de Lyon, Revue Sites, hors-série, 30.

\section{KC̈HLBORN J. S.}

1989 : Oberaden, in : 2000 Jahre Römer in Weslfalen, Landschaftsverband Westfalen-Lippe, Westfälisches Museum für Archäologie, Mainz am Rhein, Philipp von Zabern, p. 44-51.

I.ANCFI. S.

1975 : Rhône, in : Informations archéologiques, Circonscription de RhôneAlpes, Gallia, 33, 2, p. 545-547.

LAVRUT D.

1984: La datation de l'aqueduc du Gier, Cahiers d'Histoire, XXIX, I, p. 47-58.
1986 : La chronologie des aqueducs lyonnais, l'Araire, 66, p. 95-98.

I.FGI.AY M.

1966 : Rhône, in : Informations archéologiques, Circonscription de RhôneAlpes, Gallia, XXIV, 2, p. 496.

1973 : Rhône, in : Informations archéologiques, Circonscription de RhôneAlpes, Gallia, 31, 2, p. 522.

MANDY B.

1983 : Lyon, le quartier antique du Verbe-Incarné, Histoire et archéologie, Les dossiers, 78, nov. 1983, p. 23-26.

1986 : Une fontaine publique dans le clos du Verbe-Incarné à Lyon, L'Araire, 66, p. 87-93.

1987 : Le forum de Lyon, in : Los forms romanos de las provincias occidentales, Actes du Colloque de Madrid, 1987.

MignON J.-M.

1996 : Approche morphologique et fonctionnelle de la maison; le lotissement augustéen de Saint-Florent à Orange, in : Borgard Ph. (éd.), La maison urbaine d'époque romaine, en Gaule Narbonnaise et dans les provinces voisines, Actes du Colloque d'Avignon, 11-13 nov. 1994, Documents d'Archéologie Vauclusienne, 6, Avignon, vol. 1, p. 219-233.

RODDAZ J.-M.

1984 : Marcus Agrippa, Rome, Collection de l'École française de Rome, Rome.
SAVAY-GLERRaz H., Desbat A.

1992 : Les matériaux et techniques de construction des thermes de la rue des Farges à Iyon (I ${ }^{\mathrm{er}}$ et II $\mathrm{II}^{\mathrm{e}}$ siècless ap. J.-C.), in : $117^{\circ}$ Congrès national des Sociétés savantes, Clermont-Ferrand, 1992, p. 255-272.

STEYER' A.

1895: Nouvelle histoire de Lyon-I- Antiquité, Iyon, Bernoux et Cumin.

TARPIN M.

1994 : Une stèle à sommet cintré du musée de Lyon, l'Afrique, la Gaule, la religion à l'époque romaine, Mélanges à la mémoire de Marcel Le Glay, Latomus, 226, p. 329-343.

TURCAN. R.

1978a : Les religions " orientales » à Lugdunum en 177, in: Les Martyrs de Iyon (177), Actes du Colloque international du CNRS, Lyon, 20-23 sept. 1977.

1978b : Note sur la pierre de Chagnon, Bulletin de liaison de la Direction des Antiquités historiques Rhône-Alpes, 8, p. $67-71$.

WUIL.L.FMIFR P.

1951 : Fouilles de Fourvière à Lyon, IV suppl. à Gallia, Paris, Éditions du CNRS, 86 p., 8 fig., 8 plans h. t., XX pl. h. t.

1953 : Lyon, Métropole des Gaules, Paris, Les Belles Lettres. 